\title{
New approaches to improve Extracorporeal Photopheresis for the treatment of Graft-versus-Host Disease
}

\author{
Dissertation \\ In partial fulfillment of the requirements for the degree \\ "Doctor rerum naturalium (Dr. rer. nat.)" \\ in the Molecular Medicine Study Program \\ at the Georg-August University Göttingen
}

submitted by

Susanne Papert (geb. Kolb)

born in Coburg

Göttingen, 2016 


\section{Members of the Thesis Committee:}

Supervisor: Prof. Dr. Holger Reichardt

Department of Cellular and Molecular Immunology, University Medical Center Göttingen

Second member of the thesis committee: Prof. Dr. Hubertus Jarry

Department of Research Animal Welfare Officer, University Medical Center Göttingen

Third member of the thesis committee: Prof. Dr. Tobias Legler

Department of Transfusion Medicine, University Medical Center Göttingen 


\section{AFFIDAVIT}

Here I declare that my doctoral theses entitled "New approaches to improve Extracorporeal Photopheresis for the treatment of Graft-versus-Host Disease" has been written independently with no other sources and aids than quoted.

Göttingen, March 2016 


\section{Table of Contents}

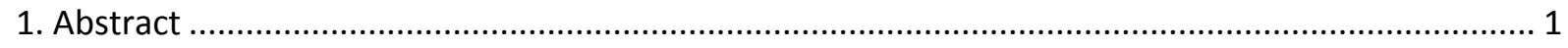

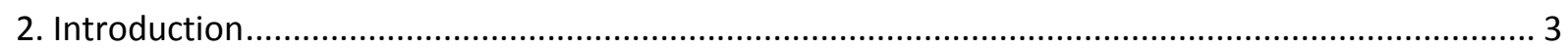

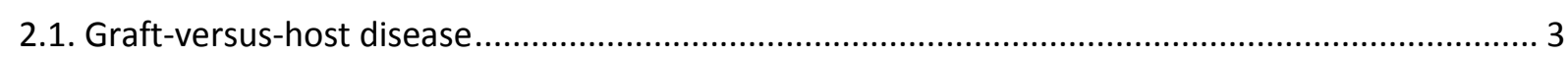

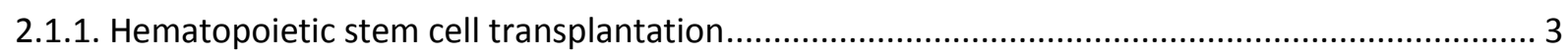

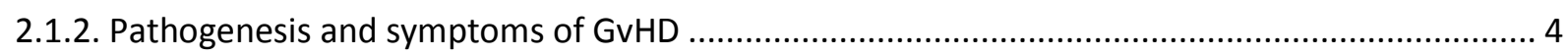

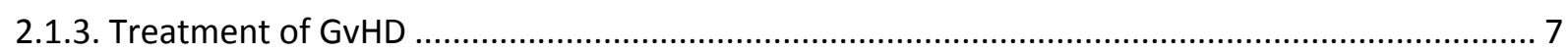

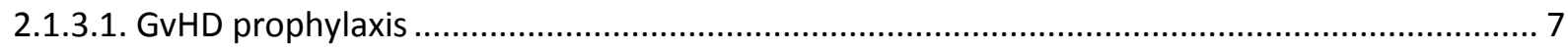

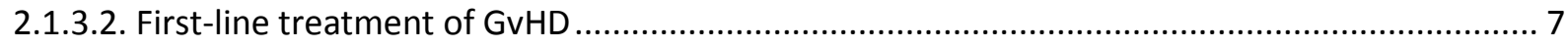

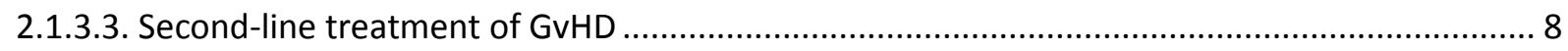

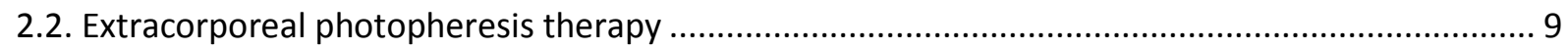

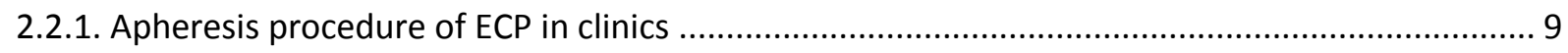

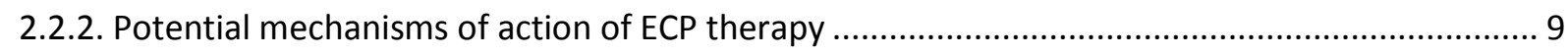

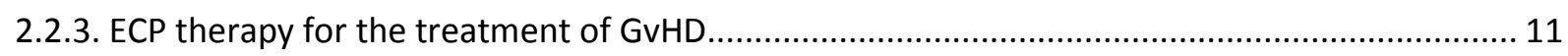

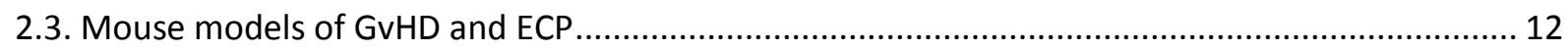

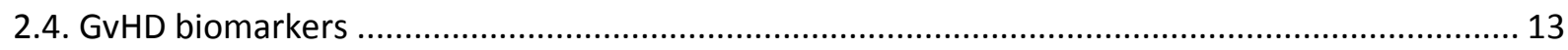

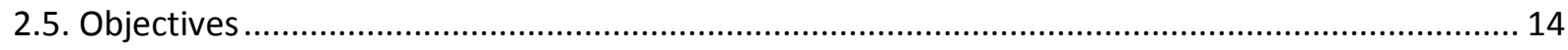

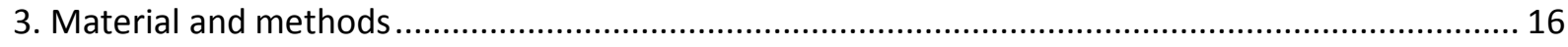

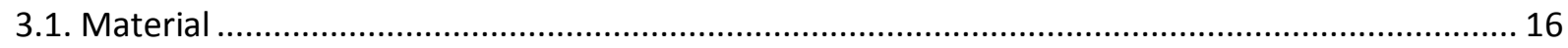

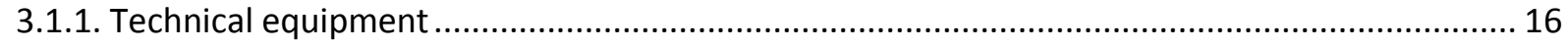

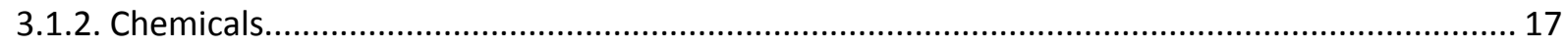

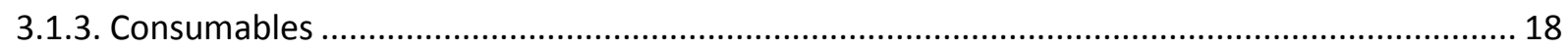

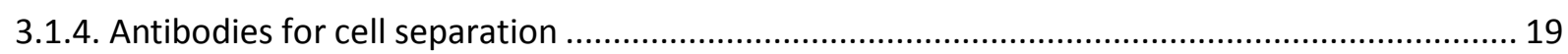

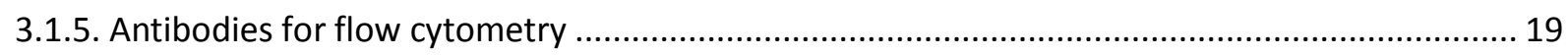

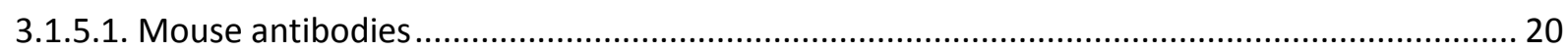

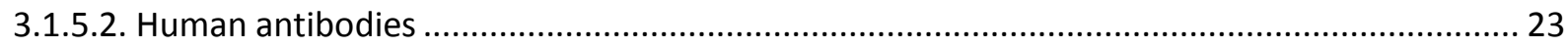

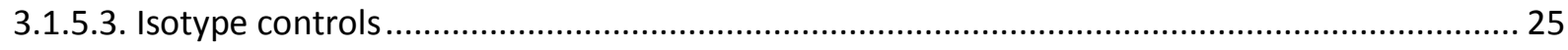

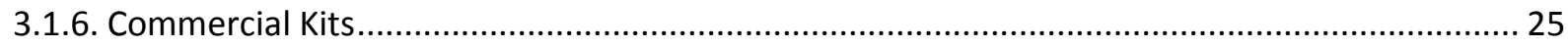

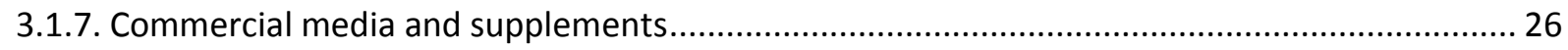

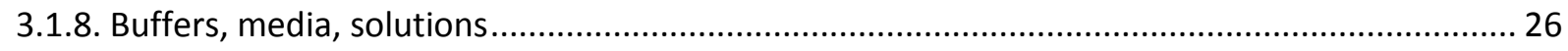

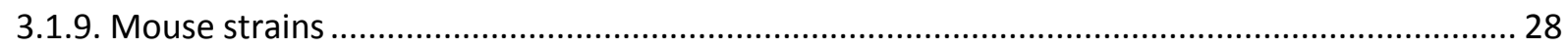

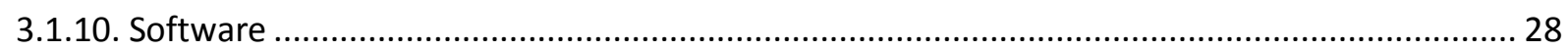

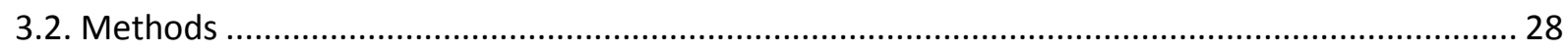

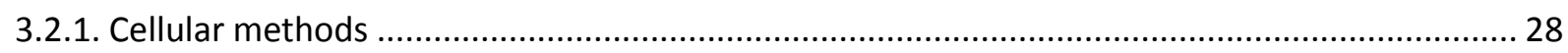

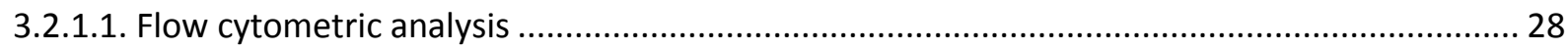




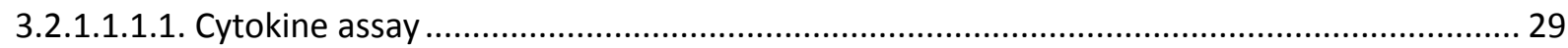

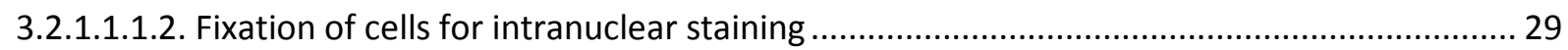

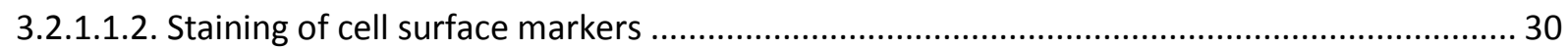

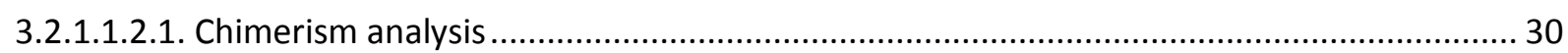

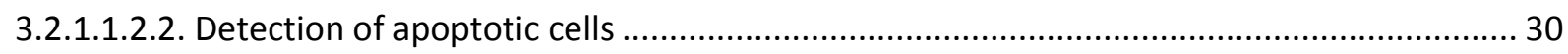

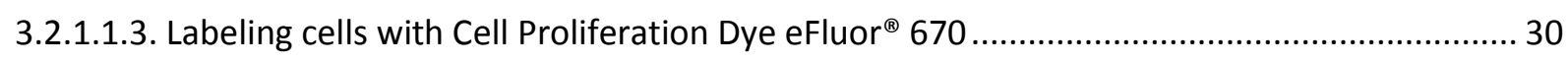

3.2.1.1.4. Preparation of lymphocyte single cell suspension ....................................................... 31

3.2.1.1.4.1. Isolation of human lymphocytes .................................................................... 31

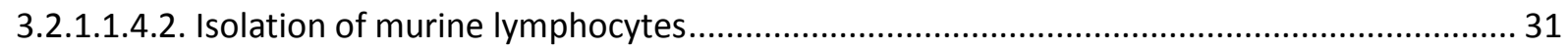

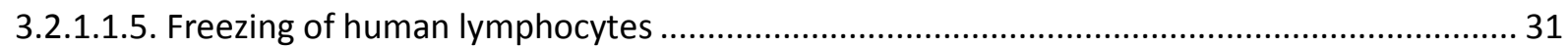

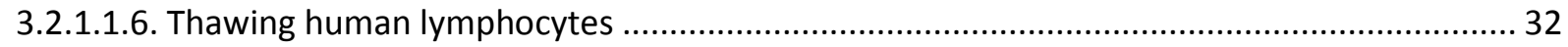

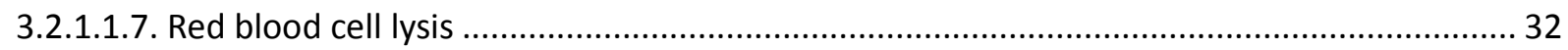

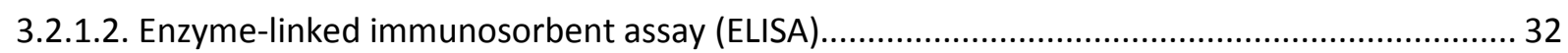

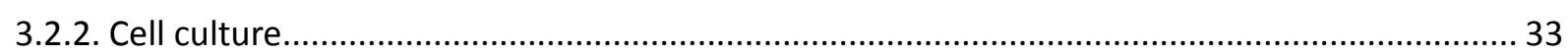

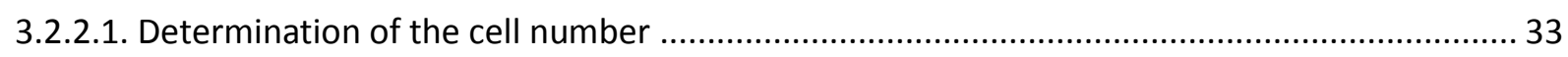

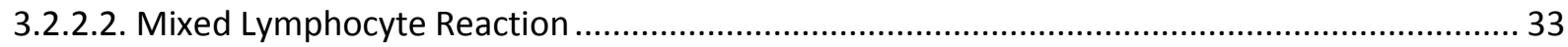

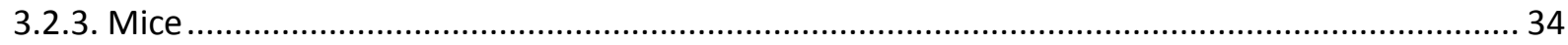

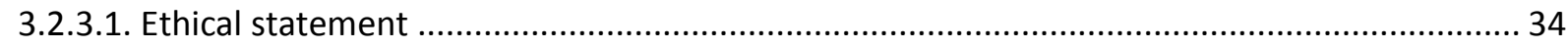

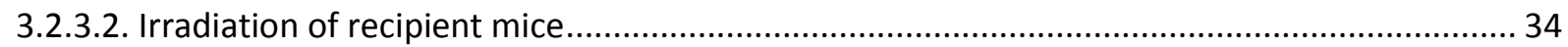

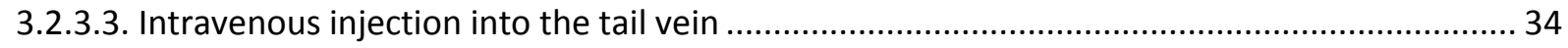

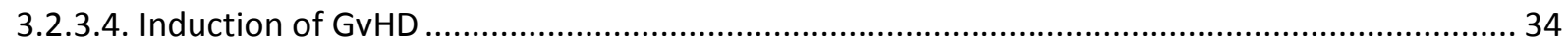

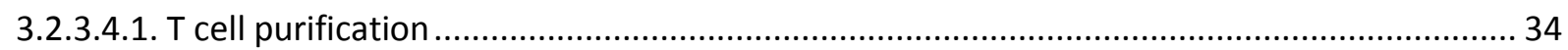

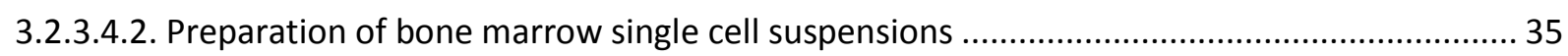

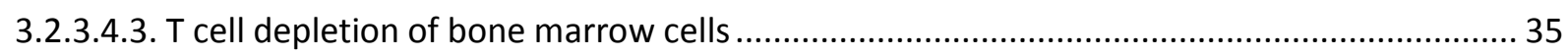

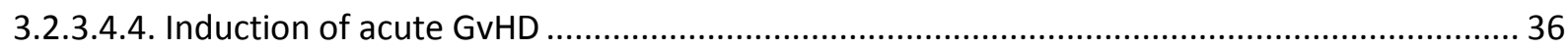

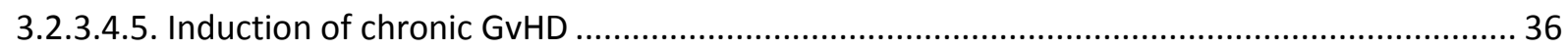

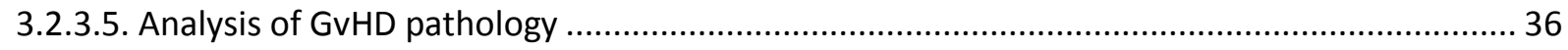

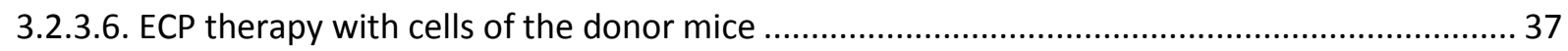

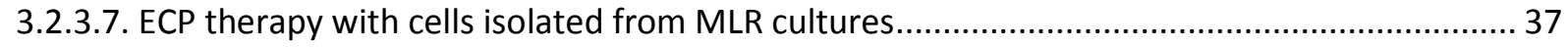

3.2.3.8. Disinfection of the workplace and dissection set....................................................... 38

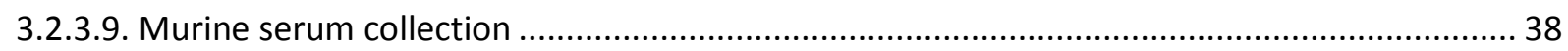

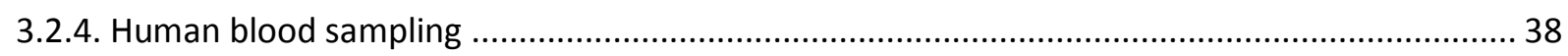

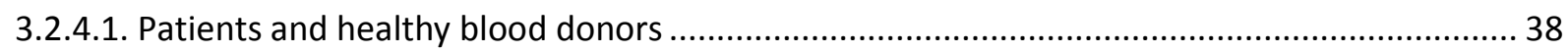

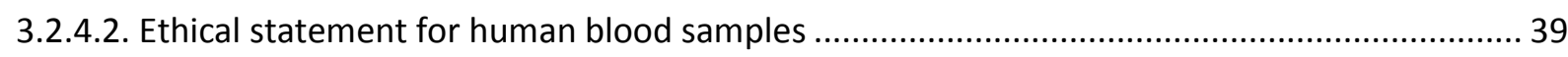




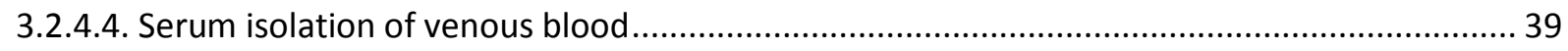

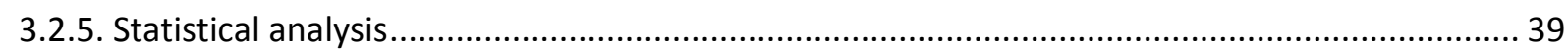

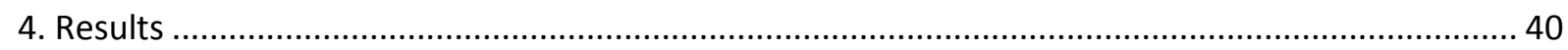

4.1. Impact of ECP therapy on mouse models of $\mathrm{aGvHD}$ and $\mathrm{cGvHD}$..........................................40

4.1.1. Impact of ECP therapy with cells from healthy mice on mouse models of GvHD ................... 40

4.1.1.1. ECP therapy with C57BL/6 splenocytes in a mouse model of aGvHD................................ 40

4.1.1.2. ECP therapy with C57BL/6 splenocytes in a mouse model of cGvHD ................................43

4.1.1.3. ECP therapy with splenocytes of BALB/c origin ....................................................... 44

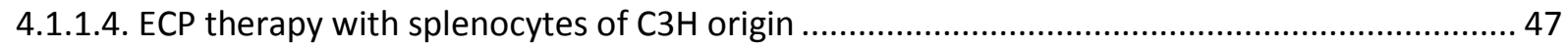

4.1.1.4.1. ECP therapy with splenocytes from C3H mice in an aGvHD mouse model ......................48

4.1.1.4.2. Analysis of the first peak in ECP therapy of aGvHD with splenocytes of C3H origin ........... 51

4.1.1.6. ECP therapy with cells activated in a mixed lymphocyte reaction.....................................52

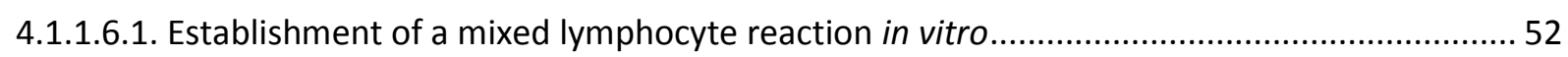

4.1.1.6.2. ECP therapy with MLR cells from BALB/c and C57BL/6 donor mice .................................53

4.1.1.7. ECP therapy using cells from MLR of $\mathrm{C} 3 \mathrm{H}$ cells activated by irradiated BALB/c splenocytes .. 55

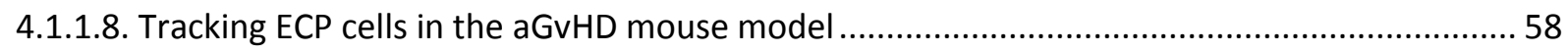

4.2. Potential GvHD and ECP biomarkers in human patients receiving allogeneic BMT and cGvHD

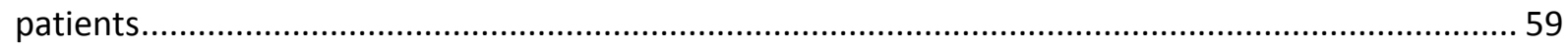

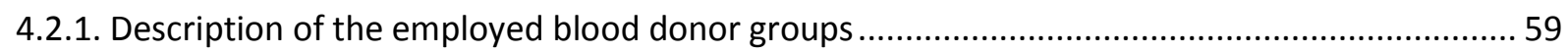

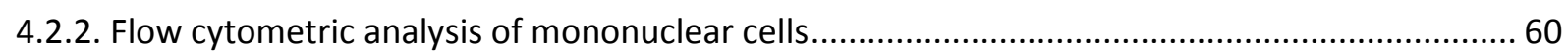

4.2.2.1. Reference ranges for potential cellular biomarkers.......................................................60

4.2.2. Comparison of both blood donations from control samples for differences in potential

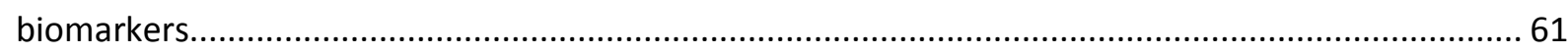

4.2.2.3. Comparison of cellular subpopulations as potential GvHD and ECP biomarkers ..................62

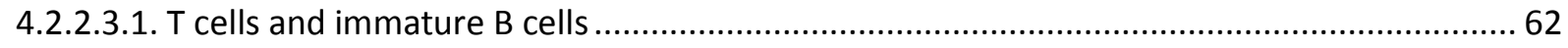

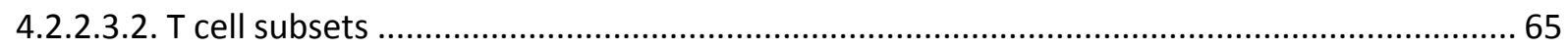

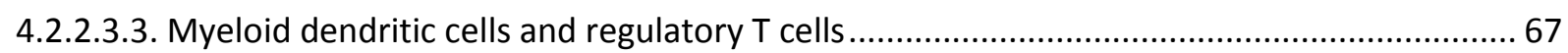

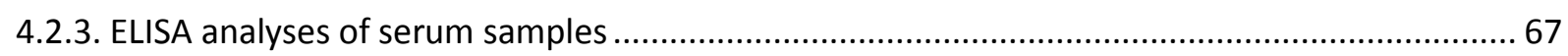

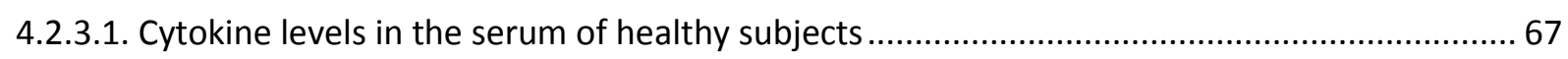

4.2.3.2. Comparison of two blood donations from control subjects for the identification of differences

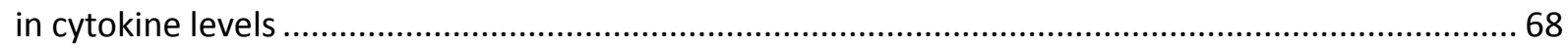

4.2.3.3. Comparison of cellular subpopulations as potential GvHD and ECP biomarkers ................. 68

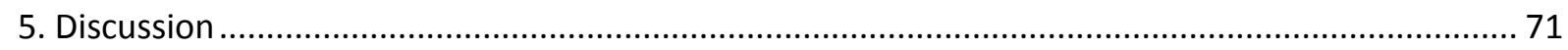

5.1. ECP therapy of GVHD in mice using cells of different genetic origin......................................... 71 
5.2. Differential impact of ECP cells on splenocyte subpopulations in GVHD mice depending on their

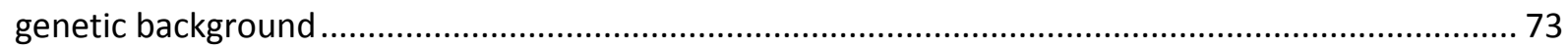

5.3. Effects of pre-activated ECP cells on the course and severity of GvHD in a mouse model ........... 75

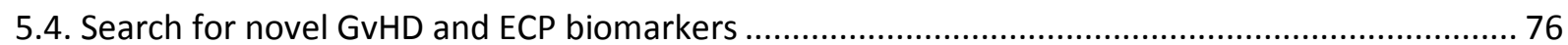

5.4.1. Suitability of cellular subpopulations as potential biomarkers ................................................ 76

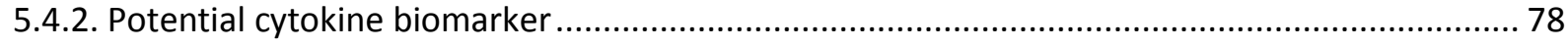

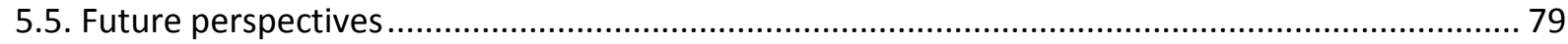

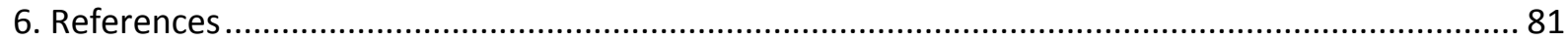

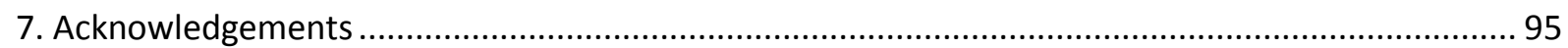

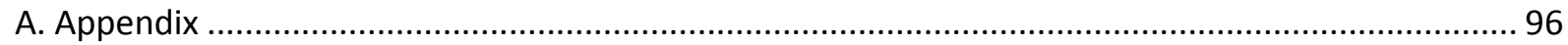

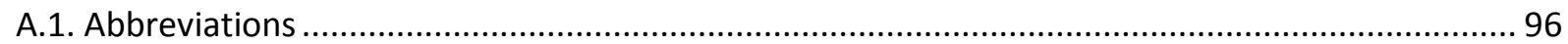

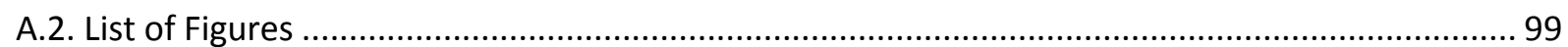

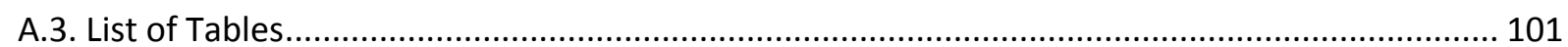

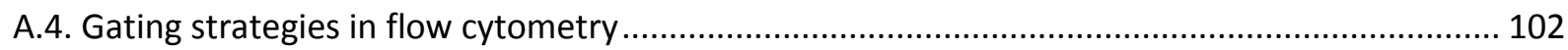

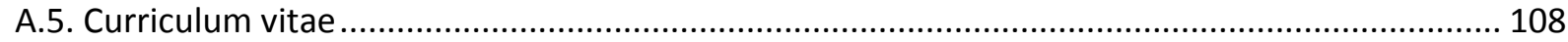




\section{Abstract}

Graft-versus-host disease (GvHD) is a severe complication occurring after hematopoietic stem cell transplantation (HSCT). It is caused by alloreactive T cells contained in the graft, and associated with severe morbidity and mortality. Glucocorticoids (GC) are the gold standard for first-line treatment of GvHD but once patients become steroid-refractory, they need to be treated with second-line therapies such as extracorporeal photopheresis (ECP). ECP is an immunomodulatory therapy currently used in the clinic for treating patients suffering acute GvHD (aGvHD) or chronic GvHD (cGvHD). During ECP therapy leukocytes from the patient are collected by apheresis procedure and treated with 8-methoxypsoralen (8-MOP) and ultraviolet light type-A (UV-A) generating apoptotic cells which are then reinfused into the patient. These apoptotic cells are taken up by myeloid dendritic cells (mDCs) and may lead to cross-tolerization of T cells. Whether ECP therapy could be modified by using leukocytes from healthy blood donors instead of the patient's own cells has not yet been explored although this option would offer the possibility to avoid the exhausting apheresis procedure.

In this study, established mouse models of aGvHD (C57BL/6->BALB/c) and cGvHD (B10D2$>\mathrm{BALB} / \mathrm{C}$ ) were used to evaluate the effects of 8-MOP/UV-A (PUVA)-treated splenocytes derived from healthy genetically different mouse strains. ECP therapy using $\mathrm{C} 3 \mathrm{H}$ mice as donors of splenocytes had a significant therapeutic effect on the course and severity of aGvHD whereas this was not the case for splenocytes with BALB/C and C57BL/6 origin. ECP therapy of cGvHD was successful when apoptotic splenocytes from B10D2 were used. Flow cytometric analysis did not reveal any cellular signature of cGvHD. Overall, the obtained results suggest that the therapeutic effect of ECP therapy might be achieved when there are extensive disparities in the human leukocyte antigen (HLA) haplotype between ECP recipient and cell donors.

In addition, efforts were made to identify biomarkers that could predict the risk to develop GvHD and the patient's response to ECP therapy. Several potential biomarkers were analyzed in peripheral blood by flow cytometry or enzyme-linked immunosorbent assay (ELISA). Reference values were determined for each potential biomarker in healthy blood donors and compared to the values measured in patients suffering from hematological malignancies before HSCT and after engraftment and in CGvHD patients before as well as three and six months after initiation of ECP therapy. Dependent on the time points of blood sampling we found significant differences in the percentages or cell counts of regulatory $T$ (Treg) cells, immature B cells, mDCs, soluble interleukin-2 receptor- $\alpha$ (sIL-2R $\alpha$ ), soluble tumor necrosis-factor receptor 1 (sTNF-R), and hepatocyte growth factor (HGF) between healthy controls, HSCT patients and ECP patients. 
Taken together, the combination of GvHD mouse models and the analysis of patient material represent a promising strategy to optimize the clinical application of ECP therapy in the future and should thereby contribute to a safer application of HSCT in patients suffering from hematological malignancies. 


\section{Introduction}

\subsection{Graft-versus-host disease}

\subsubsection{Hematopoietic stem cell transplantation}

Hematopoietic stem cells (HSCs) are pluripotent, able to self-renew, and give rise to a limited set of differentiated cells. Since these cells can be directly isolated from adult bone marrow (BM) and peripheral blood, HSCs are a very promising therapeutic tool. HSCT is a treatment for severe disorders of the hematopoietic system where HSCs are transferred from a healthy donor to a recipient suffering for instance from leukemia or lymphoma. If the donor and the recipient are the same person one speaks of an autologous HSCT, if both are distinct persons it is an allogeneic HSCT (Hołowiecki, 2008).

HSCs can be isolated from the BM or cord blood. Alternatively, peripheral blood stem cells (PBSCs) may be used. The low cell content of HSCs in cord blood limits the usage of their transplantation to children. In the past, most HSCTs were performed with BM cells whereas nowadays peripheral blood is the preferred source of HSCs (Körbling and Freireich, 2011). To increase the concentration of PBSCs in peripheral blood, donors are treated with human granulocyte colony-stimulating factor to mobilize the HSCs from the BM to move into the periphery (Dale, 1998).

Indications for allogeneic HSCT are various haematological malignancies such as acute lymphoblastic (ALL) or acute/-chronic myeloid leukemia (AML/CML), and Hodgkin's or NonHodgkin's lymphoma. Furthermore immunodeficiencies like X-linked lymphoproliferative disease and Wiskott-Aldrich syndrome, severe combined immunodeficiency (SCID) and defective haematopoiesis like sickle cell disease or platelet disorders are indications for HSCT (Hołowiecki, 2008; Lankester et al., 2005).

A prerequisit for allogeneic HSCT is that, donors should be either HLA identical or as similar as possible. The first allogeneic HSCT was performed in 1968 by Good and colleagues to cure an immunodeficient 5-month-old infant by transplanting BM cells and peripheral blood buffy coat cells from a histo-compatible donor (Gatti et al., 1968). As a first step in HSCT, patients have to be conditioned to eliminate malignant cells and to reduce the risk of graft rejection. The outcome of the HSCT is highly influenced by the intensity of pretransplant conditioning regimen. Based on the toxicity and immunologic consequences of the conditioning a reduced intensity is associated with higher graft rejection whereas increased intensity results in higher risk of developing GvHD (Hill et al., 1997; Truitt and Atasoylu, 1991). Patients are conditioned with chemotherapy, often combined with radiotherapy and $T$ cell-depleting antibodies. Next, a cellular graft from the donor enriched in HSCs and containing mature $\mathrm{CD}^{+}$and $\mathrm{CD} 8^{+} \mathrm{T}$ cells is infused into the preconditioned patient. Hereby haematopoietic engraftment and the graft-versus-leukemia (GvL), an anti-tumor effect, is 
boosted. However, mature $\mathrm{CD} 4^{+}$and $\mathrm{CD}^{+} \mathrm{T}$ cells in parallel are also known to induce GvHD (Shlomchik, 2007).

\subsubsection{Pathogenesis and symptoms of GvHD}

GvHD is a severe complication occuring after allogeneic HSCT that is associated with a high transplant-related morbidity and mortality (Pasquini et al., 2010). In 1966, Billingham postulated three criteria for the development of GvHD: 1. the host must be incapable of rejecting the transplanted cells; 2. transplantation antigens must differ between donor and host; 3. the graft must contain immunologically competent cells (Billingham, 1966). These immunocompetent cells have been identified as mature $T$ cells and their number correlates with disease severity (Kernan et al., 1986; Korngold and Sprent, 1978).

Originally, two forms of GvHD were definded based on the onset of disease. aGvHD is characterized by the occurrence of symptoms within the first 100 days after HSCT whereas cGvHD occurs at least 100 days after transplantation. However, nowadays a pathological classification of GvHD is thought to be more useful since symptoms of aGvHD can also occur later than 100 days post transplantation and additionally an overlap syndrome with characteristics of both forms exists (Filipovich et al., 2005; Griffith et al., 2008). The pathogenesis of aGvHD is characterized by tissue damage of organ such as skin, liver, the gastrointestinal (GI) tract, and mucosa. In most patients the first manifestation of aGvHD are in skin leading to a maculopapular rash, and/-or in the GI tract (Greinix et al., 2006a; Martin et al., 1990). If the Gl tract is involved patients suffer from diarrhea, vomiting, anorexia, and abdominal pain (Ferrara and Deeg, 1991). GvHD involving the liver is characterized by bile duct damage and cholestatic hyperbilirubinemia (Ferrara et al., 2009; Snover et al., 1984). In cGvHD not only the organs affected in aGvHD are targets but also connective tissue and exocrine glands can be affected (Ramadan and Paczesny, 2015). However, compared to the acute form of GvHD the pathophysiology of cGvHD is poorly understood (Ferrara et al., 2009). Ferrara and colleagues described three phases for the pathophysiology of aGvHD (Fig. 1). The first phase involves the activation of antigen-presenting cells (APCs) and is initiated by tissue damage caused by the underlying malignancy and/or the conditioning regimen. Damaged tissues and cells produce inflammatory cytokines such as tumor necrosis factor alpha (TNF- $\alpha$ ), interleukin 1 (IL-1) and -6 (IL-6), and release of other "danger" signals such as damage-associated molecular patterns or pathogen-associated molecular patterns including lipopolysaccharide (LPS) from intestinal microbiota (Hill and Ferrara, 2000; Ramadan and Paczesny, 2015). 
In the second phase of GvHD, the interaction between donor T cells and host APCs leads to $T$ cell activation followed by proliferation and differentiation of the T cells. Activation of these cells results in complex intracellular biochemical cascades leading to production of many proinflammatory cytokines including interferon gamma (IFN-y), TNF- $\alpha$ and IL-2 (Ferrara et al., 2009).

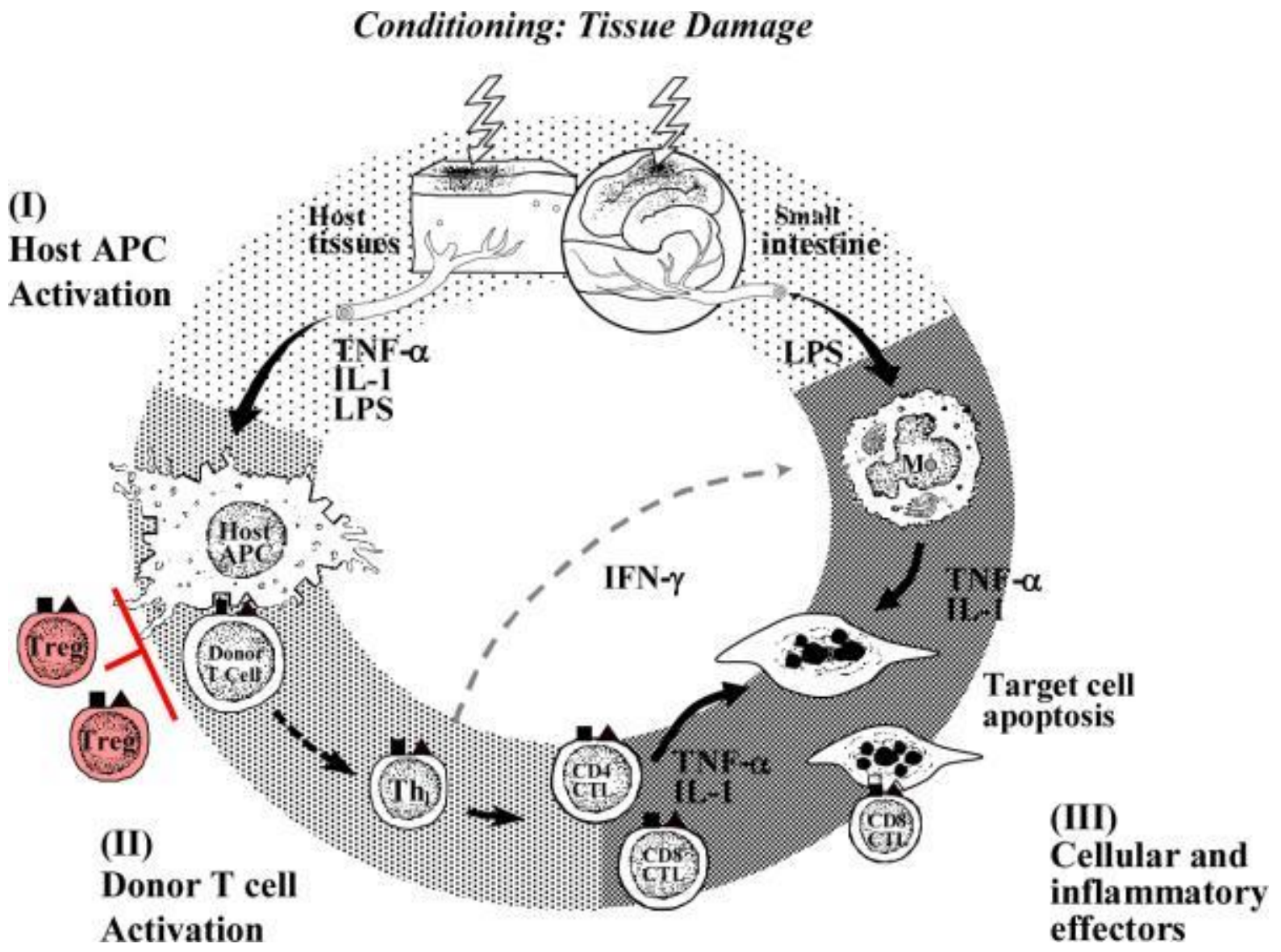

Fig. 1: Schematic overview of GvHD pathophysiology. (Reprinted from The Lancet, Vol. 373, James L M Ferrara, John E Levine, Pavan Reddy, Ernst Holler, Graft-versus-host disease, Pages No. 1550-61, Copyright (2009), with permission from Elsevier.)

In the third cellular and inflammatory effector phase the pathogenic T cells enter GvHD target organs and release additional effector molecules leading to further local tissue destruction. Cellular effector cells are mostly cytotoxic T lymphocytes (CTLs) and natural killer (NK) cells (Ferrara et al., 2009). Apoptosis induction in liver is mainly caused by the cytolytic activity of CTLs via the Fas/FasL pathway whereas in the Gl tract and skin the perforin/granzyme pathway dominates (Lowin et al., 1994; Schmaltz et al., 2001). Furthermore, migration of donor $\mathrm{T}$ cells from lymphoid tissues to GvHD target organs is mediated by several 
chemokines such as CCL2-5, CXCL2, CXCL9-11, CCL17 and CCL27 which respond to inflammatory stimuli such as TNF-a (Wysocki et al., 2005). Damaged skin or mucosa allow the infiltration of LPS and other microbial products and activate secretion of inflammatory cytokines (Hill and Ferrara, 2000). TNF- $\alpha$ is known to promote skin and gut lesions and has a variety of functions. First of all, it triggers APCs and hereby amplifies the presentation of alloantigens. Second, through activating effector cells it induces inflammatory chemokines to target specific organs, and third it damages tissues by necrosis (Brown et al., 2002; Hill et al., 2000; Piguet et al., 1987). Based on all these functions of TNF-a, one would hypothesize that inhibition of TNF- $\alpha$ after HSCT would be an approach to foster the GvL effect while diminishing the risk of developing GvHD. However, it has been found that the p55 TNF- $\alpha$ receptor submits to GvL effect by impairing CTL activity after HSCT (Hill et al., 1999).

Several risk factors for GVHD have been defined. The most important one is HLA disparity. Those patients receiving transplants from unrelated donors have a higher likelihood of developing GvHD and a worse overall outcome the greater the degree of the HLA-mismatch is (Beatty et al., 1985; Kernan et al., 1993; Szydlo et al., 1997). However, even if patients receive HLA-matched grafts they still can develop GvHD (Bortin et al., 1991). This is most likely due to disparities in minor histocompatibility antigens (miHAs) between donor and recipient (Goulmy et al., 1996; Martin, 1991). miHAs are polymorphic peptides which are presented by major histocompatibility antigens (MHC) class I or II molecules and can be recognized by $T$ lymphocytes in the transplant. Disparities of miHAs can for instance be derived from gene deletions or amino acid polymorphism (Falkenburg et al., 2003). As mentioned above, PBSCs are the preferred source of HSCs these days. Interestingly, however meta analyses have shown that aGvHD is slighty increased in patients transplanted with PBSCs compared to BM transplants (Cutler et al., 2001). Additionally, the amounts of CD34 ${ }^{+}$cells in PBSC grafts is higher, which correlates with an increased likelihood to develop GvHD (Przepiorka et al., 1999). Furthermore, the probability of GvHD rises if recipient and donor are of older age (Weisdorf et al., 1991). The likelihood of developing aGvHD is also higher if recipient and donor are of different sex, especially if a male recipient received HSCs from a female donor (Flowers et al., 1990; OKunewick et al., 1993). Finally, the intensity of the conditioning regimen correlates with an increased tissue damage resulting in a higher probability for developing aGvHD (Clift et al., 1990). 


\subsubsection{Treatment of GvHD}

\subsubsection{GvHD prophylaxis}

GvHD is a major complication after allogeneic HSCT but at the same time the GvL effect plays an important role in eradicating residual malignant cells. Therefore, GvHD prophylaxis is an important issue. After myeloablative conditioning a combination of immunosuppressant drugs such as the calcineurin inhibitor cyclosporin $A(C s A)$ and low-dose methotrexate (MTX) is routinely administrated for prevention of aGvHD (Ruutu et al., 2014; Storb et al., 1988). CsA inhibits T cell activation by blocking the calcineurin/NFAT pathway as well as the Jun amino-terminal kinases (JNK) and p38 signaling pathways (Matsuda and Koyasu, 2000). The folate antagonist MTX is able to delete proliferating donor lymphocytes (Pavletic and Fowler, 2012). Furthermore, another calcineurin inhibitor named tacrolimus (TAC) was tested in clinical trials and found to reduce the incidence of aGvHD in patients receiving TAC/MTX combination therapy as compared to those administered CsA/MTX alone (Nash et al., 2000; Ratanatharathorn et al., 1998). Patients treated with a reduced intensity conditioning regularly receive a combination of $\mathrm{CsA}$ and mycophenolate mofetil (MMF). Via its metabolite mycophenolic acids, MMF inhibits proliferation of activated lymphocytes (Bornhäuser et al., 1999).

Although the administration of calcineurin inhibitors combined with MMF or MTX results in a good survival rate, many patients are still dying from GvHD. Since T cells play a key role in pathogenesis of GvHD several attempts to reduce $T$ cell numbers with monoclonal antibodies were made to prevent GvHD. However, this attempt resulted in an increased risk of leukemia relapse, infections and graft failure (Antin, 2011). Another strategy regularly used in the clinics is the anti-thymocyte globulin (ATG) an in vivo used anti-Jurkat antibody. ATG recipients had significantly reduced aGvHD severity and additionally a reduced 3-yearincidence of cGvHD (Socié et al., 2011).

\subsubsection{First-line treatment of GvHD}

Despite the standard use of preventive approaches many allogeneic transplanted patients are still diagnosed with GvHD. However, before GvHD treatment can be initiated the severity of the disease has to be graded according to the Keystone Consensus 1994 (Przepiorka et al., 1995) or the CIBMTR criteria (Rowlings et al., 1997).

Until now, GC treatment is the standard first-line therapy for aGVHD. Except for aGvHD patients with upper GI tract involvement receiving $1 \mathrm{mg} / \mathrm{kg}$ per day, most aGvHD patients receive methylprednisolone at $2 \mathrm{mg} / \mathrm{kg} /$ day or prednisone at 2 to $2.5 \mathrm{mg} / \mathrm{kg}$ per day (Hockenbery et al., 2007). This therapy results in a complete response rate of 25 to $54 \%$ 
(Martin et al., 2012a). It is noteworthy that higher doses of corticosteroids of $10 \mathrm{mg} / \mathrm{kg} / \mathrm{day}$ seem to have no advantage compared to the normal dose (Van Lint et al., 1998). On the other hand, in a retrospective study a reduced corticosteroid dose of $1 \mathrm{mg} / \mathrm{kg} /$ day resulted in no disadvantages as compared to the normal dose of $2 \mathrm{mg} / \mathrm{kg} /$ day (Mielcarek et al., 2009). GCs have broad anti-inflammatory, pro-apoptotic and immunosuppressive activity (Martin et al., 2009). Nonetheless, it has to be taken into account that the prolonged application of highdose GCs may come along with several side effects such as opportunistic infections, diabetes, or osteoporosis (Martin et al., 2012b; Martínez and Urbano-Ispízua, 2011).

Several approaches were taken and failed to find a possibility to intensify the first-line treatment. As an example, the addition of antibodies against IL-2 (daclizumab) or TNF- $\alpha$ (infliximab) did not improve response rates (Couriel et al., 2009; Lee et al., 2004; Levine et al., 2008).

The initial dose of the first-line treatment is administrated for five to ten days and is tapered slowly when patients respond. When patients do not respond to GC treatment or show progression of the disease, administration is continued and second-line treatment initiated (Martin et al., 2012a).

Compared to aGvHD the chronic form of GvHD is generally treated with GCs often combined with CsA and TAC (Wolff et al., 2010). However the response to this treatment cannot be predicted and overall only 20 to $50 \%$ of cGvHD patients gain complete resolution of GvHD (Martin et al., 2009). It is noteworthy that it even may occur that organs respond differently in the same patient.

\subsubsection{Second-line treatment of GvHD}

In cases where GCs fail to sufficiently control GVHD, a second-line treatment needs to be initiated. Up to now specific guidelines for the administration of second-line treatment are not defined and differ among clinicians (Martin et al., 2012a). In 2012, Martin and colleagues compared several studies with possible agents for second-line treatment in GC-refractory aGvHD patients: antimetabolites, ECP, monoclonal antibodies against IL-2, TNF- $\alpha$, CD52, and ATG. However, based on the overall survival and complete response rates they found no evidence that any of these therapies were better or worse than the other. In contrast, it was found a higher survival rate in patients suffering from GC-refractory grade II aGvHD treated with ECP therapy compared to those treated with anticytokine therapy (Jagasia et al., 2013). 


\subsection{Extracorporeal photopheresis therapy}

\subsubsection{Apheresis procedure of ECP in clinics}

ECP combines two well-known treatment modalities in dermatology. The first modality "PUVA" is a combination of the light-sensitive agent 8-MOP and UV-A. The second modality is leukapheresis where nucleated cells are separated from patient's blood.

The first closed system of an instrument for ECP treatment was developed by Richard Edelson. It consisted of a large radiation chamber and a standard blood circulating system also used in dialysis. Since then, the photopheresis device was improved with regard to the efficacy of cell separation and handling, treatment time and applicability for low body weight patients.

During the ECP procedure, whole blood is drawn from the patient and mechanically separated into plasma and cellular fractions. The mechanical separation is based on density centrifugation. Erythrocytes are directly returned to the patient whereas approximately $5-10 \%$ of the circulating mononuclear cells (MNCs) are collected and treated with $200 \mathrm{ng} / \mathrm{ml} 8-\mathrm{MOP}$. Afterwards these leukocytes are irradiated at $2 \mathrm{~J} / \mathrm{cm}^{2}$ in an UV-A irradiator. During PUVA treatment 8-MOP quickly permeates the nuclear membrane and cross-links the deoxyribonucleic acid (DNA) leading to the induction of apoptosis in treated lymphoid cells, in particular natural killer and T cells (Wolnicka-Glubisz et al., 2010). Subsequently, these cells undergo cell death one to two days after reinfusion into the patient (Greinix et al., 2006a). ECP is recommended on two consecutive days (one cycle) per week until therapeutic response is achieved, and then tapered to alternate weeks before discontinuation (DasGupta et al., 2014).

Although ECP therapy is well tolerated and associated with minimal side effects, there are some limitations to this procedure. First of all, patients must have a good venous access for performing ECP therapy. Especially in patients with skin involvement the access may be difficult, which limits ECP performance. Furthermore, patients must be able to tolerate reinfusion of PUVA-treated MNCs and must be able to resist the sings of volumes during apheresis. Another rare but regularly occurring contraindication is an allergy against 8-MOP or heparin. Furthermore, patients with low numbers of white blood cells ( $<1 \times 10^{9}$ per liter) would probably not benefit from ECP therapy. (Greinix and Knobler, 2012)

\subsubsection{Potential mechanisms of action of ECP therapy}

Although ECP therapy has been used in the clinic for more than 30 years treating several diseases, the mechanism of action is yet poor understood. Some studies pointed out that the therapeutic effect of ECP therapy is based on the induction of lymphocyte apoptosis (Bladon 
and Taylor, 1999; Gerber et al., 2000). In contrast to other immunosuppressive therapies ECP therapy induces immune tolerance by inhibiting alloantigen-responding $T$ cells using apoptotic leukocytes (Marshall, 2006; McKenna et al., 2006). The immunmodulatory effect may include the modulation of dendritic cells (DCs), induction of $T$ cell subpopulations and changes in cytokine levels (Goussetis et al., 2012; Voss et al., 2010). After ECP therapy monocytes seem to differentiate into immature DCs which subsequently, phagocytose apoptotic lymphocytes and present their antigenic peptides (Hannani et al., 2010; Spisek et al., 2006). This differentiation process is accompanied by secretion of various cytokines such as TNF- $\alpha$ and IL-6 and an activation of macrophages (Fimiani et al., 1997). Additionally, ECP therapy seems to increase the release of anti-inflammatory cytokines whereas proinflammatory cytokines are reduced (Bladon and Taylor, 2006).

In GvHD patients it was shown that ECP therapy modulates the arginine metabolism known to play a role in immune tolerance by upregulating IL-10 (Merlin et al., 2011). Furthermore ECP therapy also induces Treg cells suppressing the activity of other lymphocytes but without causing general immunosuppression (Maeda et al., 2005a, 2008a). Thus IL-10 is thought to be involved in these processes since it plays a role in Treg cells that inhibit the effector phase of GvHD (Maeda et al., 2008b).

Up to now several research groups have studied the effect of ECP on Treg cells. Rezwani and colleagues found that allogeneic transplanted patients with low number of Treg cells have a higher risk of developing aGvHD (Rezvani et al., 2006; Wolf et al., 2007). Additionally, the induction of Treg cells was confirmed in a mouse model (Gatza et al., 2008). 


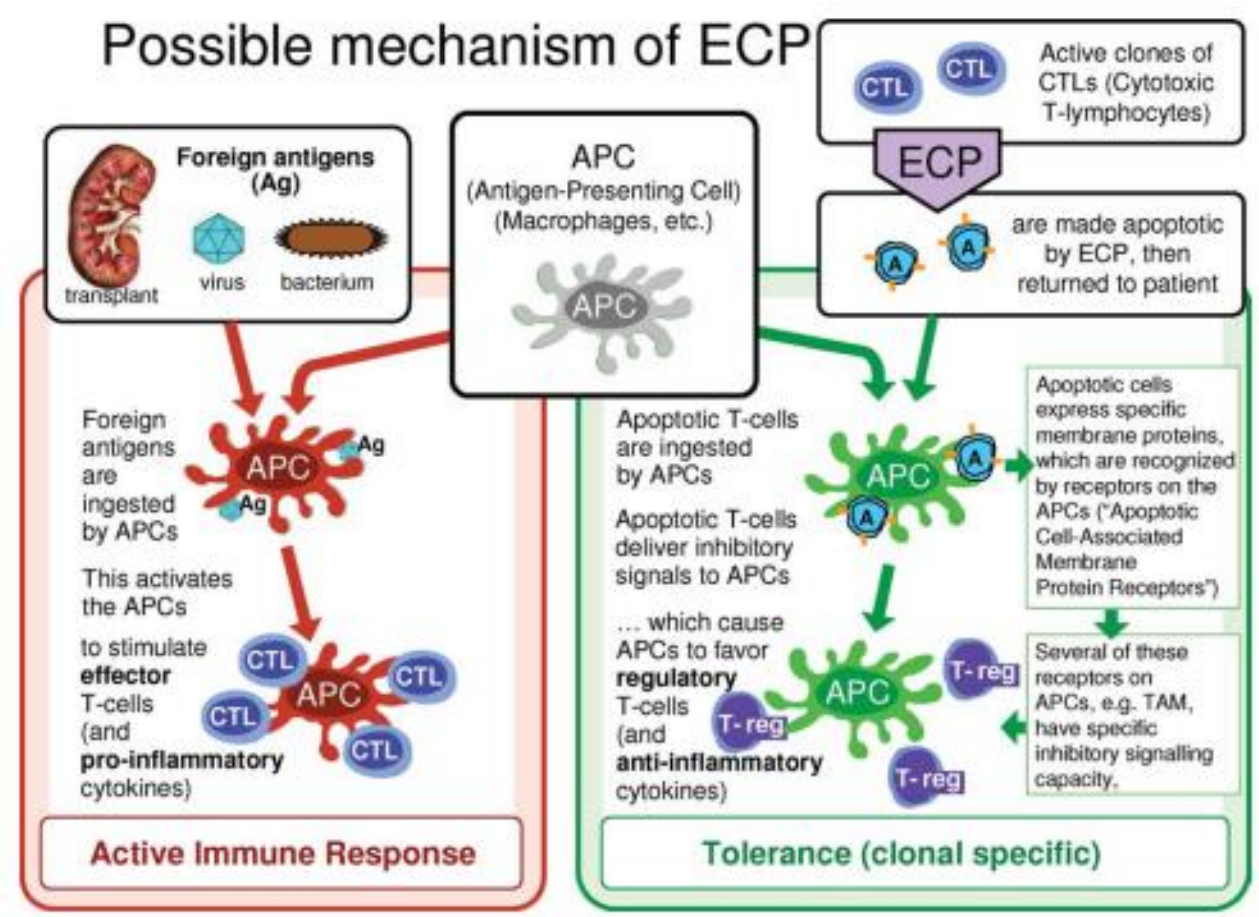

Fig. 2: Scheme of possible modes of action of ECP treatment. During GvHD, APCs phagocytose foreign antigens and present them to $T$ cells. Subsequently, cytokines are secreted which start to stimulate CTL activity directed against foreign antigens. ECP therapy causes apoptosis in activated CTLs. After reinfusion of these apoptotic CTLs into the patient, APCs recognize apoptosis-specific proteins and start producing anti-inflammatory cytokines as well as promoting the development of Treg cells. (Reprinted from Journal of Clinical Apheresis, Vol. 26, David M. Ward, Extracorporeal photopheresis: How, when, and why, Pages No. 276-85, Copyright (2011), with permission from Wiley-Liss, Inc.)

\subsubsection{ECP therapy for the treatment of GvHD}

In 2000 BC Egyptian healers had treated patients suffering from a pigment disorder "vitiligo" with 8-MOP which was part of a boiled extract acquired from the weed Ammi majus and exposed them to natural sun light (Pathak and Fitzpatrick, 1992). Several millenniums and modifications later, Richard Edelson introduced ECP in 1981 as treatment of cutaneous T cell lymphoma (CTCL) (Edelson et al., 1987). In 1988, the FDA approved ECP as the first authorized cellular immunotherapy for any cancer (Worel and Leitner, 2012). Based on the high efficacy of ECP in CTCL, the potential therapeutic effect of ECP was studied in other T cell mediated diseases as well, including systemic sclerosis (Rook et al., 1992), solid organ rejection (Barr et al., 1998; Costanzo-Nordin et al., 1992) and GvHD (Flowers et al., 2008; Greinix et al., 1998).

ECP therapy is well tolerated and has minimal side effects (Hart et al., 2013). In comparison to immunosuppressive therapies, it is not associated with increasing rates of opportunistic 
infections (Greinix et al., 2000). Several studies were performed to determine the therapeutic effect of ECP in GvHD patients. In a cohort of 59 aGVHD patients, ECP therapy led to a complete remission (CR) in $82 \%, 61 \%$ and $60 \%$ of patients, respectively having either cutaneous, liver or gut involvement (Greinix et al., 2006a). In addition, patients with only cutaneous symptoms had the highest CR rate (87\%). Those where two organ systems were involved had lower CR rates (40-62\%) and those with three organ systems involved had even lower CR rates (25\%). Cutaneous cGVHD completely resolved in $80-92 \%$ of patients treated with ECP (Dignan et al., 2012; Greinix et al., 1998).

\subsection{Mouse models of GvHD and ECP}

Precise and reproducible mouse models of GvHD are crucial in advancing our understanding of the pathomechanism of GVHD in its acute and chronic forms. Mouse models are essential for finding new therapies or for modifying current treatment regimens aimed to increase their efficacy. The understanding of the biology of GvHD has largely been defined using mouse models. Korngold and colleagues found in 1978 that T cell alloreactivity is the underlying cause of both forms of GvHD (Korngold and Sprent, 1978; Sprent et al., 1986). In mice, both forms of GvHD have different phenotypes which mainly results from the differential involvement of CTLs or T helper (Th) cells (Schroeder and DiPersio, 2011a).

The severity of aGvHD in mice depends on several factors. The conditioning of the recipient mice is usually performed by body irraditation and the dose correlates with the degree of tissue damage. The resulting cytokine storm is directly proportional to the mortality of the recipient mice (Hill et al., 1997; Schwarte and Hoffmann, 2005). Furthermore, the type, genetic source and dose of the $\mathrm{T}$ cell subsets in the graft can influence the severity and outcome of aGvHD (Korngold, 1992; Korngold and Sprent, 1978; Sprent et al., 1988). Another factor affecting the severity of aGvHD are the slight the differences between mice obtained from individual suppliers concerning environmental pathogens and genetic factors.

There are several mouse models of aGvHD existing. The most commonly studied total MHCmismatch model of aGvHD involves the grafting of BM and T cells from the C57BL/6 mice into irradiated BALB/c recipient mice (C57BL/6->BALB/C). In this model both, CD8 ${ }^{+}$CTLs and $\mathrm{CD}^{+}{ }^{+}$Th cells contribute to the phenotype (Sprent et al., 1990). CD8 ${ }^{+}$T cells are activated by recipient APCs via binding of the T cell receptor (TCR) to MHC class I peptide complexes leading to the release of perforin, granzymes and the expression of Fas ligand (Graubert et al., 1997; Maeda et al., 2005b; Shlomchik et al., 1999; Via et al., 1996). In contrast, CD4 ${ }^{+}$ cells can be activated by donor or recipient APCs leading to a TNF- $\alpha$-mediated cytotoxic effect in the recipient epithelium (Schroeder and DiPersio, 2011a). 
Compared to aGvHD models, the induction of cGvHD in bone marrow transplantation (BMT) models using inbred mouse strains is difficult. The sclerodermatous (pro-fibrotic) cGvHD model is characterized by fibrotic damages in the dermis of lung, liver and salvary glands. The mostly studied scleroderma model is based on BALB/C mice receiving a B10.D2 graft (B10.D2->BALB/C) (Jaffee and Claman, 1983). This model is a MHC-match but miHAmismatch model of $C G v H D$ with mainly $C D 4^{+} \mathrm{T}$ cells contributing to its phenotype. Recipient mice are irradiated sublethally and transplanted with BM cells and splenocytes. The development of fibrotic changes in cGvHD mouse model starts within 30 days after transplantation which is more rapid than in patients. (Schroeder and DiPersio, 2011)

Gatza and co-workers transferred the clinically used human ECP setup into a MHC-matched but miHA-mismatched mouse model of aGvHD. They found that the conventional ECP had a therapeutic effect on aGvHD (Gatza et al., 2008). This finding was confirmed by Budde and colleagues who observed a therapeutic effect of conventional ECP in a total MHC-mismatch mouse model of aGvHD (Budde et al., 2014).

\subsection{GvHD biomarkers}

Biological markers also named biomarkers are molecular, biochemical or cellular alterations which can be measured in tissues, fluids and cells of species. Biomarkers help differentiating between normal or pathologic biological processes and can contribute to the understanding of disease causes or the prediction and response rates to treatment regimens (Naylor, 2003; Talbott and Craun, 1995).

An ideal biomarker has to be non-invasively accessible. Its measurements should be precise, reproducible, and cost-effective. Furthermore, it should be able to measure the biomarkers with high specificity and sensitivity. Concerning GvHD, a biomarker should be able to differentiate between patients with and those without GvHD. Additionally the most valuable biomarker will be able to categorize the risk of each patient to develop GvHD in order to begin preventive therapies even before symptoms manifest. (Paczesny et al., 2013).

With regard to GvHD, one looks for biomarkers that indicate the risk to develop GvHD after HSCT, the prognosis, and responsiveness to treatment. Several types of biomarkers are currently under investigation. In this context, cellular immunoregulatory and inflammatory biomarkers are discussed. In aGvHD and cGvHD there are various immune cell populations which are already thought to represent GvHD biomarkers.

Amongst others, $\mathrm{CD}^{+} \mathrm{T}$ cells as well as $\mathrm{CD}^{+}$and $\mathrm{CD}^{+} \mathrm{T}$ cells levels are known to be increased in cGvHD (Abrahamsen et al., 2005; D’Asaro et al., 2006; Yamashita et al., 2004). 
In contrast, $\mathrm{CD}^{+}$cells are increased in aGvHD (August et al., 2011). Furthermore, immature $\mathrm{B}$ cells $\left(\mathrm{CD} 19^{+} \mathrm{CD} 21^{-}\right)$were found to be elevated when comparing patients developing cGvHD and to those not suffering from cGvHD (Greinix et al., 2008).

mDCs are APCs that bind antigens in the periphery and migrate to lymphoid organs in order to initiate immunity (Steinman and Inaba, 1999). In aGvHD and cGvHD patients the absolute numbers of mDCs in blood were found to be decreased (Akhtari et al., 2010; Lau et al., 2007). Increased numbers of Treg cells $\left(\mathrm{CD} 4^{+} \mathrm{CD} 5^{+} \mathrm{FoxP}^{+}\right)$which help to maintain immune tolerance and to promote immune reconstitution after HSCT, were found to prevent aGvHD (Magenau et al., 2010; Rezvani et al., 2006; Wolf et al., 2007).

HGF is a multifunctional cytokine produced by mesenchymal cells and mainly targeting epithelial cells. In the serum of aGvHD patients increased HGF concentrations correlated with the severity of aGvHD (Okamoto et al., 2001). However, HGF also has anti-apoptotic properties resulting in enhanced liver repair and regeneration (Luft et al., 2007). For instance, HGF administration in an aGvHD mouse model resulted in the prevention of aGvHD (Kuroiwa et al., 2001). Therefore it may not only indicate the degree of organ damage but also estimate the response to narrow down further damage from GvHD.

Several studies confirmed that sIL-2R levels are elevated in aGvHD and cGvHD patients (Foley et al., 1998; Miyamoto et al., 1996; Visentainer et al., 2003). Presumably a set of several biomarkers will be more informative for the prediction of GvHD than one single biomarker. In 2011, August et al. monitored the mean serum level of sIL-2R and TNF-R1 during the first month after allogeneic HSCT. They found that that SIL-2R and TNF-R1 levels increased during the first two weeks after transplantation in patients with aGvHD. Based on these findings they postulated that aGvHD occurrence is predictable using sIL-2R and TNF$\mathrm{R} 1$ levels together with CD8 as biomarkers (August et al., 2011).

\subsection{Objectives}

This PhD project deals with cellular mechanisms and the optimization of the ECP protocol currently used in the clinic and the identification of related biomarkers. ECP therapy is a second-line treatment frequently performed in patients suffering from aGvHD and cGvHD. However, the apheresis procedure is physically exhausting especially for patients with severe aGvHD. In addition several patients are refractory to this treatment. In this case, a modification of the ECP procedure would be beneficial. This could be achieved, for instance, by replacing the patient's own leukocytes by those from a third party donor, thereby saving the patient from doing the apheresis procedure 
Based on this background, we wanted to modify and optimize ECP therapy using well known mouse models of aGvHD and cGvHD. One major goal was to improve the course of disease by changing the original ECP setup using cells derived from healthy mice. For this purpose, MHC matched and mismatched leukocytes derived from different donor mouse strains ( $\mathrm{C} 57 \mathrm{BL} / 6, \mathrm{C} 3 \mathrm{H}, \mathrm{BALB} / \mathrm{c})$ as well as cells activated in vitro were used as grafts and their efficacy in ameliorating the clinical disease course was tested. Additionally, the cellular mechanism was investigated by studying the frequency of different leukocyte populations.

In parallel, we not only wanted to improve ECP therapy but also try to predict whether patients would suffer from GvHD or respond to ECP therapy. Biomarkers could be a helpful tool to achieve both.

Hence, in the course of this study the ground for identification of putative GvHD and ECP biomarker should be layed. As a first step blood and serum samples of allogeneic transplanted patients, steroid-refractory patients receiving ECP therapy, and healthy blood donors were collected. As a second step, different cell subpopulations and cytokine levels should then be compared to determine reference values of healthy blood donors. During the last step we aimed to compare levels of potential biomarkers between healthy donors, HSCT patients and ECP patients.

By combining mouse models and human samples we thought to obtain new insight allowing to make ECP therapy more tolerable for the patients and to predict the occurrence of GvHD and the responsiveness to ECP therapy. Taken together, this should contribute to a safer future application of HSCT for patients suffering from hematological malignancies. 


\section{Material and methods}

\subsection{Material}

\subsubsection{Technical equipment}

Tab. 1: Technical equipment

\begin{tabular}{|c|c|c|}
\hline Equipment & Type & Manufacturer \\
\hline Accu Jet & pipetus & Hirschmann, Eberstadt \\
\hline Autoclave & FVA3 & Fedegari, Munich \\
\hline \multirow[t]{4}{*}{ Centrifuges } & Rotanta 46 RS & Hettich, Kirchlengern \\
\hline & Mikro 22R & Hettich, Kirchlengern \\
\hline & Universal 32R & Hettich, Kirchlengern \\
\hline & ProFuge $^{T M} 10 \mathrm{~K}$ & $\begin{array}{l}\text { Stratagene California, La } \\
\text { Jolla, USA }\end{array}$ \\
\hline Cooling container & NALGENE ${ }^{\mathrm{R}}$ labtop cooler & $\begin{array}{l}\text { Thermo Fisher Scientific, } \\
\text { Waltham, USA }\end{array}$ \\
\hline $\begin{array}{l}\text { Counting chambers, bright- } \\
\text { lined (Neubauer) }\end{array}$ & $\begin{array}{l}\text { Neubauer improved } \\
\text { cell chamber }\end{array}$ & Sarstedt, Nümbrecht \\
\hline ELISA spectrophotometer & Magellan Sunrise Remote & TECAN, Männedorf, Schweiz \\
\hline Flow Cytometer & BD FACS CANTO II & $\begin{array}{l}\text { BD Bioscience, San Jose, } \\
\text { USA }\end{array}$ \\
\hline Forceps & variant types & $\begin{array}{l}\text { Fine Science Tools, } \\
\text { Heidelberg }\end{array}$ \\
\hline Freezer & $-20^{\circ} \mathrm{C}$, Comfort & Liebherr, Kirchdorf \\
\hline Gamma Irradiator & Biobeam 8000 & $\begin{array}{l}\text { Gamma-Service Medical, } \\
\text { Leipzig }\end{array}$ \\
\hline Incubator & Hera cell & Heraeus, Hanau \\
\hline Infrared lamp & Sollux 750 & Original Hanau, Hanau \\
\hline Irradiation unit & Xstrahl RS225 & $\begin{array}{l}\text { Gulmay Medical Limited, } \\
\text { Surray, UK }\end{array}$ \\
\hline MACS cell separator & MACS $^{\text {TM }}$ Separator & $\begin{array}{l}\text { Miltenyi Biotec GmbH, } \\
\text { Bergisch Gladbach }\end{array}$ \\
\hline Microplate mixer & MTS-2 & IKA- Werke, Staufen \\
\hline Mouse restrainer & & $\begin{array}{l}\text { scientific shop UMG, } \\
\text { Göttingen }\end{array}$ \\
\hline Multi- Axle Rotating mixer & IDL TRM-50 & IDL, Schmitten \\
\hline PH- Meter & Lab-pH-Meter 765 & Knick, Berlin \\
\hline Pipettes & $\begin{array}{l}\text { Research, Reference, } \\
\text { Multipette Plus }\end{array}$ & Eppendorf, Hamburg \\
\hline Perspex box & & $\begin{array}{l}\text { scientific shop UMG, } \\
\text { Göttingen }\end{array}$ \\
\hline Pocket scale for mice & TEE150-1 & Kern\& Sohn, Balingen \\
\hline Refrigerator & $8^{\circ} \mathrm{C}$, Premium & Liebherr, Kirchdorf \\
\hline Scale & BP 41OS & Sartorius AG, Göttingen \\
\hline Scissors & variant types & $\begin{array}{l}\text { Fine Science Tools, } \\
\text { Heidelberg }\end{array}$ \\
\hline Sterile bench & $\begin{array}{l}\text { Mikroflow biological } \\
\text { safety cabinet }\end{array}$ & NUNC, Roskilde, Denmark \\
\hline $\begin{array}{l}\text { Transmitted-light } \\
\text { microscope }\end{array}$ & Axiostar & ZEISS, Göttingen \\
\hline
\end{tabular}




\begin{tabular}{|c|c|c|}
\hline Ultralow freezer & $-80^{\circ} \mathrm{C}$ & NuAire, Plymouth, USA \\
\hline UV radiation device & & Vilber Lourmat, Eberhardzell \\
\hline Vortexer & Vortex-Genie 2 & $\begin{array}{l}\text { Scientific industries, New } \\
\text { York, USA }\end{array}$ \\
\hline Water bath & & $\begin{array}{l}\text { Köttermann GmbH \& Co KG, } \\
\text { Uetze }\end{array}$ \\
\hline
\end{tabular}

\subsubsection{Chemicals}

Tab. 2: Chemicals

\begin{tabular}{|c|c|}
\hline Chemicals & Manufacturer \\
\hline 9-Methoxyfuro[3,2-g][1]benzopyran-7-one (8-MOP) & UMG, pharmacy, Göttingen \\
\hline 2-Propanol & Merck, Darmstadt \\
\hline Alkopharm 80 & BrüggemannAlcohol, Heilbronn \\
\hline Ampuwa & Fresenius Kabi, Bad Homburg \\
\hline Annexin Binding Buffer & BioLegend, San Diego, USA \\
\hline Aqua bidest & B.Braun, Melsungen \\
\hline $\begin{array}{l}\text { AutoMACS Running Buffer- } \\
\text { MACS R Separation Buffer }\end{array}$ & $\begin{array}{l}\text { Miltenyi Biotec, Bergisch } \\
\text { Gladbach }\end{array}$ \\
\hline Cell Proliferation Dye eFluor R 450 & $\begin{array}{l}\text { eBioscience, Inc., San Diego, } \\
\text { USA }\end{array}$ \\
\hline Concanavalin A & Sigma-Aldrich, St. Louis, USA \\
\hline Dimethyl Sulfoxide $\geq 99.8 \%$ & Sigma-Aldrich, St. Louis, USA \\
\hline Ficoll-Paque TM PLUS & $\begin{array}{l}\text { GE Healthcare, } \\
\text { Buckinghamshire, UK }\end{array}$ \\
\hline $\begin{array}{l}\text { Foxp3 / Transcription Factor Fixation/Permeabilization } \\
\text { Concentrate and Diluent }\end{array}$ & $\begin{array}{l}\text { eBioscience, Inc., San Diego, } \\
\text { USA }\end{array}$ \\
\hline Heparin-Natrium 5000 (iE/0,2ml) & Ratiopharm, Ulm \\
\hline Ionomycin calcium salt & Sigma-Aldrich, St. Louis, USA \\
\hline Monensin Solution $(1,000 \mathrm{X})$ & BioLegend, San Diego, USA \\
\hline Neomycin trisulfate salt hydrate & Sigma-Aldrich, St. Louis, USA \\
\hline Novaminsulfon Lichtenstein Tropfen $(500 \mathrm{mg} / \mathrm{ml})$ & $\begin{array}{l}\text { Zentiva, Prague, Czech } \\
\text { Republic }\end{array}$ \\
\hline PBS without $\mathrm{Ca}^{2+}$ and $\mathrm{Mg}^{2+}$ & $\begin{array}{l}\text { Thermo Fisher Scientific, } \\
\text { Waltham, USA }\end{array}$ \\
\hline Phorbol 12-Myristate 13-Actetate & Sigma-Aldrich, St. Louis, USA \\
\hline Phosphate Buffered Saline without $\mathrm{Ca}$ and $\mathrm{Mg}$ & Lonza Group, Basel, Schweiz \\
\hline RBC Lysis buffer (10X) & Sigma-Aldrich, St. Louis, USA \\
\hline Recombinant Murine PDGF-AA & $\begin{array}{l}\text { PeproTech EC Ltd., London, } \\
\text { UK }\end{array}$ \\
\hline Tri- Sodium citrate dihydrate & Merck, Darmstadt \\
\hline
\end{tabular}




\subsubsection{Consumables}

Tab. 3: Consumables

\begin{tabular}{|c|c|c|}
\hline Equipment & Specification & Manufacturer \\
\hline Cell culture flasks & $25 \mathrm{~cm}^{2}$ T-25 Flask, Cyto One & Starlab, Ahrensburg \\
\hline Cell culture flasks & $75 \mathrm{~cm}^{2}$, Cellstar & $\begin{array}{l}\text { Greiner Bio-One, Kremsmünster, } \\
\text { Österreich }\end{array}$ \\
\hline Cell culture plates & $5 \mathrm{~cm}$ & Sarstedt, Nümbrecht \\
\hline Cell culture plates & $10 \mathrm{~cm}$ & Nunc A/S, Roskilde, Danmark \\
\hline Cell strainer & $70 \mu \mathrm{m}$ Nylon, Falcon & $\begin{array}{l}\text { Thermo Fisher Scientific, Waltham, } \\
\text { USA }\end{array}$ \\
\hline Cell strainer & $40 \mu \mathrm{m}$ Nylon, Falcon & $\begin{array}{l}\text { Thermo Fisher Scientific, Waltham, } \\
\text { USA }\end{array}$ \\
\hline Centrifuge tube & $50 \mathrm{ml}$ Cellstar & $\begin{array}{l}\text { Greiner Bio-One, Kremsmünster, } \\
\text { Österreich }\end{array}$ \\
\hline $\begin{array}{l}\text { Combitips } \\
\text { advanced }\end{array}$ & $5 \mathrm{ml}$ & Eppendorf, Hamburg \\
\hline $\begin{array}{l}\text { Culture multiwell } \\
\text { plates }\end{array}$ & 6-well & $\begin{array}{l}\text { Greiner Bio-One, Kremsmünster, } \\
\text { Österreich }\end{array}$ \\
\hline FACS tube & $\begin{array}{l}5 \mathrm{ml}, \text { FALCON round bottom } \\
\text { tube }\end{array}$ & Corning Science, Mexico \\
\hline Freezing tube & Cryo.S, $2 \mathrm{ml}$ & $\begin{array}{l}\text { Greiner Bio-One, Kremsmünster, } \\
\text { Österreich }\end{array}$ \\
\hline $\begin{array}{l}\text { Glass Pasteur } \\
\text { Pipettes }\end{array}$ & & Brand, Wertheim \\
\hline Gloves & Nitril & $\begin{array}{l}\text { Rösner-Mautby Meditrade, } \\
\text { Kiefersfelden }\end{array}$ \\
\hline Insulin syringe & U-100 Insulin, 30G, 0,3 ml & BD, Durham, USA \\
\hline $\begin{array}{l}\text { MACS LS } \\
\text { Separation Columns }\end{array}$ & & $\begin{array}{l}\text { Miltenyi Biotec } \mathrm{GmbH} \text {, Bergisch } \\
\text { Gladbach }\end{array}$ \\
\hline Parafilm & & Pechiney, Paris, Frankreich \\
\hline Pipette tip & $10 \mu \mathrm{l}, 100 \mu \mathrm{l}, 1000 \mu \mathrm{l}$ & Starlab, Ahrensburg \\
\hline Pipette tip & $2.5 \mu \mathrm{l}$ & Biozym Scientific, Hessisch Oldendorf \\
\hline $\begin{array}{l}\text { Polystyrene } \\
\text { conical tube }\end{array}$ & $15 \mathrm{ml}$ & BD, Durham, USA \\
\hline Reaction tube & $0.5 \mathrm{ml}, 1 \mathrm{ml}, 2 \mathrm{ml}$ & Sarstedt, Nümbrecht \\
\hline Serological pipet & $2 \mathrm{ml}, 5 \mathrm{ml}, 25 \mathrm{ml}$ & Falcon, Durham, USA \\
\hline Serological pipet & $10 \mathrm{ml}$ & Sarstedt, Nümbrecht \\
\hline S-Monovette & Heparin, $4.7 \mathrm{ml}$ & Sarstedt, Nümbrecht \\
\hline S-Monovette & $\begin{array}{l}\text { Clotting Activator/Serum } 2.7 \\
\mathrm{ml}\end{array}$ & Sarstedt, Nümbrecht \\
\hline Surgical headwear & & $\begin{array}{l}\text { Mölnlycke Health Care, Göteburg, } \\
\text { Sweden }\end{array}$ \\
\hline Surgical mask & & Farstar medical GmbH, Barsbüttel \\
\hline Syringe & $5 \mathrm{ml}$ & BD, Durham, USA \\
\hline $\begin{array}{l}\text { Syringe with } \\
\text { needle }\end{array}$ & $\begin{array}{l}1 \mathrm{ml}, 26 \mathrm{GA} 3 / 4 \mathrm{IN}, 0.45 \times 10 \\
\mathrm{~mm}\end{array}$ & BD, Durham, USA \\
\hline
\end{tabular}




\subsubsection{Antibodies for cell separation}

Tab. 4: Antibodies for cell separation

\begin{tabular}{|c|c|c|c|c|}
\hline Antigen & Isotype & Manufacturer & $\begin{array}{l}\mu \mathrm{g} \text { or } \mu \mathrm{l} \\
/ 100 \mu \mathrm{l}\end{array}$ & $\begin{array}{l}\text { incubation } \\
{[\mathrm{min}]\left[{ }^{\circ} \mathrm{C}\right]}\end{array}$ \\
\hline $\begin{array}{l}\text { CD90.2 Micro } \\
\text { Beads }\end{array}$ & Rat lgG2b & $\begin{array}{l}\text { Miltenyi Biotec } \mathrm{GmbH} \text {, } \\
\text { Bergisch Gladbach }\end{array}$ & $10 \mu \mathrm{l}$ & 15 \\
\hline
\end{tabular}

3.1.5. Antibodies for flow cytometry 
3.1.5.1. Mouse antibodies

Tab. 5: Mouse antibodies

\begin{tabular}{|c|c|c|c|c|c|c|c|}
\hline Antigen & Fluorochrome & Clone & Isotype & Manufacturer & $\begin{array}{l}\mu \mathrm{g} \text { or } \mu \mathrm{l} \\
/ 100 \mu \mathrm{l}\end{array}$ & \multicolumn{2}{|c|}{$\begin{array}{l}\text { incubation } \\
{\left[\text { min] }\left[{ }^{\circ} \mathrm{C}\right]\right.}\end{array}$} \\
\hline Annexin V & Pacific Blue & - & $\begin{array}{l}\text { all mammalian } \\
\text { species }\end{array}$ & BioLegend, San Diego, USA & $0.1 \mu \mathrm{g}$ & 10 & $\mathrm{RT}$ \\
\hline Annexin V & FITC & - & $\begin{array}{l}\text { all mammalian } \\
\text { species }\end{array}$ & BioLegend, San Diego, USA & $0.2 \mu \mathrm{g}$ & 10 & $\mathrm{RT}$ \\
\hline $\begin{array}{l}\text { CD117 } \\
\text { antibodies }\end{array}$ & APC & $3 \mathrm{C1}$ & Rat IgG2b & $\begin{array}{l}\text { Miltenyi Biotec GmbH, Bergisch } \\
\text { Gladbach }\end{array}$ & $10 \mu \mathrm{l}$ & 10 & 4 \\
\hline CD229.1 & APC & $30 \mathrm{C7}$ & Rat IgG2a & BD Biosciences, New Jersey, USA & $0.5 \mu \mathrm{g}$ & 20 & 4 \\
\hline CD25 & $\mathrm{PE}$ & PC61.5 & Rat IgG1, lambda & eBioscience, Inc., San Diego, USA & $0.1 \mu \mathrm{g}$ & 10 & 4 \\
\hline CD3 & Pacific Blue & $17 \mathrm{~A} 2$ & Rat IgG2b & BioLegend, San Diego, USA & $0.25 \mu \mathrm{g}$ & 15 & 4 \\
\hline CD3 Epsilon & Pacific Blue TM & $145-2 \mathrm{C} 11$ & $\begin{array}{l}\text { Armenian Hamster } \\
\text { lgG }\end{array}$ & BioLegend, San Diego, USA & $2.5 \mu \mathrm{g}$ & 15 & $\mathrm{RT}$ \\
\hline CD3e & $\mathrm{PE}$ & $145-2 \mathrm{C} 11$ & Amenian Hamster lgG & eBioscience, Inc., San Diego, USA & $0.3 \mu \mathrm{g}$ & 10 & $\mathrm{RT}$ \\
\hline CD4 & FITC & RM4-5 & Rat IgG2a, k & eBioscience, Inc., San Diego, USA & $0.25 \mu \mathrm{g}$ & 10 & $\mathrm{RT}$ \\
\hline CD45 & $\mathrm{PE}$ & $30-\mathrm{F} 11$ & Rat IgG2b, k & BioLegend, San Diego, USA & $0.1 \mu \mathrm{g}$ & 10 & $\mathrm{RT}$ \\
\hline CD45 & eFluor & $30-\mathrm{F} 11$ & Rat IgG2b, k & eBioscience, Inc., San Diego, USA & $0.1 \mu \mathrm{g}$ & 20 & 4 \\
\hline CD45 & FITC & $30-\mathrm{F} 11$ & Rat IgG2b, k & eBioscience, Inc., San Diego, USA & $0.25 \mu \mathrm{g}$ & 20 & 4 \\
\hline CD45.1 & APC & A20 & Mouse IgG2a, $\mathrm{k}$ & BioLegend, San Diego, USA & $0.1 \mu \mathrm{g}$ & 10 & $\mathrm{RT}$ \\
\hline CD45R/B220 & FITC & RA3-6B2 & Rat IgG2a, k & BioLegend, San Diego, USA & $0.5 \mu \mathrm{g}$ & 20 & 4 \\
\hline $\begin{array}{l}\text { CD49b } \\
\text { (pan-NK cells) }\end{array}$ & $\overline{A P C}$ & DX5 & Rat IgM, $\mathrm{k}$ & BioLegend, San Diego, USA & $0.25 \mu \mathrm{g}$ & 15 & $\mathrm{RT}$ \\
\hline CD8a & $\mathrm{PE}$ & $53-6.7$ & Rat IgG2a, k & BioLegend, San Diego, USA & $0.25 \mu \mathrm{g}$ & 15 & RT \\
\hline
\end{tabular}




\begin{tabular}{|c|c|c|c|c|c|c|c|}
\hline CD8a & APC & $53-6.7$ & Rat IgG2a, k & BioLegend, San Diego, USA & $0.1 \mu \mathrm{g}$ & 10 & RT \\
\hline FoxP3 & APC & FJK-16s & Rat IgG2a, k & eBioscience, Inc., San Diego, USA & $0.5 \mu \mathrm{g}$ & 20 & 4 \\
\hline $\begin{array}{l}\text { gamma delta } \\
\text { TCR }\end{array}$ & APC & GL3 & Hamster IgG & BioLegend, San Diego, USA & $0.2 \mu \mathrm{g}$ & 10 & $\mathrm{RT}$ \\
\hline H-2Db & PE & KH95 & $\begin{array}{l}\text { Mouse (BALB/c) } \\
\operatorname{lgG} 2 \mathrm{~b}, \mathrm{k}\end{array}$ & BioLegend, San Diego, USA & $0.1 \mu \mathrm{g}$ & 20 & 4 \\
\hline H-2Dd & $\begin{array}{l}\text { Alexa Fluor R } \\
647\end{array}$ & $34-2-12$ & $\begin{array}{l}\text { Mouse }(\mathrm{C} 3 \mathrm{H} / \mathrm{HeJ}) \\
\text { IgG2a, } \mathrm{k}\end{array}$ & BioLegend, San Diego, USA & $0.15 \mu \mathrm{g}$ & 20 & 4 \\
\hline H-2Dk & PE & $15-5-5$ & $\begin{array}{l}\text { Mouse (C3H.SW) } \\
\text { lgG2a, k }\end{array}$ & BioLegend, San Diego, USA & $0.2 \mu \mathrm{g}$ & 20 & 4 \\
\hline $\mathrm{H}-2 \mathrm{~Kb}$ & Pacific Blue & AF6-88.5 & Mouse (Balb/c) H-2Kb & BioLegend, San Diego, USA & $0.5 \mu \mathrm{g}$ & 20 & 4 \\
\hline IFN gamma & PE & XMG1.2 & Rat IgG1, $\mathrm{k}$ & BioLegend, San Diego, USA & $1 \mu g$ & 15 & $\mathrm{RT}$ \\
\hline IL-2 & APC & JES6-5H4 & Rat IgG2b, k & BioLegend, San Diego, USA & $0.25 \mu \mathrm{g}$ & 15 & $\mathrm{RT}$ \\
\hline $\begin{array}{l}\text { Lineage Cell } \\
\text { Detection } \\
\text { Cocktail-Biotin }\end{array}$ & & $\begin{array}{l}\text { CD3 (clone } \\
\text { SK7); CD16 } \\
\text { (clone } \\
\text { 3G8), } \\
\text { CD19 } \\
\text { (clone } \\
\text { SJ25C1), } \\
\text { CD20 } \\
\text { (clone L27); } \\
\text { CD14 } \\
\text { (clone } \\
\text { MOP9); } \\
\text { CD56 } \\
\text { (NCAM16.2 }\end{array}$ & $\lg \mathrm{G} 1, \mathrm{k} ; \lg \mathrm{G} 2 \mathrm{~b}, \mathrm{k}$ & $\begin{array}{l}\text { Miltenyi Biotec GmbH, Bergisch } \\
\text { Gladbach }\end{array}$ & $10 \mu \mathrm{l}$ & 10 & 4 \\
\hline $\begin{array}{l}\text { MACS Control } \\
\text { CD90.2 T Cell } \\
\text { Cocktail }\end{array}$ & PE, VioBLue & $\begin{array}{l}\text { 30-H12; } \\
\text { 30F11 }\end{array}$ & Rat IgG2b; Rat IgG2b & $\begin{array}{l}\text { Miltenyi Biotec GmbH, Bergisch } \\
\text { Gladbach }\end{array}$ & $10 \mu \mathrm{l}$ & 10 & 4 \\
\hline
\end{tabular}




\begin{tabular}{|c|c|c|c|c|c|c|}
\hline TNF alpha & MP6-xT22 & Rat IgG1, k & BioLegend, San Diego, USA & $0.25 \mu \mathrm{g}$ & 15 & RT \\
\hline Trustain fcXTM (CD16/32) & 93 & Rat IgG2a y & BioLegend, San Diego, USA & $1 \mu \mathrm{g}$ & 10 & 4 \\
\hline $\begin{array}{l}\text { Anti-Biotin } \\
\text { antibodies }\end{array}$ & Bio3-18E7 & Mouse IgG1 & $\begin{array}{l}\text { Miltenyi Biotec } \mathrm{GmbH} \text {, Bergisch } \\
\text { Gladbach }\end{array}$ & $10 \mu \mathrm{l}$ & 10 & 4 \\
\hline
\end{tabular}


3.1.5.2. Human antibodies

Tab. 6: Human antibodies

\begin{tabular}{|c|c|c|c|c|c|}
\hline tigen & Fluorochrome & Clone & Isotype & Manufacturer & $\begin{array}{l}\text { incubation } \\
\text { [min] }\left[{ }^{\circ} \mathrm{Cl}\right.\end{array}$ \\
\hline
\end{tabular}

Annexin V FITC $\quad-\quad-$

BioLegend, San Diego, USA

$1 \mu \mathrm{l}$

CD 45 PE

APC

2D1

Mouse IgG1, $\mathrm{k}$

eBioscience, Inc., San Diego, USA

CD11C

APC

Bu15

Mouse IgG1, $\mathrm{k}$

BioLegend, San Diego, USA

$0.0125 \mu g$

10 RT

CD19

HIB19

Mouse IgG1, $\mathrm{k}$

CD21

APC HB5

HB5

Mouse IgG2a, $\mathrm{k}$

eBioscience, Inc., San Diego, USA

$0.25 \mu \mathrm{g}$

$\begin{array}{cc}10 & \text { RT } \\ 30 & 4\end{array}$

CD25 $P$

M-A251

Mouse IgG1, $k$

eBioscience, Inc., San Diego, USA

$0.125 \mu \mathrm{g}$

30

\begin{tabular}{ll}
\hline CD3 \\
\hline CD4
\end{tabular}

FITC HIT3a

30

\begin{tabular}{ll}
\hline CD4 & Pacific Blue \\
\hline CD4 & eFluor
\end{tabular}

RPA-T4

Mouse IgG2a, k BioLegend, San Diego, USA

$0.5 \mu \mathrm{g}$

10 RT

$\begin{array}{lll}\text { CD4 } & \text { eFluor } & \text { RP } \\ \text { CD8a } & \text { PE } & \text { SK }\end{array}$

FoxP3

Alexa 647

SK1

HLA-DR

PerCP-Cy5.5

206D

Mouse IgG1, k

BioLegend, San Diego, USA

$1 \mu \mathrm{g}$

10 RT

\section{Human}

TruStain FcX

Lineage

Cocktail

(CD3,CD14,

CD16,CD19,

CD20,CD56)

FITC

LN3

Mouse IgG1, $\mathrm{k}$

eBioscience, Inc., San Diego, USA

$2.5 \mu \mathrm{g}$

\begin{tabular}{|c|c|c|}
\hline Vouse IgGI, & i., & $0.05 \mathrm{~F}$ \\
\hline
\end{tabular}

Mour

Mouse $\lg \mathrm{G} 1, \mathrm{k}$

Bioscience, Inc., San Diego, USA

$0.3 \mu \mathrm{g}$

20 RT

Mouse IgG2b, $\mathrm{k}$

eBioscience, Inc., San Diego, USA BioLegend, San Diego, USA

$0.0075 \mu \mathrm{g}$

\begin{tabular}{cc}
20 & $\mathrm{RT}$ \\
\hline 30 & 4 \\
\hline
\end{tabular}

$\begin{array}{ll}\text { CD3 } & \text { Mouse IgG1; } \\ \text { (clone:SK7); } & \text { mouse lgG2b }\end{array}$

BD Biosciences, New Jersey, USA

$5 \mu l$

10 RT

CD16 (clone:

3G8),

CD19 (clone:

SJ25C1); CD20

(clone: L27),

CD14 (clone:

MoP9); CD56

(clone:

NCAM16.2) 
TCR Valpha24- APC

Jalpha18

(iNKT)
Mouse IgG1, k

BioLegend, San Diego, USA
$0.125 \mu g$

30
4 


\subsubsection{Isotype controls}

Tab. 7: Isotype controls

\begin{tabular}{|c|c|c|c|}
\hline Antigen & Fluorochrome & Clone & Manufacturer \\
\hline $\begin{array}{l}\text { Armenian } \\
\text { Hamster IgG }\end{array}$ & Pacific Blue & HTK888 & $\begin{array}{l}\text { BioLegend, San Diego, } \\
\text { USA }\end{array}$ \\
\hline ms lgG1 k & APC & P3.6.2.8.1 & $\begin{array}{l}\text { eBioscience, Inc., San } \\
\text { Diego, USA }\end{array}$ \\
\hline ms IgG1 k & eFluor 450 & P3.6.2.8.1 & $\begin{array}{l}\text { eBioscience, Inc., San } \\
\text { Diego, USA }\end{array}$ \\
\hline ms lgG1 k & $\mathrm{PE}$ & MOPC-21 & $\begin{array}{l}\text { BioLegend, San Diego, } \\
\text { USA }\end{array}$ \\
\hline ms lgG1 k & Alexa Fluor 647 & MOPC-21 & $\begin{array}{l}\text { BioLegend, San Diego, } \\
\text { USA }\end{array}$ \\
\hline ms IgG1 k & PerCP-Cy5.5 & P3.6.2.8.1 & $\begin{array}{l}\text { eBioscience, Inc., San } \\
\text { Diego, USA }\end{array}$ \\
\hline ms IgG2a k & eFluor 450 & eBM2a & $\begin{array}{l}\text { eBioscience, Inc., San } \\
\text { Diego, USA }\end{array}$ \\
\hline ms lgG2a k & APC & eBM2a & $\begin{array}{l}\text { eBioscience, Inc., San } \\
\text { Diego, USA }\end{array}$ \\
\hline ms lgG2b k & PerCP Cy5.5 & eBMG2b & $\begin{array}{l}\text { eBioscience, Inc., San } \\
\text { Diego, USA }\end{array}$ \\
\hline mslgG1 & FITC & MOPC-21 & $\begin{array}{l}\text { BD Bioscience, San Jose, } \\
\text { USA }\end{array}$ \\
\hline mslgG1 k & eFluor 450 & P3.6.2.8.1 & $\begin{array}{l}\text { eBioscience, Inc., San } \\
\text { Diego, USA }\end{array}$ \\
\hline mslgG1 k & $\mathrm{PE}$ & P3.6.2.8.1 & $\begin{array}{l}\text { eBioscience, Inc., San } \\
\text { Diego, USA }\end{array}$ \\
\hline mslgG2a k & FITC & MOPC-173 & $\begin{array}{l}\text { BioLegend, San Diego, } \\
\text { USA }\end{array}$ \\
\hline rat IgG1, $k$ & APC & RTK2071 & $\begin{array}{l}\text { BioLegend, San Diego, } \\
\text { USA }\end{array}$ \\
\hline rat IgG1, $k$ & $\mathrm{PE}$ & RTK2071 & $\begin{array}{l}\text { BioLegend, San Diego, } \\
\text { USA }\end{array}$ \\
\hline rat IgG2a $k$ & APC & R35-95 & $\begin{array}{l}\text { BD Bioscience, San Jose, } \\
\text { USA }\end{array}$ \\
\hline rat IgG2a k & $\mathrm{PE}$ & eBR2a & $\begin{array}{l}\text { eBioscience, Inc., San } \\
\text { Diego, USA }\end{array}$ \\
\hline rat IgG2b k & Pacific Blue & RTK4530 & $\begin{array}{l}\text { BioLegend, San Diego, } \\
\text { USA }\end{array}$ \\
\hline rat IgG2b, $k$ & APC & RTK4530 & $\begin{array}{l}\text { BioLegend, San Diego, } \\
\text { USA }\end{array}$ \\
\hline
\end{tabular}

\subsubsection{Commercial Kits}

Tab. 8: Commercial Kits

\begin{tabular}{|ll|}
\hline Name & Manufacturer \\
\hline BIOSOURCE sTNF-R1 EASIA kit & BioSource Europe S.A., Nivelles, Belgium \\
\hline Cell Proliferation Dye eFluor R 450 & eBioscience, Inc., San Diego, USA \\
\hline ELISA Kit Human HGF & Invitrogen, Camarillo, USA \\
\hline ELISA Kit Human sIL-2R Instant ELISA & eBioscience, Inc., San Diego, USA \\
\hline ELISA Kit sTNF-R (60kDa) Instant ELISA & eBioscience, Inc., San Diego, USA \\
\hline
\end{tabular}




\begin{tabular}{|ll|}
\hline ELISA Mouse TGF beta 1 Platinum & eBioscience, Inc., San Diego, USA \\
\hline HUMAN HGF Instant ELISA & eBioscience, Inc., San Diego, USA \\
\hline IL2R Human ELISA Kit & Thermo Fisher Scientific, Waltham, USA \\
\hline Pan T Cell Isolation Kit II & Miltenyi Biotec GmbH, Bergisch Gladbach \\
\hline
\end{tabular}

\subsubsection{Commercial media and supplements}

Tab. 9: Commercial media and supplements

\begin{tabular}{|ll|}
\hline Name & Manufacturer \\
\hline HI Fetal Calf serum (FCS) & Thermo Fisher Scientific, Waltham, USA \\
\hline $\begin{array}{l}\text { Penicillin/Streptomycin } \\
\text { (Pen/Strep)(10000U/ml) }\end{array}$ & Gibco by Thermo Fisher Scientific, Waltham, \\
\hline RPMI Medium 1640 (1x)+ GlutaMAX & $\begin{array}{l}\text { GSA } \\
\text { USA }\end{array}$ \\
\hline
\end{tabular}

\subsubsection{Buffers, media, solutions}

Tab. 10: Buffers, media, solutions

\begin{tabular}{|ll|}
\hline Buffers/media/solutions & Composition \\
\hline Drinking water for mice & $100 \mathrm{ml} \mathrm{Neomycine} \mathrm{Stock} \mathrm{Solution}$ \\
& $900 \mathrm{ml} \mathrm{H} \mathrm{O}_{2}$ \\
& $2.8 \mathrm{ml}$ Metapyrin \\
\hline Fixation/Permeabilization Buffer (1X) & \\
& 1 part of Fixation/Permeabilisation \\
& 3 parts of Fixation/Permeabilisation \\
& Diluent \\
& \\
\hline Freezing medium & \\
& \\
\hline MACS Buffer & $70 \%$ RPMI Medium 1640 (1x)+ \\
& GlutaMAX \\
& $20 \%$ HI Fetale Calf Serum \\
& \\
\hline
\end{tabular}




\begin{tabular}{|c|c|}
\hline $\begin{array}{l}\text { MLR cell culture medium } \\
\text { (MLR Medium) }\end{array}$ & $\begin{array}{l}500 \mathrm{ml} \text { RPMI Medium } 1640(1 \mathrm{x})+ \\
\text { GlutaMAX } \\
5 \mathrm{ml} \text { Penicillin/Streptomycin } \\
\text { (Pen/Strep) }(10000 U / \mathrm{ml}) \\
50 \mathrm{ml} \text { HI Fetal Calf serum }\end{array}$ \\
\hline Sodium acetate (NaCi) Buffer & $\begin{array}{l}1 \text { part } \mathrm{NaCi} \text { Stock solution } \\
1 \text { part } \mathrm{PBS} \text { without } \mathrm{Ca}^{2+} \text { and } \mathrm{Mg}^{2+}\end{array}$ \\
\hline Sodium acetate $(\mathrm{NaCi})$ Stock solution & $\begin{array}{l}73.5 \mathrm{~g} \text { tri- Sodium acetate dihydrate } \\
1 \mathrm{I} \text { distilled } \mathrm{H}_{2} \mathrm{O}\end{array}$ \\
\hline Neomycin Stock solution & $\begin{array}{l}250 \mathrm{mg} \text { Neomycin trisulfate salt } \\
\text { hydrate } \\
\text { in } 1 \mathrm{I}_{2} \mathrm{O}\end{array}$ \\
\hline Permeabilization Buffer (1X) & $\begin{array}{l}1 \text { part Permeabilisation Buffer (10X) } \\
9 \text { parts distilled water }\end{array}$ \\
\hline Drinking water for mice & $\begin{array}{l}100 \mathrm{ml} \mathrm{Neomycine} \mathrm{Stock} \mathrm{Solution} \\
900 \mathrm{ml} \mathrm{H} \mathrm{O} \\
2.8 \mathrm{ml} \text { Metapyrin }\end{array}$ \\
\hline Fixation/Permeabilization Buffer (1X) & $\begin{array}{l}1 \text { part of Fixation/Permeabilisation } \\
\text { Concentrate }(4 \mathrm{X}) \\
3 \text { parts of Fixation/Permeabilisation } \\
\text { Diluent }\end{array}$ \\
\hline Freezing medium & $\begin{array}{l}\text { 70\% RPMI Medium } 1640(1 \mathrm{x})+ \\
\text { GlutaMAX } \\
20 \% \text { HI Fetale Calf Serum } \\
10 \% \text { DMSO }\end{array}$ \\
\hline MACS Buffer & AutoMACS Running Buffer \\
\hline MLR cell culture medium & $\begin{array}{l}500 \mathrm{ml} \text { RPMI Medium } 1640(1 \mathrm{x})+ \\
\text { GlutaMAX } \\
5 \mathrm{ml} \text { Penicillin/Streptomycin } \\
\text { (Pen/Strep) }(10000 U / \mathrm{ml}) \\
50 \mathrm{ml} \text { HI Fetal Calf serum }\end{array}$ \\
\hline
\end{tabular}




\begin{tabular}{|c|c|}
\hline $\begin{array}{l}\text { Sodium citrate Buffer } \\
\text { (NaCi Buffer) }\end{array}$ & $\begin{array}{l}1 \text { part } \mathrm{NaCi} \text { Stock solution } \\
1 \text { part } \mathrm{PBS} \text { without } \mathrm{Ca}^{2+} \text { and } \mathrm{Mg}^{2+}\end{array}$ \\
\hline Sodium citrate stock solution & $\begin{array}{l}73.5 \mathrm{~g} \text { tri- Sodium acetate dihydrate } \\
1 \text { I distilled } \mathrm{H}_{2} \mathrm{O}\end{array}$ \\
\hline Neomycin stock solution & $\begin{array}{l}250 \mathrm{mg} \text { Neomycin trisulfate salt } \\
\text { hydrate } \\
\text { in } 1 \mathrm{I} \mathrm{H}_{2} \mathrm{O}\end{array}$ \\
\hline Permeabilization Buffer (1X) & $\begin{array}{l}1 \text { part Permeabilisation Buffer (10X) } \\
9 \text { parts distilled water }\end{array}$ \\
\hline
\end{tabular}

\subsubsection{Mouse strains}

Tab. 11: Mouse strains

\begin{tabular}{|ll|}
\hline Strain & Company \\
\hline B10.D2n5nJ & The Jackson Laboratory, Bar Harbor, USA \\
\hline B6.SJL_Ptprc ${ }^{\text {aPepc }}{ }^{\mathbf{b}}$ /BoyJ & AG Lühder, Genetical Neuroimmunology, UMG, Göttingen \\
\hline BALB/cAnNCrl & Charles River Laboratories, Wilmington, USA \\
\hline C3H/HeN Rj & JANVIER LABS, Le Genest-Saint-Isle, France \\
\hline C57BL/6JRj & JANVIER LABS, Le Genest-Saint-Isle, France \\
\hline
\end{tabular}

\subsubsection{Software}

Tab. 12: Software

\begin{tabular}{|ll|}
\hline Software & Manufacturer \\
\hline $\begin{array}{l}\text { BD FACS Diva Software Version } \\
\text { Graphpad Prism 6 }\end{array}$ & BD Biosciences, New York, USA \\
\hline Magellan Software & GraphPad Software, Inc., La Jolla, USA \\
\hline Microsoft Office 2007 \& 2010 & TECAN, Männedorf, Schweiz \\
\hline
\end{tabular}

\subsection{Methods}

\subsubsection{Cellular methods}

\subsubsection{Flow cytometric analysis}

Human MNCs or murine cells in suspension were transferred into a fluorescence-activating cell sorting (FACS) tube and washed wit $2 \mathrm{ml}$ magnetic-activating cell sorting (MACS) buffer for $10 \mathrm{~min}$ at $350 \mathrm{~g}$. The supernatant was discarded and the cell pellet resuspended in MACS buffer. Afterwards Fc-receptors were blocked using $2 \mu \mathrm{l}$ TruStain for human and CD16/32 for murine cells for $10 \mathrm{~min}$ at $4^{\circ} \mathrm{C}$. Following Fc-receptor blockage, the cells were incubated with one or more monoclonal antibodies conjugated to fluorochromes in the dark. Optimization of 
incubation time and temperature was performed for each antibody and is listed in 3.1.5.1. , and 3.1.5.2.. Subsequently the cells were washed with $2 \mathrm{ml}$ MACS buffer and analyzed with a flow cytometer (FACS Canto II). The usage of more than one antibody required a compensation setup to control spectral overlap. Data were analyzed with BD FACS DIVA software version 6.1.2..

\subsection{Intracellular staining methods}

\subsection{Cytokine assay}

This procedure was performed with mouse spleen or lymph node cell suspensions. Single cell suspensions were prepared (3.2.1.1.4.) and centrifuged at $300 \mathrm{~g}$ at RT for $7 \mathrm{~min}$. Afterwards the supernatant was aspirated with a glass pasteur pipette. The cell pellet was resuspended in RPMI medium and added on multi-well culture plates or cell culture flasks. Prior to detection of intracellular cytokine expression by flow cytometry, the cells had to be stimulated. Therefore $40 \mathrm{ng} / \mathrm{ml}$ phorbol 12-myristate 13 acetate (PMA), $2 \mu \mathrm{M}$ ionomycin calcium salt (IM) and $1 \mu \mathrm{l} / \mathrm{ml}$ of $1 \mathrm{x}$ monensin solution (MN) were added to the cells and incubated for $5 \mathrm{hrs}$ at $37^{\circ} \mathrm{C}$ and $0.5 \% \mathrm{CO}_{2}$. Following incubation, the cells were transferred into $50 \mathrm{ml}$ centrifuge tubes and washed with MACS buffer twice by centrifugation at $300 \mathrm{~g}$ for $7 \mathrm{~min}$ at room temperature (RT). Afterwards, the cells were counted using a Neubaur chamber (3.2.2.1.) and $1 \times 10^{6}$ cells diluted in $100 \mu$ MACS buffer were transferred into $5 \mathrm{ml}$ FACS tubes. The cells were fixed (3.2.1.1.1.2.) and incubated in the dark with IFN- $\gamma-P E$, IL2-APC or TNF- $\alpha-A P C$ for 20 min at RT. Subsequently, the cells were washed twice with $2 \mathrm{ml}$ permeabilization buffer and centrifuged at $300 \mathrm{~g}$ for $5 \mathrm{~min}$ at RT. Finally, the supernatant was decanted, the cells resuspended in $200 \mu$ MACS buffer and analyzed using flow cytometry.

\subsection{Fixation of cells for intranuclear staining}

This procedure was performed using the forkhead box protein 3 (FoxP3) Fixation and Permeabilization Buffer Set from eBioscience. $1 \times 10^{6}$ cells were resuspended in $500 \mu \mathrm{l}$ fixation buffer and incubated at $4^{\circ} \mathrm{C}$ for $10 \mathrm{~min}$. In this step, live cells were fixed with formaldehyde to stabilize cellular structures. Afterwards, the cells were washed twice with 2 $\mathrm{ml}$ permeabilization buffer and centrifuged at $350 \mathrm{~g}$ for $5 \mathrm{~min}$ at RT to generate pores in the membrane so that fluorochrome-conjugated monoclonal antibodies could enter the cell. The supernatant was discarded and the cells were resuspended in $100 \mu \mathrm{l}$ permeabilization buffer. Subsequently, the optimized amount of fluorochrome-conjugated antibody was added and incubated in the dark (3.1.5.1. and 3.1.5.2.). Following incubation the cells were washed twice with permeabilization buffer and analyzed using flow cytometry. 


\subsection{Staining of cell surface markers}

\subsection{Chimerism analysis}

The analysis of chimerism is a tool to assess the origin of leukocytes after allogeneic stem cell transplantation. This analysis was conducted at least 6 weeks post BMT. Therefore transplanted C57BL/6->BALB/c mice were sacrificed with carbon dioxide $\left(\mathrm{CO}_{2}\right)$ and cervical dislocation. Femur and tibia were isolated and placed into a petri dish containing icecold MACS buffer. After cleaning bones from skin, muscles and flesh both ends of the bones were cut off with sterile scissors. The BM was flushed out of the shaft with MACS buffer using a 1$\mathrm{ml}$ syringe and a $26 \mathrm{GA} 3 / 8 \mathrm{IN}$ needle. The shaft was flushed until the bone appeared white and the cells were collected into a $50 \mathrm{ml}$ tube. The cells were washed with $20 \mathrm{ml}$ MACS buffer and centrifuged at $300 \mathrm{~g}$ for $10 \mathrm{~min}$ at $4^{\circ} \mathrm{C}$. The supernatant was discarded and the cells counted with a Neubaur chamber (3.2.2.1.). $1 \times 10^{6} \mathrm{BM}$ cells resuspended in $100 \mu \mathrm{l}$ MACS buffer were incubated with $2 \mu \mathrm{lCD} 16 / 32$ for $10 \mathrm{~min}$ at $4^{\circ} \mathrm{C}$. Afterwards $0.5 \mu \mathrm{l}$ of antiCD45 and $0.3 \mu \mathrm{l}$ anti- $\mathrm{H}-2 \mathrm{D}^{\mathrm{d}}$ monoclonal antibodies were added and the mixture was incubated for $20 \mathrm{~min}$ at $4{ }^{\circ} \mathrm{C}$ in the dark. The cells were then washed with $2 \mathrm{ml}$ MACS buffer and centrifuged at RT at $350 \times \mathrm{g}$ for $5 \mathrm{~min}$. The cell pellet was resuspended in $200 \mu \mathrm{l}$ MACS buffer and analyzed using a FACS Canto II and FACS DIVA software.

\subsection{Detection of apoptotic cells}

To identify apoptotic cells by flow cytometry, $10^{7}$ cells were transferred into a $5 \mathrm{ml}$ FACS tube and washed twice with MACS buffer following centrifugation at $350 \mathrm{~g}$ for $5 \mathrm{~min}$ at RT. The supernatant was discarded and the cells were resuspended in $100 \mu \mathrm{l}$ Annexin-V-binding buffer. Afterwards $2 \mu \mathrm{g}$ Annexin-V-FITC was added and incubated for $10 \mathrm{~min}$ at RT in the dark. Following incubation, $400 \mu \mathrm{l}$ Annexin-V-binding buffer was added and the cells were analyzed using a flow cytometer.

\subsection{Labeling cells with Cell Proliferation Dye eFluor ${ }^{\circledR} 670$}

Murine splenocytes in single cell suspension (3.2.1.1.4.2.) were labeled with $10 \mu \mathrm{g} / \mathrm{ml}$ Cell Proliferation Dye eFluor ${ }^{\circledR} 670$ according to the manufacturer's instructions. In brief, the cells were resuspended at 2-fold the desired final concentration with MACS buffer in a $50 \mathrm{ml}$ centrifuge tube and mixed 1:1 with $10 \mu \mathrm{M}$ Cell Proliferation Dye solution diluted in MACS buffer. This suspension was incubated for $10 \mathrm{~min}$ at $37^{\circ} \mathrm{C}$ in the dark. Labeling was stopped by adding five volumes of cold RPMI medium without P/S and incubation on ice for 5 min. Subsequently, the cells were washed three times with RPMI medium and centrifuged at 300 
$\mathrm{g}$ for $7 \mathrm{~min}$ at RT. Following these washing steps, $10^{7}$ cells were plated on 6 -well culture plates with $2 \mathrm{ml}$ RPMI medium per well.

\subsection{Preparation of lymphocyte single cell suspension}

\subsection{Isolation of human lymphocytes}

Venous blood was drawn into two $4.7 \mathrm{ml} \mathrm{S}$-Monovettes containing Lithium/Heparin-gel and mixed thoroughly. MNCs were separated via Ficoll Paque density centrifugation. Blood from both S-Monovettes was transferred into a $50 \mathrm{ml}$ centrifugation tube and mixed with an equal volume of sodium acetate buffer ( $\mathrm{NaAc}$ buffer). The diluted blood was carefully layered into another $50 \mathrm{ml}$ centrifugation tube containing $20 \mathrm{ml}$ Ficoll-Paque PLUS and centrifuged at 800 $\mathrm{g}$ for $30 \mathrm{~min}$ at RT. The upper layer of plasma was removed using a glass pasteur pipette without disturbing the lymphocyte layer at the interface. The lymphocyte layer was then transferred into a $50 \mathrm{ml}$ centrifugation tube, mixed with at least three volumes of $\mathrm{NaAc}$ buffer and centrifuged at $100 \mathrm{~g}$ for $10 \mathrm{~min}$ at RT. Subsequently, the cells were frozen as described in chapter 3.2.1.1.5.

\subsection{Isolation of murine lymphocytes}

Mice were sacrificed and the lymph nodes (superficial cervicals, axillary, brachial, mesenteric, inguinal) and/-or spleen were removed and transferred to a cell culture plate containing ice-cold MACS buffer. Under sterile conditions (3.2.2.) single cell suspensions were prepared by pushing lymph nodes through cell strainers with a $40 \mu \mathrm{m}$ nylon mesh using the plunger of a $5 \mathrm{ml}$ syringe. The nylon mesh was washed several times with MACS buffer. Alternatively splenocytes were flushed out of the spleen with MACS buffer by using a $1 \mathrm{ml}$ syringe armed with a needle. The spleen was washed about 30 times until the organ appeared white and the cells were transferred into a $50 \mathrm{ml}$ centrifugation tube. Subsequently, the cell number was determined by counting using a Neubaur chamber (3.2.2.1.).

\subsection{Freezing of human lymphocytes}

After having centrifuged the lymphocytes, the supernatant was aspirated with a glass pasteur pipette and the pellet mixed with $700 \mu \mathrm{l} \mathrm{RPMI}$ medium and $200 \mu \mathrm{HI}$ fetal calf serum and placed on ice for $10 \mathrm{~min}$. Following incubation, the cell suspension was transferred into freezing tubes. $100 \mu \mathrm{l}$ DMSO was added drop-wise and carefully mixed. Afterwards, the tubes were placed in a cold isopropanol-filled cooling container at $-80^{\circ} \mathrm{C}$. 


\subsection{Thawing human lymphocytes}

Frozen human lymphocytes were thawed quickly to minimize cell damage. Therefore freezing tubes containing the samples were transferred to a $37{ }^{\circ} \mathrm{C}$ water bath and $1 \mathrm{ml}$ prewarmed RPMI medium was added drop-wise to the freezing tube. Afterwards, the cell suspension was transferred to a $50 \mathrm{ml}$ centrifugation tube that was filled with prewarmed 9 $\mathrm{ml} \mathrm{RPMI} \mathrm{medium} \mathrm{and} \mathrm{centrifuged} \mathrm{at} \mathrm{RT} \mathrm{for} 7 \mathrm{~min}$ at $350 \mathrm{~g}$. The supernatant was decanted and the cell pellet resuspended in $1 \mathrm{ml}$ MACS buffer for further flow cytometric analyses (3.2.1.1.).

\subsubsection{Red blood cell lysis}

After preparation of splenic single cell suspensions in MACS buffer (3.2.1.1.4.2.), the cells were centrifuged at RT at $400 \mathrm{~g}$ for $5 \mathrm{~min}$. To remove erythrocytes, the cell pellet was resuspended in $1 \mathrm{ml}$ Red Blood Cell Lysis Buffer (1 $\mathrm{ml}$ per spleen) and mixed on a roller mixer for $1 \mathrm{~min}$. The remaining white blood cells were washed with $20 \mathrm{ml}$ MACS buffer and centrifuged at RT at $400 \mathrm{~g}$ for $7 \mathrm{~min}$. The cells were resuspended in $1 \mathrm{ml}$ MACS buffer and enumerated using a Neubaur chamber (3.2.2.1.).

\subsubsection{Enzyme-linked immunosorbent assay (ELISA)}

ELISA analysis of human or mouse serum (3.2.4.4.) served to quantify human HGF, sTNF-R, sIL-2R or murine transforming growth factor- $\beta 1$ (TGF- $\beta 1$ ). Instant ELISA kits were purchased from eBioscience and performed according to the manufacturer's instructions. The principle of the ELISA assay exemplified for the human sIL-2R Instant ELISA kit.

The samples were diluted 1:10 with distilled water and added to the wells of a microtiter plate pre-coated with anti-human sIL-2R antibody. During incubation at RT on a microplate shaker for 3 hrs human sIL-2R present in the sample bound to the absorbed antibody on the botton of the wells. A second horseradish peroxidase (HRP)-conjugated monoclonal anti-human sIL-2R antibody was added and incubated to bind to human sIL-2R captured by the first antibody. Subsequently, each well was washed 3 times with $400 \mu \mathrm{l}$ wash buffer to remove unbound enzyme-conjugated anti-human sIL-2R. After the washing steps, $100 \mu \mathrm{l}$ TMB substrate solution that was reactive with HRP was added to all wells and incubated for 10 min at RT. The substrate reaction was stopped by adding $100 \mu \mathrm{l}$ stop solution when the highest standard changed to a dark blue colour. The absorbance in each well was determined using a spectrophotometer at $450 \mathrm{~nm}$ wave length. 


\subsubsection{Cell culture}

Primary cell culture work such as the preparation of murine BMT, ECP treatment or the establishment of mixed lymphocyte reaction (MLR) was conducted under a sterile bench and by using sterile reagents and consumables. If not otherwise specified, primary murine cells were cultured at $37^{\circ} \mathrm{C}$ and $5 \% \mathrm{CO}_{2}$. Dependent on each purpose, the cells had to be cultured in flasks or multiwell plates. During each washing steps, the cells were transferred into sterile tubes and centrifuged outside of the sterile bench. Following centrifugation, the tubes were disinfected before returning them to the sterile bench.

\subsubsection{Determination of the cell number}

The number of cells was determined using a haemocytometer. To this end, $10 \mu \mathrm{l}$ of the cell suspension was added to a Neubaur chamber. Two squares placed at the corner of the chamber were used for counting white blood cells. The number of cells was calculated using the following formula: average of counted cells per square $x$ dilution factor $x$ volume $(\mathrm{ml}) \mathrm{x}$ $10^{4}$.

\subsubsection{Mixed Lymphocyte Reaction}

For conduction a MLR, the spleens of two donor mice (BALB/C, C57BL/6 or C3H) were dissected. Splenocytes of BALB/C origin served as stimulator cells whereas splenocytes of $\mathrm{C} 57 \mathrm{BL} / 6$ or $\mathrm{C} 3 \mathrm{H}$ origin served as responder cells. The splenocytes were placed into two separate cell culture plates filled with ice-cold MACS buffer. The cell suspensions were prepared under sterile conditions (3.2.1.1.4.2.) and transferred into sterile $50 \mathrm{ml}$ centrifugation tubes. After red blood cell lysis (3.2.1.1.7), responder cells derived from C57BL/6 or $\mathrm{C} 3 \mathrm{H}$ mice were resuspended in MLR medium (RPMI medium + 10-\% FCS + 1-\% $\mathrm{P} / \mathrm{S}$ ). The stimulator cells were mixed with $5 \mathrm{ml}$ MACS buffer transferred into a $25 \mathrm{~cm}^{2}$ cell culture flask, and y-irradiated with a dose of 30 Gy to abolish the capacity to proliferate. Afterwards, the stimulator cells were washed with $10 \mathrm{ml}$ MACS buffer, centrifuged at $350 \mathrm{~g}$ for $10 \mathrm{~min}$ at RT and resuspended in $5 \mathrm{ml} \mathrm{MLR} \mathrm{medium.} \mathrm{Both,} \mathrm{the} \mathrm{stimulator} \mathrm{and} \mathrm{the}$ responder cells were counted using a Neubauer chamber (3.2.2.1.). MLRs were carried out in 6 -well plates with $2.5 \times 10^{6}$ irradiated stimulator cells and $2.5 \times 10^{6}$ responder cells in a volume of $2 \mathrm{ml} \mathrm{MLR}$ medium. This co-culture was incubated at $37^{\circ} \mathrm{C}$ and $0.5 \% \mathrm{CO}_{2}$ for 4 days. As a control for ECP therapy with MLR-derived cells, $5 \times 10^{6}$ irradiated stimulator cells were cultured alone in $2 \mathrm{ml} \mathrm{MLR} \mathrm{medium} \mathrm{for} 4$ days at $37^{\circ} \mathrm{C}$ and $0.5 \% \mathrm{CO}_{2}$. 


\subsubsection{Mice}

Male and female BALB/cAnNCrl (BALB/c) mice were purchased from Charles River. Male C57BL/6J Rj and C3H/HeN Rj mice were obtained from JANVIER. Female B10.D2n5nJ mice were purchased from The Jackson Laboratories. Male C57BL/6.SJLPtprc ${ }^{\mathrm{a} P e p c} \mathrm{C}^{\mathrm{b}} / \mathrm{BoyJ}$ mice (CD45.1 congenic mice C57BL/6J) (Uhmann et al., 2011) were used as donor animals and were a kind gift of Dr. Fred Lühder (UMG Göttingen). The animals were housed in groups under pathogen-free conditions in individual ventilated cages (IVC) in the animal facility of the UMG in Göttingen. The mice were supplied with food and water ad libitum and housed in a standard 12 hour light/ dark cycle.

\subsubsection{Ethical statement}

All animal experiments were conducted according to Lower Saxony state regulations and approved by the responsible authority (Nds. Landesamt für Verbraucherschutz und Lebensmittelsicherheit). Starting one day prior to BMT, the drinking water of the recipient mice was supplemented with the analgetics metamizole to reduce pain, and with neomycin to avoid bacterial infection. The drinking water was changed every other day.

\subsubsection{Irradiation of recipient mice}

One day before BMT male BALB/c recipient mice were irradiated. The dose rate of $1 \mathrm{~Gy} / \mathrm{min}$ was delivered by using a RS 225 X-Ray Research System operated at $200 \mathrm{kV}, 15 \mathrm{~mA}$ and with $0.5-\mathrm{mm} \mathrm{Cu}$ filtration. To this end, the mice were placed in a customized Perspex box and received a total dose of 9.5 Gy.

\subsubsection{Intravenous injection into the tail vein}

Initially, the mice were warmed up carefully with an infrared lamp to stimulate dilatation of the tail veins. Subsequently, they were placed in a mouse restrainer to limit the movements. The tail was straightened with one hand while with the other one the material was injected into one of the lateral tail veins with an insulin syringe. Right afterwards the mouse was released and the restraining device was disinfected thoroughly to avoid infections.

\subsubsection{Induction of GvHD}

\subsubsection{1. $T$ cell purification}


After sacrificing the mice, lymph nodes and spleen were dissected. The T cells were isolated under sterile conditions using MACS technology. o this end Pan T Cell Isolation Kit II was used according to manufacturer's instructions. Each cell suspension was centrifuged at 300 $\mathrm{g}$ for $10 \mathrm{~min}$ at $4^{\circ} \mathrm{C}$. The supernatant was removed completely and the cells were resuspended in $13 \mu \mathrm{l}$ MACS buffer per $10^{7}$ cells. The cells were then incubated with $3 \mu \mathrm{l}$ Pan $T$ Cell Isolation Kit II Antibody per $10^{7}$ cells for $10 \mathrm{~min}$ at $4^{\circ} \mathrm{C}$. Subsequently, $6.5 \mu$ anti-Biotin Beads and $10 \mu \mathrm{l}$ MACS buffer per $10^{7}$ cells were added and incubated for $15 \mathrm{~min}$ at $4^{\circ} \mathrm{C}$. Following incubation, the cells were washed with $4 \mathrm{ml}$ MACS buffer and centrifuged at $300 \mathrm{~g}$ for $10 \mathrm{~min}$ at $4^{\circ} \mathrm{C}$. The supernatant was discarded and cells were resuspended in $3 \mathrm{ml}$ MACS buffer. Cell suspension was then pushed through a $40 \mu \mathrm{m}$ nylon mesh and separated using a MACS Separator magnetically attached to MACS MultiStand. Purification of T cells was controlled by flow cytometry (3.2.1.1.) using a CD90.2 antibody. T cell purity was usually $>95 \%$.

\subsection{Preparation of bone marrow single cell suspensions}

The mice were sacrificed with $\mathrm{CO}_{2}$ followed by cervical dislocation. Tibia and femur were prepared, gently cleaned of skin and muscles and placed into ice cold MACS buffer in a petri dish. The following work was performed under sterile conditions under a bench (3.2.2.). Both ends of the tibia and femur were trimmed with sterile scissors. BM cells were flushed out of the shaft with MACS buffer using a 1-ml syringe armed with a 26GA 3/8IN needle. The shaft was flushed until the bones appeared white and the cells were collected in a $50 \mathrm{ml}$ centrifugation tube. The BM cells were washed by filling up the tube with MACS buffer and centrifuged at $300 \mathrm{~g}$ for 10 minutes at $4^{\circ} \mathrm{C}$. The supernatant was aspirated completely with a glass pasteur pipette and the cells were gently disaggregated by pipetting them up and down several times. Afterwards the cell suspension was passed through a $40 \mu \mathrm{m}$ nylon mesh and the cell number was determined as described above (3.2.2.1.).

\subsubsection{4. $T$ cell depletion of bone marrow cells}

After having prepared the single cell suspension of bone marrow cells, the $T$ cells were depleted using MACS CD90.2 MicroBeads according to the manufacturer's instructions. In brief, bone marrow cells were centrifuged at $300 \mathrm{~g}$ for $10 \mathrm{~min}$ at $4^{\circ} \mathrm{C}$ and the supernatant discarded. The cells were resuspended in $25 \mu$ MACS buffer per $10^{7}$ cells and incubated with $2.8 \mu \mathrm{l}$ CD90.2 MicroBeads per $10^{7}$ cells for $15 \mathrm{~min}$ at $4^{\circ} \mathrm{C}$. The cells were passed through a $40 \mu \mathrm{m}$ nylon mesh and separated using MACS Separator attached to MACS MultiStand. The T cell-depleted bone marrow cells were stained with $10 \mu$ Lineage Cocktail, 
$10 \mu \mathrm{l}$ anti-Biotin Beads, $10 \mu \mathrm{l}$ anti-CD117 and $10 \mu \mathrm{l}$ anti-CD90.2 cocktail and analyzed with flow cytometry. The preparation generally contained $<1 \% \mathrm{~T}$ cells.

\subsection{Induction of acute GvHD}

One day after irradiation (3.2.3.2.), BMT was performed to induce aGvHD in mice (modified after Tischner et al., 2011). Male BALB/c mice between 10-12 weeks of age were used as recipients, whereas male 10 to 12 weeks old C57BL/6J Rj mice served as bone marrow and $\mathrm{T}$ cell donors. The donor mice were sacrificed with $\mathrm{CO}_{2}$ and cervical dislocation, spleen, lymph nodes, femur and tibia were dissected and single cell suspensions were prepared (3.2.1.1.4.2.). Next, $T$ cell depletion of $B M$ (3.2.3.4.3.) and $T$ cell purification from spleen and lymph nodes were performed using MACS technique (3.2.3.4.1.). Afterwards the recipient mice were intravenously injected (3.2.3.3.) with $150 \mu \mathrm{l}$ MACS buffer containing $10^{7} \mathrm{~T}$ celldepleted bone marrow cells, $10^{6} \mathrm{~T}$ cells from spleen and $10^{6} \mathrm{~T}$ cells from lymph nodes.

\subsection{Induction of chronic GvHD}

Eleven weeks old female BALB/c mice were used as recipients whereas female B10.D2n5nJ served as donors for bone marrow and spleen. One day before bone marrow transplantation the recipient mice were irradiated with 9.5 Gy (3.2.3.2.). One day later, BMT was performed. To this end, the donor mice were sacrificed with $\mathrm{CO}_{2}$ and cervical dislocation and the spleen and bone marrow were dissected. Single cell suspensions were prepared (3.2.1.1.4.2.) and the T cells contained in bone marrow were depleted using MACS technology (3.2.3.4.3.) Red blood cell lysis was additionally performed with spleen cells (3.2.1.1.7.). Afterwards, the recipient mice were intravenously injected (3.2.3.3.) with $200 \mu$ MACS buffer containing $10^{7}$ $\mathrm{T}$ cell-depleted bone marrow cells and $10^{8} \mathrm{~T}$ cells from spleen.

\subsubsection{Analysis of GvHD pathology}

Starting one day after bone marrow transplantation, the recipient mice were weighed and monitored daily for clinical GvHD symptoms. The mice were assigned a score between 0 and 2 for each of the following five criteria: posture, activity level, fur and diarrhea. The posture was evaluated based on a hunched appearance. A score of 0 indicated normal body posture, 1 indicated a slightly hunched posture, 1.5 indicated a moderately hunched posture and 2 indicated a strongly hunched posture. The activity level was evaluated based on the intensity with which the mouse moved in the cage. A score of 0 indicated a very active and normally moving behavior, 1 indicated a slightly reduced activity level, 1.5 indicated a mouse with 
strongly reduced activity level, and 2 indicated a mouse that did not move at all or only moved after stimulation. Diarrhoea was evaluated after visual inspection of the anus of the mice. A mouse with a score of 0 indicated no diarrhea, 1 indicated little diarrhea or signs of inflammation, 1.5 indicated moderate diarrhea, and 2 indicated severe or sanguineous diarrhoea. The appearance of the fur was scored based on the level of hirsuteness. A score of 0 indicated normal fur, 1 indicated slightly fuzzy fur or scaly skin, 1.5 indicated severe fuzzy fur and 2 indicated severe fuzzy fur and regional fur loss. Each criterium was assigned a value between 0 (no symptoms) to 2 (severe symptoms) as outlined above. Hereby a maximum score of 8 could be reached. Due to ethical reasons mice were sacrificed when reaching a score of 6 of greater. Mice were also sacrificed when losing more than $25 \%$ weight within 24 hours. To this end, the body weight of the mice was converted into percent of baseline body weight (referred to the day of BMT) to calculate the percentage of body weight loss during the study period.

\subsubsection{ECP therapy with cells of the donor mice}

The donor mice were sacrificed with $\mathrm{CO}_{2}$ and cervical dislocation. The spleens were collected into a petri dish filled with ice-cold MACS buffer. The splenocytes were flushed out with a 1-ml syringe armed with a 26 GA $3 / 8$ IN needle under sterile conditions (3.2.2.) until the spleen appeared transparent. The cell suspension was collected into a $50 \mathrm{ml}$ tube and centrifuged at RT at $300 \mathrm{~g}$ for $10 \mathrm{~min}$. The supernatant was removed, the cell pellet resuspended in $1 \mathrm{ml}$ Red Blood Cell Lysis Buffer and incubated on a roller mixer for $1 \mathrm{~min}$ (3.2.1.1.7.). Subsequently, $20 \mathrm{ml}$ MACS buffer was added immediately to the cell suspension and centrifuged at RT at $350 \mathrm{~g}$ for $10 \mathrm{~min}$. After discarding the supernatant the cell pellet was resuspended in $5 \mathrm{ml}$ MACS buffer and transferred into a $15 \mathrm{ml}$ tube wrapped in aluminium foil. The single cell suspension was incubated with $50 \mu \mathrm{l}(0.2 \mu \mathrm{g} / \mathrm{ml})$ of photoactive 8-MOP for 30 min on a multi-axle rotating mixer at RT. Afterwards the suspension was transferred into a $25 \mathrm{~cm}^{2}$ cell culture flask and exposed to $2 \mathrm{~J} / \mathrm{cm}^{2}$ UV light in a UV-A irradiation device. The cell suspension was transferred into a $50 \mathrm{ml}$ centrifugation tube and washed with $10 \mathrm{ml}$ MACS buffer before determining the cell number (3.2.2.1.) and intravenous injection (3.2.3.3.) into the tail vein of $C 57 \mathrm{BL} / 6->$ Balb/c transplanted mice. ECP therapy was performed four times in weekly intervals. The recipient mice received either 1 or $5 \times 10^{6} \mathrm{ECP}$ cells diluted in $150 \mu \mathrm{l}$ MACS buffer. Control animals were injected with $150 \mu \mathrm{l}$ MACS buffer only.

\subsubsection{ECP therapy with cells isolated from MLR cultures}


Cells from MLR cultures (3.2.2.2.) were transferred into a sterile $50 \mathrm{ml}$ centrifugation tube filled with $10 \mathrm{ml}$ MACS buffer and centrifuged at $350 \mathrm{~g}$ for $7 \mathrm{~min}$ at RT. Afterwards, the cell pellet was resuspended in $5 \mathrm{ml}$ MACS buffer and transferred into a $15 \mathrm{ml}$ centrifugation tube wrapped in aluminium foil. $50 \mu \mathrm{l}(0.2 \mu \mathrm{g} / \mathrm{ml})$ of photoactive 8-MOP were added to the cells and incubated for $30 \mathrm{~min}$ on a multi-axle rotating mixer at RT. The cells were then transferred into a $25 \mathrm{~cm}^{2}$ cell culture flask and exposed to $2 \mathrm{~J} / \mathrm{cm}^{2}$ UV light in a UV-A irradiation device. The cell suspension was washed with $10 \mathrm{ml}$ MACS buffer, transferred into a $50 \mathrm{ml}$ centrifugation tube and centrifuged at $350 \mathrm{~g}$ for $10 \mathrm{~min}$ at RT. The cell pellet was resuspended in $5 \mathrm{ml}$ MACS buffer and the cell number determined using a Neubauer chamber (3.2.2.1.). C57BL/6->BALB/c transplanted mice were intravenously injected (3.2.3.3.) with $10^{6}$ ECP-treated MLR cells into the tail vein. ECP therapy with ECP-treated MLR cells was performed four times in weekly intervals. One cohort of C57BL/6->BALB/C transplanted mice received $10^{6}$ ECP-treated MLR cells diluted in $150 \mu \mathrm{l}$ MACS buffer whereas the control animals were injected with $10^{6}$ ECP-treated irradiated stimulator cells (3.2.2.2.) diluted in $150 \mu \mathrm{l}$ MACS buffer.

\subsubsection{Disinfection of the workplace and dissection set}

Before preparation of donor animals, the workplace was wiped with Alkopharm 80 and the scissors and forceps were disinfected in Alkopharm 80 for at least $20 \mathrm{~min}$ to work as sterile as possible.

\subsubsection{Murine serum collection}

Mice were sacrificed with $\mathrm{CO}_{2}$ inhalation and cervical dislocation and the thorax was opened using sterile forceps and scissors. The heart was punctured, the blood was transferred into a $2 \mathrm{ml}$ reaction contained and incubated for $10 \mathrm{~min}$ at RT. Afterwards, the blood was centrifuged for $10 \mathrm{~min}$ at RT at $350 \mathrm{~g}$. The serum was transferred into a $1.5 \mathrm{ml}$ freezing tube and stored at $-20^{\circ} \mathrm{C}$.

\subsubsection{Human blood sampling}

\subsubsection{Patients and healthy blood donors}

Blood samples were taken from 25 healthy blood donors at two different dates with a minimum of three months between both donations, 30 patients with a haematologic malignancy before and after HSCT, and 12 GvHD patients before their first ECP therapy as well as three and six months afterwards. One healthy blood donor did not provide blood for 
the second time point. Due to disease severity, blood could not be obtained from some GvHD patients three and six months after first ECP therapy. Blood samples of healthy blood donors served as control group. Serum samples were used for ELISA whereas heparin anticoagulated blood was used for further flow cytometric analysis (3.2.1.1.).

\subsubsection{Ethical statement for human blood samples}

Before conducting this study the use of whole blood and medical records was approved by the ethics committee of the UMG Göttingen. Informed consent was obtained from all study participants in written form after having been informed by a physician. Patients could withdraw their agreement any time during the study.

\subsubsection{Venous blood collection}

Venous blood was collected from patients and healthy blood donors. Blood was drawn into S-Monovettes containing either clotting activators for serum or Lithium/Heparin-Gel for heparin blood collection.

\subsubsection{Serum isolation of venous blood}

To obtain serum, the blood was drawn into S-Monovettes and stored for 30-60 min at RT in an upright position to allow clotting. The clot was removed by centrifugation at $350 \mathrm{~g}$ for 10 $\min$ at RT. The resulting supernatant, was stored in $150 \mu \mathrm{l}$ aliquots at $-20{ }^{\circ} \mathrm{C}$ in $0.5 \mathrm{ml}$ reaction tubes.

\subsubsection{Statistical analysis}

All calculations were performed with GraphPad Prism software. Survival rates were compared by Kaplan-Meier plots and the log-rank test was used to calculate the corresponding $p$-values. Flow cytometric data from different groups were compared using the non-parametric Mann-Whitney $U$ test. Unless otherwise specified, data are depicted as bars showing the mean \pm SEM. p-values $<0.05$ were considered as statistically significant. The significance levels in the graphs are depicted as ns $(p \geq 0.05),{ }^{*}(p<0.05),{ }^{* *}(p \leq 0.01)$ and ${ }^{* * *}$ $(p \leq 0.001)$. 


\section{Results}

\subsection{Impact of ECP therapy on mouse models of aGvHD and cGvHD}

This study was conducted to investigate the therapeutic impact of PUVA-treated leukocytes derived from healthy donor mice (in the following designated "ECP therapy") on the course and severity of acute and chronic GvHD.

For induction of aGvHD, a well-defined allogeneic BMT mouse model was used (Tischner et al., 2011). This aGvHD mouse model is based on MHC class I and II as well as miHAs mismatches and is mediated by both $\mathrm{CD}^{+}$and $\mathrm{CD} 8^{+}$donor T cells (Schroeder and DiPersio, 2011b).

Additionally, a cGvHD mouse model was employed to study the impact of ECP therapy. For cGvHD induction, BALB/c recipient mice were transplanted with miHA-mismatched $\mathrm{T}$ and $\mathrm{BM}$ cells from wild-type B10.D2n5nJ (B10D2) donors. This mouse model is mediated by $\mathrm{CD} 4^{+} \mathrm{T}$ cells (Schroeder and DiPersio, 2011b).

In both mouse models, the transplanted mice received the ECP therapy four times in weekly intervals starting at day two or three post BMT (Fig.3).

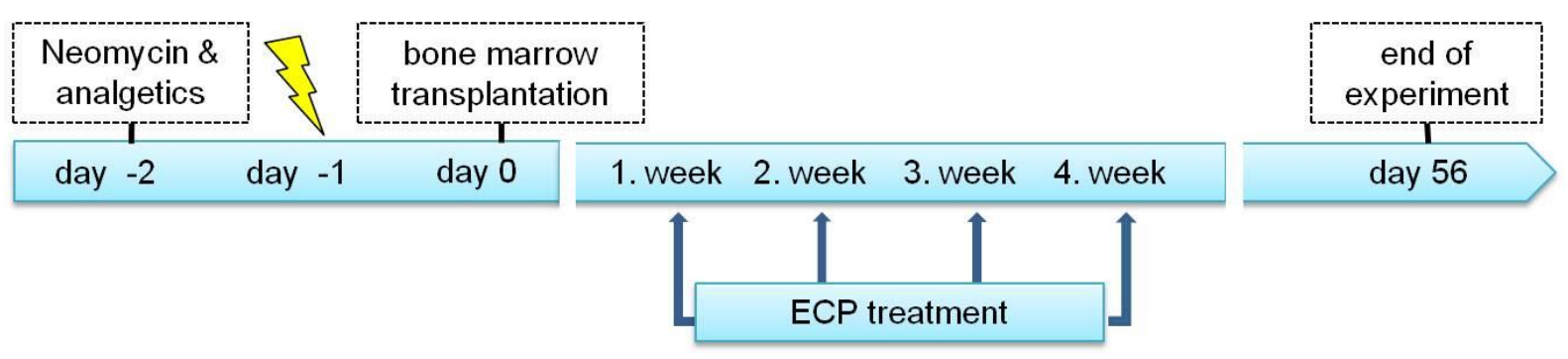

Fig. 3: Scheme of GvHD induction and ECP therapy in the mouse model.

\subsubsection{Impact of ECP therapy with cells from healthy mice on mouse models of GvHD}

\subsubsection{ECP therapy with C57BL/6 splenocytes in a mouse model of aGvHD}

An experimental system of ECP therapy with splenocytes derived from healthy donor mice was established to examine whether this setup could ameliorate the severity and course of aGvHD. To this end, a total MHC-mismatch mouse model of aGvHD was used. Following aGvHD induction, one cohort of C57BL/6->BALB/c transplanted mice received $1 \times 10^{6}$ PUVAtreated splenocytes whereas another cohort of recipient mice was injected with $5 \times 10^{6}$ PUVAtreated splenocytes from wildtype C57BL/6 mice. As controls, C57BL/6->BALB/c mice were injected with phosphate buffered saline (PBS) at all timepoints of ECP therapy. Over the 
whole course of the experiment, the clinical score, survival rate and weight loss was monitored (Fig. 4) to assess the efficacy of the different treatment protocols.
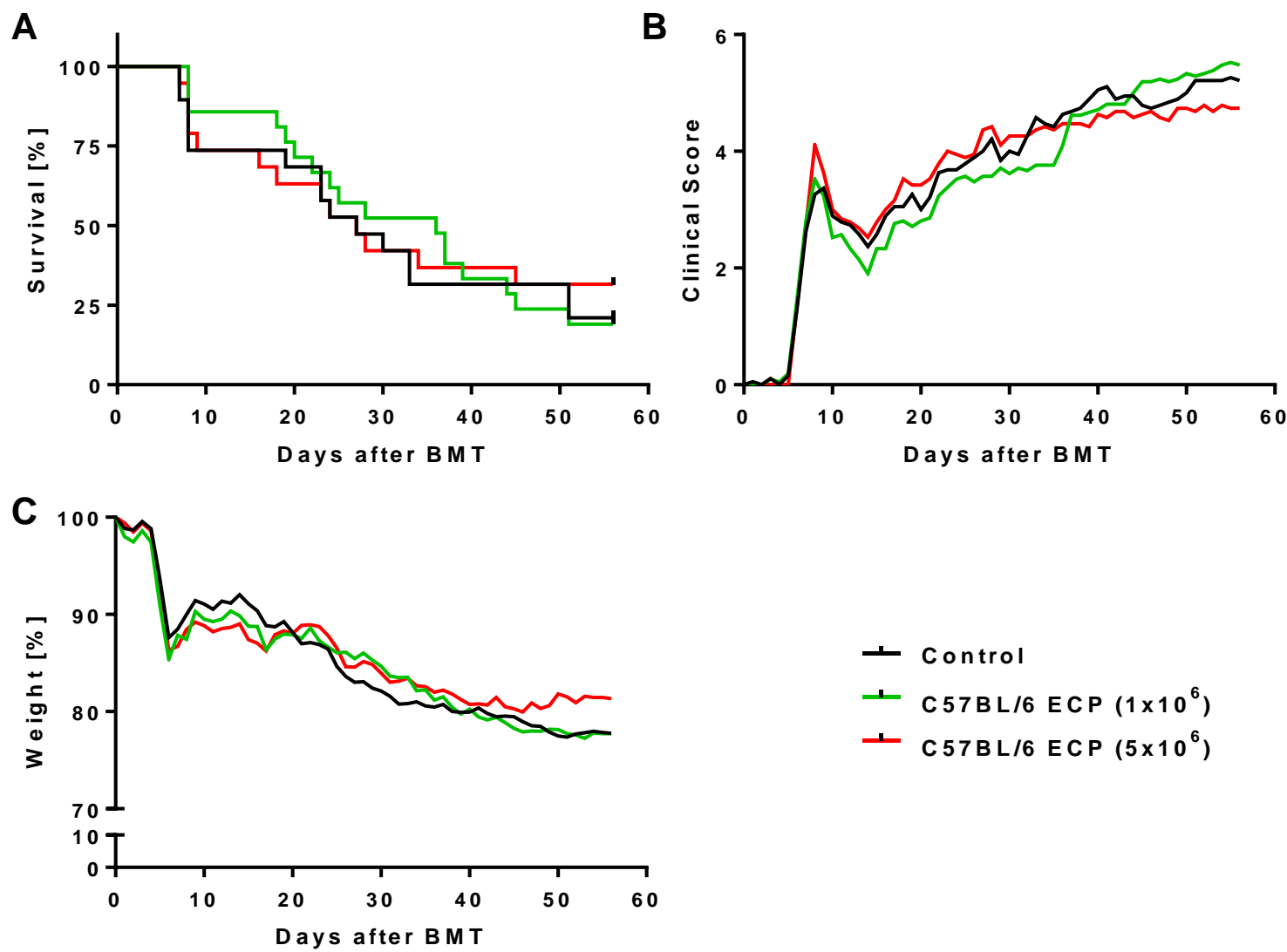

Fig. 4: C57BL/6->BALB/C transplanted mice injected with PUVA-treated C57BL/6 splenocytes as a model of ECP therapy of aGvHD. Irradiated BALB/c mice received allogeneic BMT followed by four weekly intravenous injections of PBS (black line, $n=19$ ), $1 \times 10^{6}$ (green line, $n=21$ ) or $5 \times 10^{6}$ (red line, $n=19)$ C57BL/6 splenocytes treated with 8-MOP and UV-A light. The therapeutic impact was analyzed by comparing the survival rates (A), clinical GvHD scores (B) and the weight loss (C).The Kaplan Meier plot shows survival rates and was analyzed using the log-rank test whereas the clinical scores and weight changes were analyzed with the Mann Whitney $U$ test. Data are shown as means and are representative of three independent experiments.

Fig. 4 shows that the survival rate $(A)$ and clinical GvHD score $(B)$ of mice injected with $1 \times 10^{6}$ or $5 \times 10^{6}$ PUVA-treated splenocytes derived from C57BL/6 were not improved as compared to control mice. As depicted in Fig. 4C, there was also no reduction of weight loss in ECPtreated mice compared to control mice (Budde et al., 2014). Furthermore, analysis of splenocytes by flow cytometry did not reveal any difference in the percentages of $\mathrm{CD}^{+} \mathrm{T}$ 
cells, CD4 ${ }^{+} \mathrm{T}$ cells or $\mathrm{CD}^{+} \mathrm{CD}^{+} 5^{+} \mathrm{FoxP}^{+}$Treg cells between PUVA-treated and control mice (Fig. 5 A-C).

A

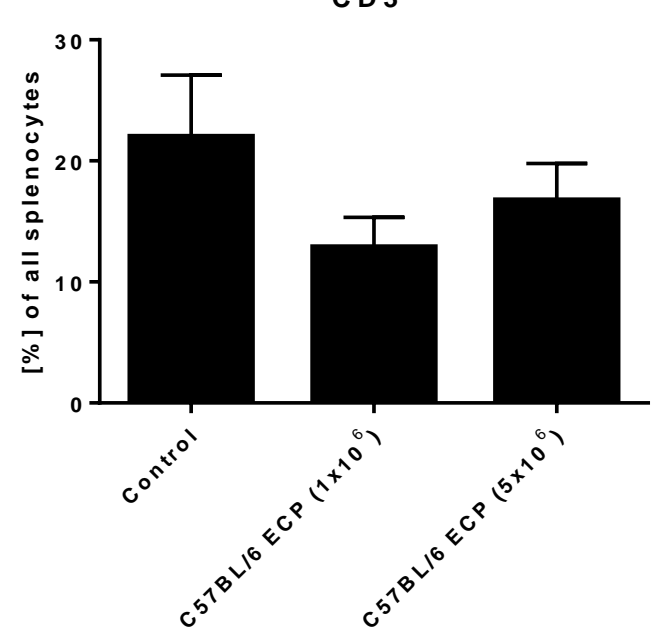

C

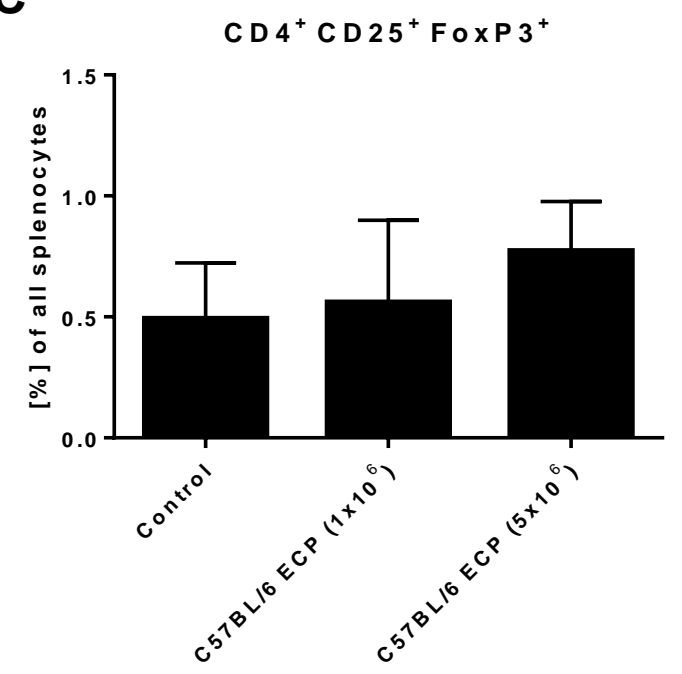

B

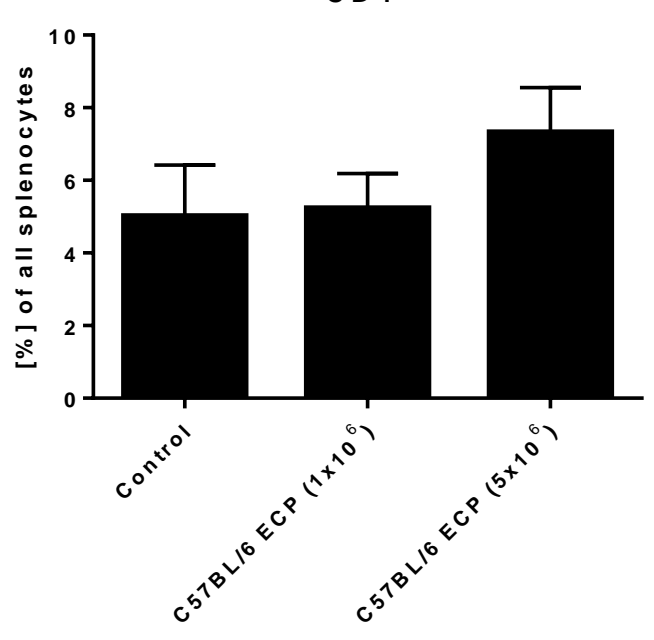

Fig. 5: FACS analysis of splenocytes from C57BL/6 $\rightarrow B A L B / c$ transplanted mice after ECP therapy with splenocytes of $\mathrm{C} 57 \mathrm{BL} / 6$ origin. $\mathrm{C} 57 \mathrm{BL} / 6->B A L B / c$ mice received $E C P$ therapy four times in weekly intervals starting from day 3 after BMT intravenous injection of $1 \times 10^{6}$ or $5 \times 10^{6}$ PUVAtreated splenocytes from C57BL/6 mice of PBS as control. The spleen of mice was analyzed when the mice had reached a clinical GvHD score of $\geq 6$ or at day 56 post BMT. The percentages of $\mathrm{CD}^{+} \mathrm{T}$ cells (A), CD4 $4^{+} \mathrm{T}$ cells (B) and $\mathrm{CD} 4^{+} \mathrm{CD} 25^{+} \mathrm{FoxP}^{+}$Treg cells (C) amongst all splenocytes are depicted. FACS analysis was conducted for 17 mice treated with $1 \times 10^{6}$ PUVA-treated splenocytes, 17 mice treated with $5 \times 10^{6}$ PUVA-treated splenocytes and 14 control mice. The bar diagrams show the means \pm SEM. 


\subsubsection{ECP therapy with C57BL/6 splenocytes in a mouse model of cGvHD}

Up to this point, we had not observed any therapeutic effect of ECP therapy on the clinical GvHD score, weight or survival rate in C57BL/6->BALB/c transplanted mice when using PUVA-treated splenocytes from the BMT donor strain (C57BL/6). Therefore we repeated the experiment in a miHA-mismatch mouse model of cGvHD to examine whether PUVA-treated splenocytes derived from BMT donor strain would have an impact on the course and severity of cGvHD. As mentioned above, B10.D2 mice were used as donors for BMT to induce cGvHD. B10.D2->BALB/c mice were intravenously injected with $1 \times 10^{6}$ PUVA-treated B10.D2 splenocytes four times in weekly intervals starting from day three post BMT. Mice injected with PBS served as controls. Subsequently, the survival rate (A), the clinical GvHD score (B) and the weight loss $(\mathrm{C})$ were monitored (Fig. 6).
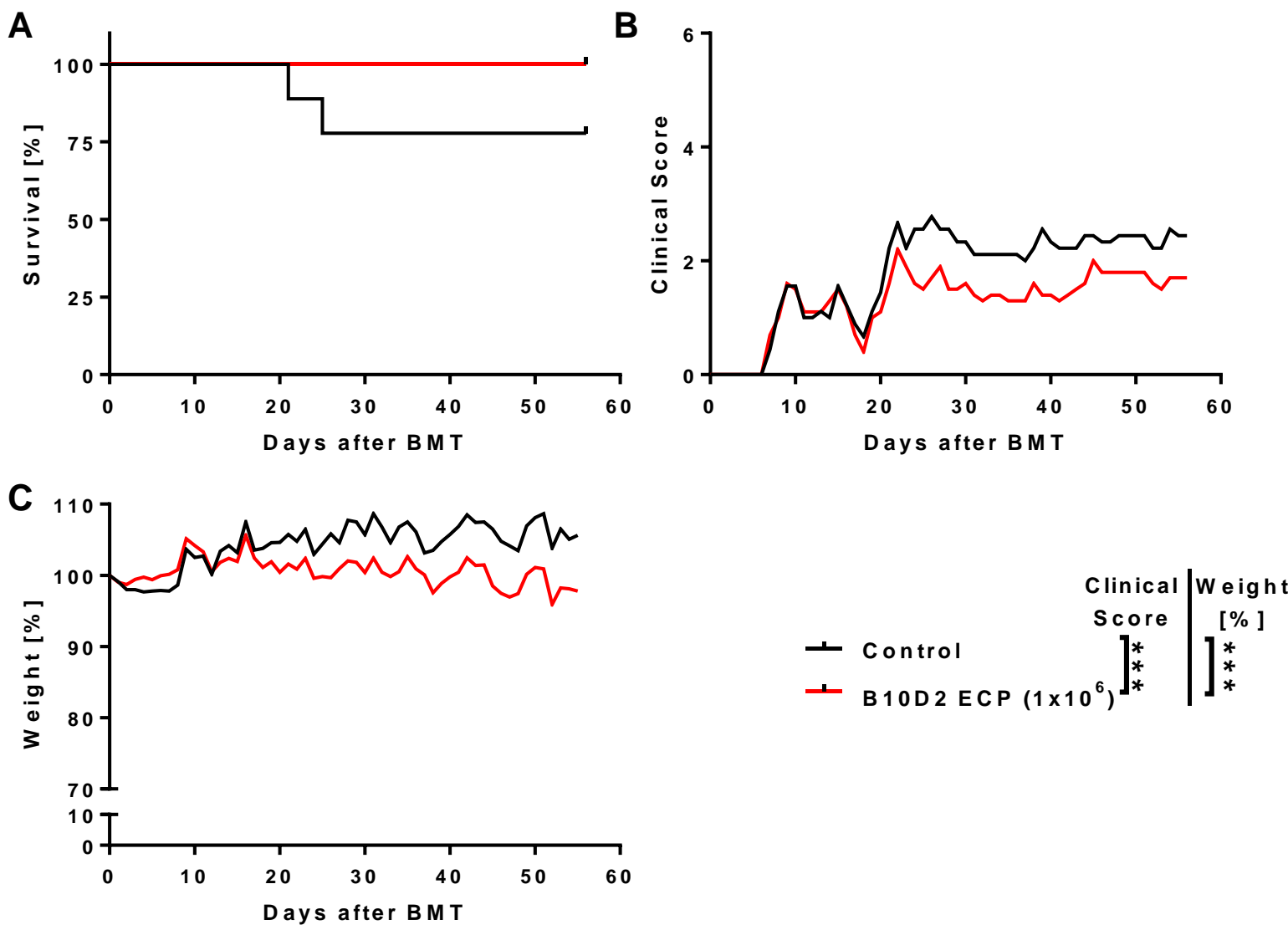

Fig. 6: ECP therapy ameliorates disease symptoms in mice suffering from chronic GvHD. cGvHD was induced in irradiated BALB/c mice by transplanting $T$ cell depleted BM cells and $T$ cells from B10D2 mice. B10D2->BALB/c mice were intravenously injected four times in weekly intervals with $1 \times 10^{6}$ PUVA-treated B10D2 splenocytes (red line, $n=9$ ) or PBS (black line, $n=10$ ). The Kaplan- 
Meier plot shows the survival rate $(A)$ and was analyzed using the log-rank test. The graphs also depict the impact of ECP therapy on the clinical score (B) and the weight loss (C), which were analyzed using the Mann Whitney $U$ test. The data represent mean values.

Fig. 6A shows that all B10D2->BALB/c mice injected with $1 \times 10^{6}$ PUVA-treated splenocytes of B10D2 origin survived whereas only $75 \%$ of the control mice survived 56 days post BMT. Furthermore, ECP-treated mice had a significantly lower clinical GvHD score than control animals (Fig. 6B, p<0.001). In contrast, ECP-treated mice lost significantly more weight than controls (Fig. 6C, p<0.001). Flow cytometric analysis of splenocytes from ECP-treated B10D2->BALB/C mice did not reveal differences in the percentages of CD4 ${ }^{+} \mathrm{T}$ cells or CD4 ${ }^{+}$ $\mathrm{CD}^{+} 5^{+} \mathrm{FoxP}^{+}$Treg cells between mice injected with $1 \times 10^{6}$ B10D2 PUVA-treated splenocytes and control mice (Fig. 7).

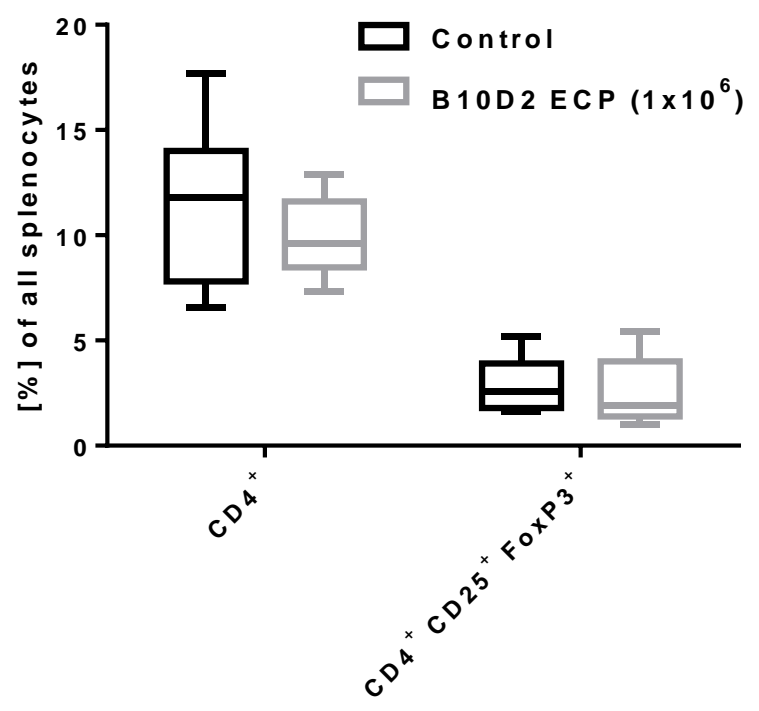

Fig. 7: FACS analysis of splenocytes after ECP therapy using cells of B10D2 origin in a mouse model of cGvHD. B10D2 -> BALB/c transplanted mice were intravenously injected with PUVA-treated splenocytes from B10D2 mice or PBS. ECP therapy was performed four times in weekly intervals starting from day 3 after BMT. The spleen was analyzed when mice reached a clinical GvHD score of $\geq 6$ or at day 56 post BMT. The percentages of $\mathrm{CD}^{+} \mathrm{T}$ cells and $\mathrm{CD} 4^{+} \mathrm{CD} 25^{+} \mathrm{FoxP}^{+} \mathrm{Treg}$ cells amongst all splenocytes are shown. FACS analysis is based on 10 mice injected with $1 \times 10^{6}$ PUVAtreated splenocytes, and 7 control mice. The box-and-whisker plots represent the median \pm 25 to 75 th percentile and $\mathrm{min} / \mathrm{max}$ values. The data were analyzed with the Mann Whitney $U$ test.

\subsubsection{ECP therapy with splenocytes of BALB/c origin}

Up to this point, ECP therapy with PUVA-treated splenocytes obtained from the BMT donor strain (C57BL/6) had not shown any improvement in survival rate, clinical GvHD score or 
weight loss. Hence, I next investigated the therapeutic impact of ECP therapy on aGvHD employing splenocytes from healthy mice of the recipient mouse strain (BALB/c). To this end, C57BL/6->BALB/C mice were injected four times in weekly intervals with PUVA-treated $B A L B / c$ leukocytes starting at day three post BMT. The mice were weighed and GvHD clinical score was assessed daily for 56 days after BMT.

As shown in Fig. 8A there was no difference in terms of survival rate between C57BL/6$>$ BALB/c mice injected with PBS and those mice injected with $1 \times 10^{6}$ or $5 \times 10^{6}$ PUVA-treated BALB/C splenocytes. Furthermore, injection of $1 \times 10^{6}$ or $5 \times 10^{6}$ PUVA-treated BALB/C splenocytes even worsened the clinical GvHD score (Fig. 8B) as compared to controls $(\mathrm{p}<$ $0.001 / p<0.045$ ), and significantly increased the weight loss (Fig. $8 \mathrm{C}$ ) when compared to PBS-injected mice $(p<0.001)$.
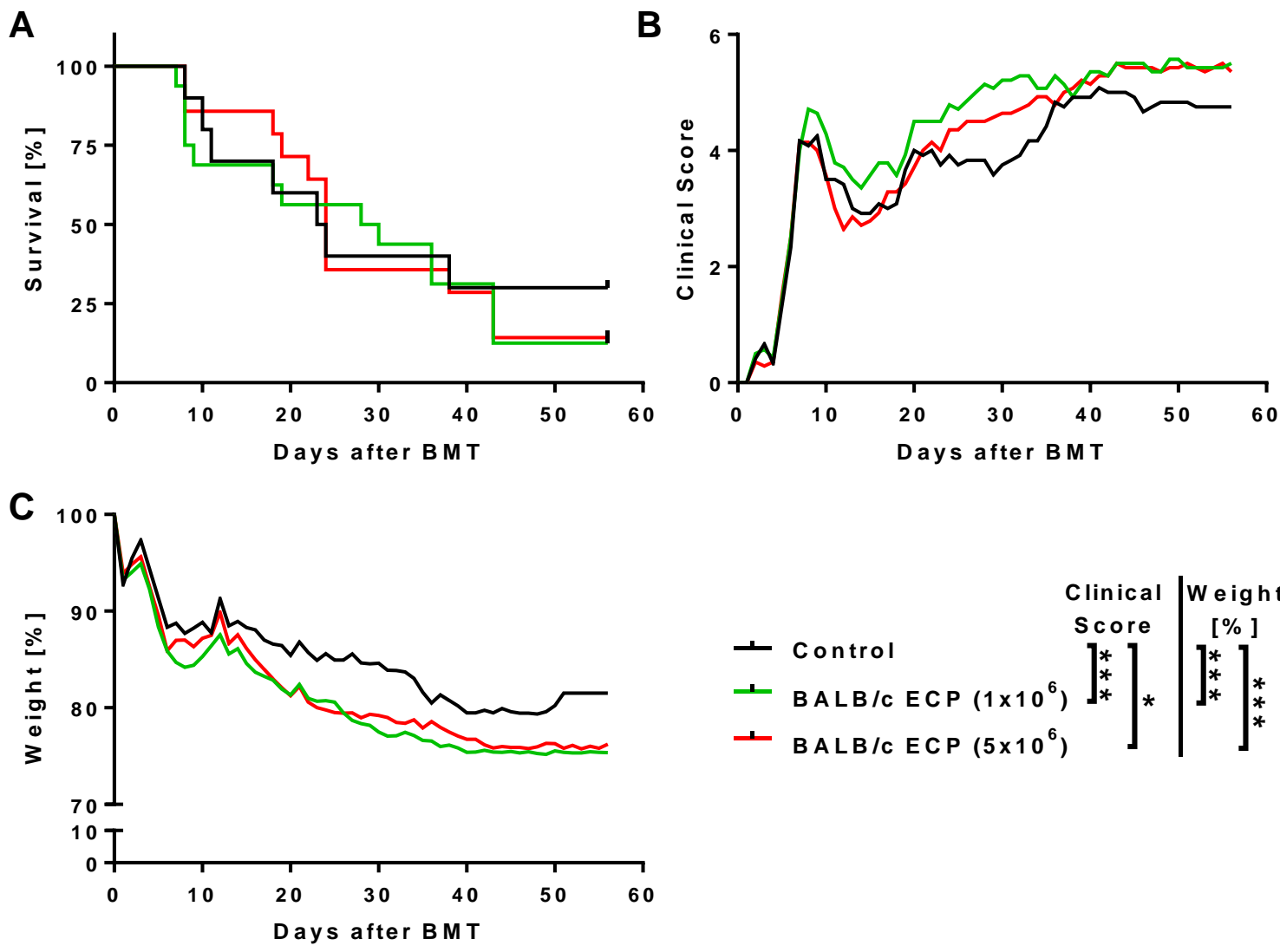

Fig. 8: ECP therapy using PUVA-treated BALB/c splenocytes aggravates aGvHD in mice. C57BL/6->BALB/c transplanted mice were injected four times in weekly intervals with either $1 \times 10^{6}$ (green line, $n=14$ ) or $5 \times 10^{6}$ (red line, $n=14$ ) PUVA-treated BALB/c splenocytes. Control mice (black line, $n=12$ ) were transplanted simultaneously and infused PBS only at all therapeutic time points. The survival rate $(A)$ is shown as Kaplan-Meier plot and was analyzed using the log-rank test. The therapeutic impact on the clinical GvHD score (B) and weight loss (C) was assessed daily after BMT 
and analyzed by use of the Mann Whitney $U$ test. Data are shown as means and are representative of two independent experiments.

To obtain more insights into the cellular processes taking place during treatment of aGvHD, splenocytes were isolated from C57BL/6->BALB/c mice after ECP therapy and analyzed by flow cytometry. More specifically the percentages of $\mathrm{CD} 3^{+} \mathrm{T}$ cells, $\mathrm{CD} 3^{+} \mathrm{y} \delta \mathrm{T}$ cells and $\mathrm{CD} 4^{+}$ $\mathrm{CD}^{2} 5^{+} \mathrm{FoxP}^{+}$Treg cells amongst all splenocytes were assessed (Fig. 9). There were no differences found in percentages of $\mathrm{CD}^{+} \mathrm{T}^{\mathrm{T}}$ cells and $\mathrm{CD} 4^{+} \mathrm{CD}^{2} 5^{+} \mathrm{FoxP}^{+}$Treg cells, whereas the percentages of $\mathrm{CD}^{+}{ }^{+} \gamma \delta \mathrm{T}$ cells are decreased in control animals that survived the experiment compared to those mice which were treated with $1 \times 10^{6}(p=0.006)$ or $5 \times 10^{6}$ $(p=0.01)$ splenocytes of BALB/c origin and died during the experiment. Furthermore, those mice that survived and were treated with $5 \times 10^{6} \mathrm{BALB} / \mathrm{c}$ splenocytes showed decreased percentages of $\mathrm{CD}^{+} \mathrm{y} \delta \mathrm{T}$ cells compared to those which were treated with $1 \times 10^{6}$ splenocytes and died during the experiment $(\mathrm{p}=0.0256)$. 
A

CD $3^{+}$

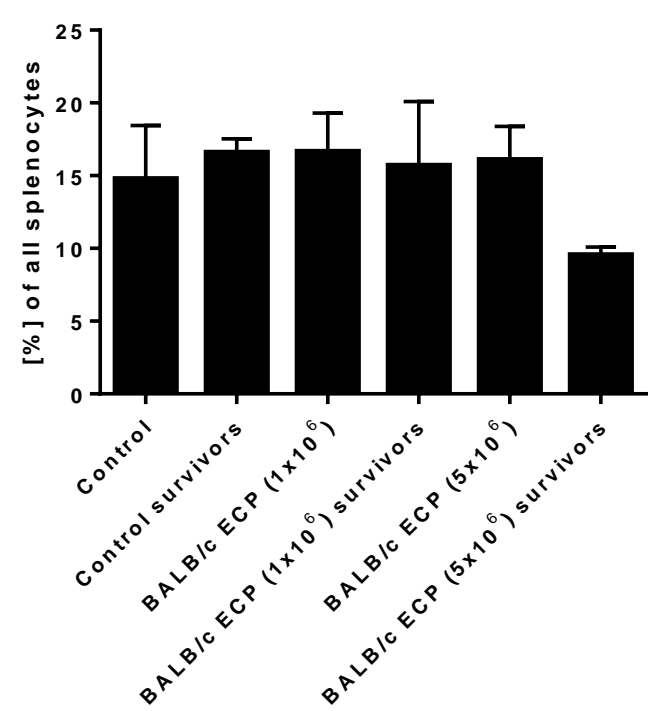

C $\quad \mathrm{CD}^{+} \mathrm{CD} 25^{+} \mathrm{FoxP}^{+}$

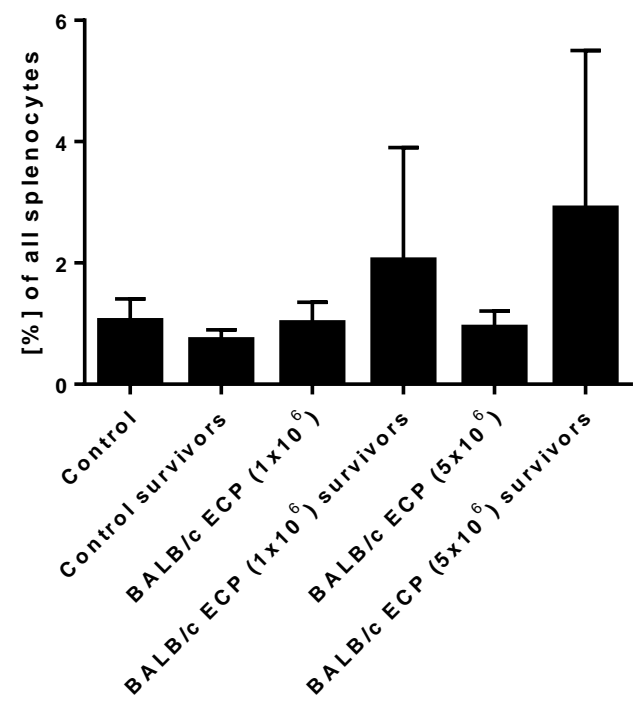

B

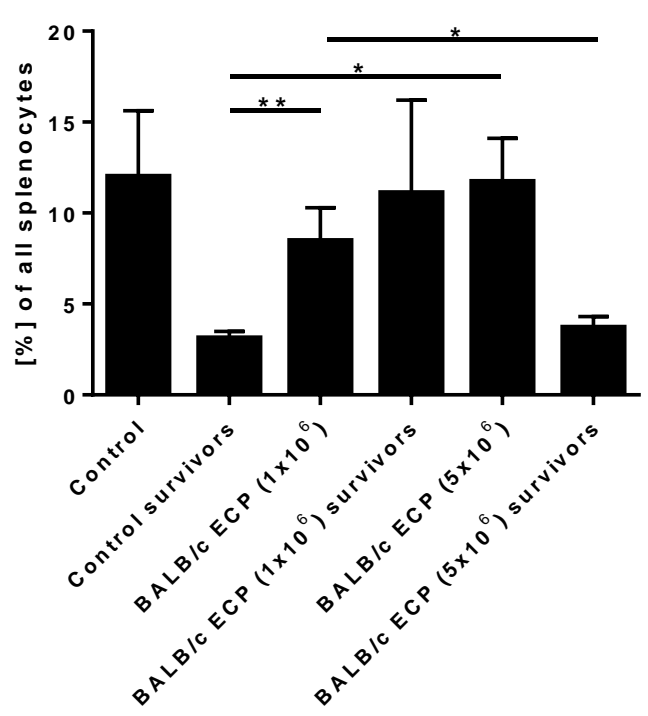

Fig. 9: Flow cytometric analysis of splenocytes isolated from C57BL/6->BALB/c mice after ECP therapy with PUVA-treated BALB/c splenocytes. Splenocytes from C57BL/6->BALB/c mice having undergone ECP therapy with $1 \times 10^{6}$ or $5 \times 10^{6}$ PUVA-treated BALB/c splenocytes or having received PBS as control were investigated. ECP therapy was performed four times in weekly intervals starting from day 3 after BMT. Flow cytometry was performed with splenocytes from mice sacrificed when reaching a GvHD score $\geq 6$ or at day 56 post BMT. Percentages of $C D 3^{+} T$ cells $(A), C D^{+} \gamma \delta T$ cells (B) and $\mathrm{CD}^{+} \mathrm{CD}^{+} 5^{+} \mathrm{FoxP}^{+}$Treg cells (C) amongst all splenocytes are shown. FACS analysis is based on 10-13 mice per group. The data are depicted as means ISEM and were analyzed using the Mann Whitney U test.

\subsubsection{ECP therapy with splenocytes of $\mathrm{C} 3 \mathrm{H}$ origin}


ECP therapy using PUVA-treated splenocytes obtained from C57BL/6 or BALB/c mice had not shown any therapeutic effects in a mouse model of aGvHD. Hence we asked whether ECP therapy with splenocytes of a third party donor mouse strain would be more successful. To address this question, $\mathrm{C} 3 \mathrm{H}$ mice were used as splenocyte donors for ECP therapy after GvHD induction in C57BL/6->BALB/c mice.

\subsection{ECP therapy with splenocytes from $\mathrm{C} 3 \mathrm{H}$ mice in an aGvHD mouse model}

Similar to the former experiments, aGvHD was induced by using C57BL/6 mice as BMT donors and $\mathrm{BALB} / \mathrm{c}$ as recipient mice. For ECP therapy splenocytes were isolated from $\mathrm{C} 3 \mathrm{H}$ mice and treated with 8-MOP and UV-A light. C57BL/6->BALB/c mice were weekly injected with PUVA-treated cells for four times starting at day 3 after BMT.

A
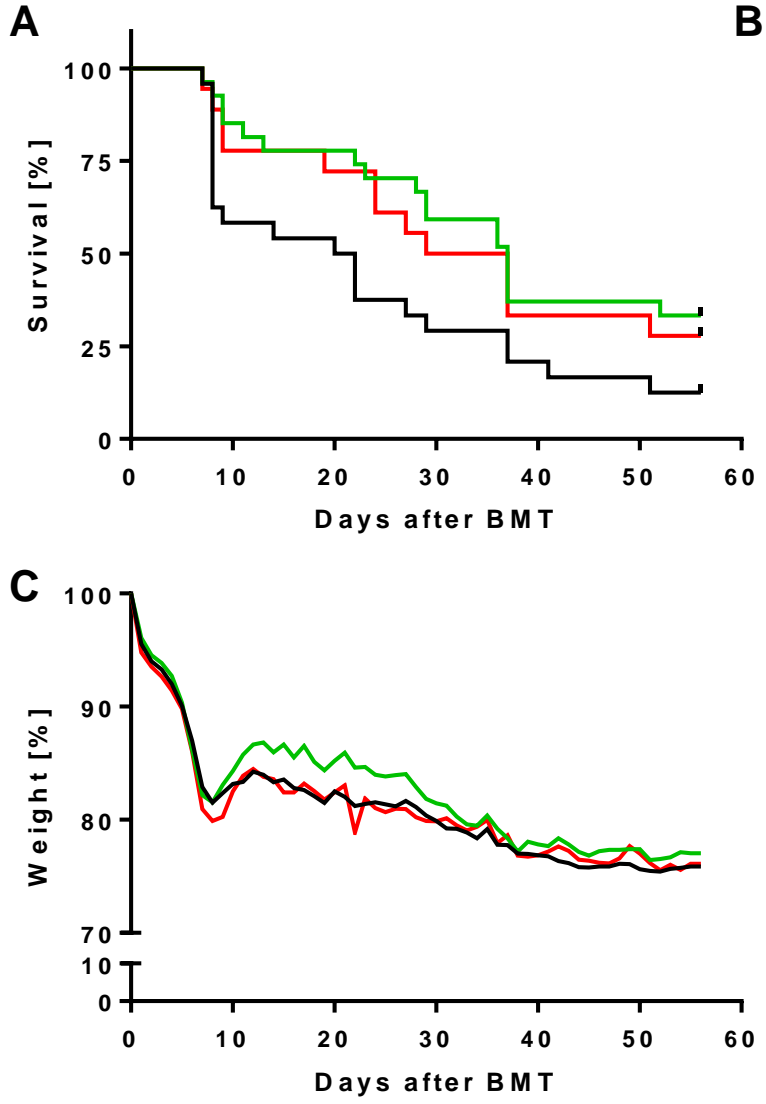

B
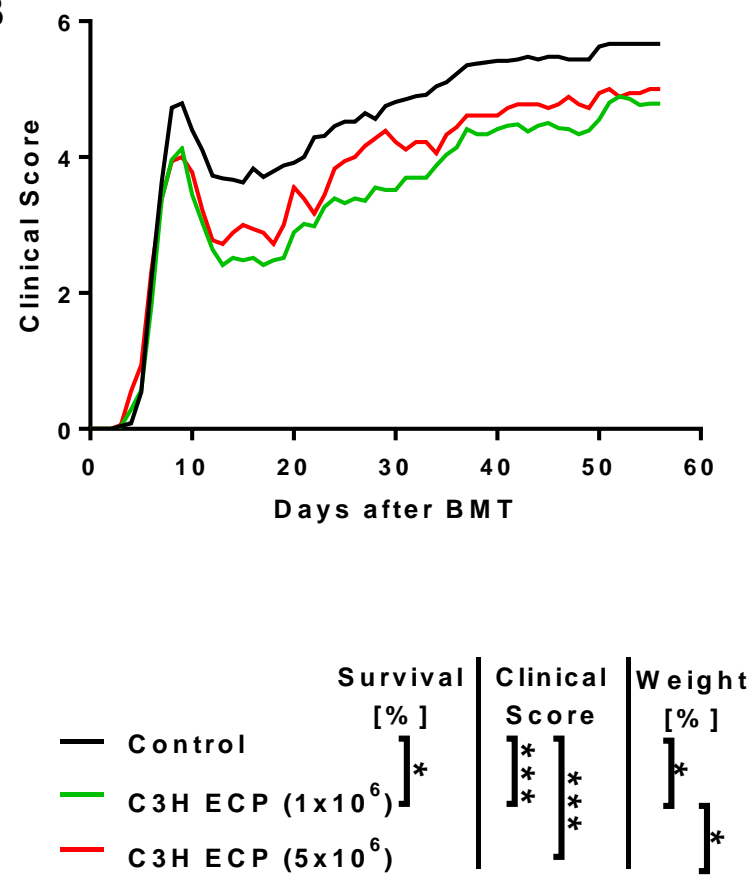

Fig. 10: ECP therapy with splenocytes of C3H origin reduces mortality, the clinical aGvHD score, and weight loss in mouse model of aGvHD. Irradiated BALB/c mice were transplanted with $\mathrm{BM}$ and T cells from C57BL/ 6 mice to induce aGvHD. For ECP therapy either $1 \times 10^{6}$ (green line, $n=27$ ) or $5 \times 10^{6}$ (red line, $n=18$ ) PUVA-treated splenocytes from $\mathrm{C} 3 \mathrm{H}$ were injected four times in weekly intervals starting from day 3 after BMT. Control mice were simultaneously transplanted and treated with PBS (black line, $n=24$ ). Kaplan Meier plots show the survival rates $(A)$ and were analyzed with the log-rank test. The therapeutic impact was analyzed by daily monitoring the clinical GvHD score (B) 
and the weight changes $(\mathrm{C})$; statistical analysis by Mann Whitney $\mathrm{U}$ test. The data show means and are pooled from four independent experiments.

C57BL/6->BALB/C mice injected with $1 \times 10^{6}$ PUVA-treated C3H splenocytes survived significantly longer $(p=0.02)$ than control animals (Fig. 10A). Injection of $1 \times 10^{6}$ or $5 \times 10^{6}$ PUVA-treated $\mathrm{C} 3 \mathrm{H}$ leukocytes significantly decreased the clinical aGvHD scores $(p<0.001)$ as compared to control mice (Fig. 10B). Furthermore, mice treated with $1 \times 10^{6} \mathrm{C} 3 \mathrm{H}$ splenocytes lost significantly less weight than control animals (Fig. 10C, $\mathrm{p}=0.02$ ). In summary, ECP therapy using PUVA-treated splenocytes from $\mathrm{C} 3 \mathrm{H}$ mice have a therapeutic potential in a mouse model of aGvHD.

To perform flow cytometric analysis, treated C57BL/6->BALB/c mice were sacrificed when reaching a GvHD score $\geq 6$ or at day 56 post BMT. Subsequently, the percentages of $\mathrm{CD}^{+} \mathrm{T}$ cells, $\mathrm{CD}^{+}{ }^{+} \mathrm{T}$ cells, $\mathrm{CD}^{+} \mathrm{CD}^{+} \mathrm{T}$ cells, $\mathrm{CD} 3{ }^{-} \mathrm{CD}_{49 b^{+}} \mathrm{NK}$ cells, and $\mathrm{CD} 4^{+} \mathrm{CD}^{2} 5^{+} \mathrm{FoxP}^{+}$Treg cells were determined in ECP-treated or control mice (Fig. 11). Mice which were treated with $5 \times 10^{6}$ PUVA-treated splenocytes with $\mathrm{C} 3 \mathrm{H}$ origin and survived the experiment had significantly less percentages of $\mathrm{CD}^{+} \mathrm{T}$ cells in comparison to those which died in the course of the experiment (Fig. $11 \mathrm{~A} ; \mathrm{p}=0.03$ ).

With the exception of PBS-injected mice, all other groups had higher percentages of $\mathrm{CD}^{+}$ $\mathrm{CD} 8^{+} \mathrm{T}$ cells than mice which survived and had been injected with $5 \times 10^{6}$ PUVA-treated $\mathrm{C} 3 \mathrm{H}$ splenocytes (Fig. 11C; $\mathrm{p} \leq 0.01$ ).

No relevant differences were found in percentages of CD3 $\mathrm{CD}^{-} 9 \mathrm{~b}^{+} \mathrm{NK}$ cells, $\mathrm{CD} 4^{+} \mathrm{T}$ cells, and $\mathrm{CD} 4^{+} \mathrm{CD} 25^{+}$FoxP3 ${ }^{+}$Treg cells (Fig. 11B, D, and E) 
A

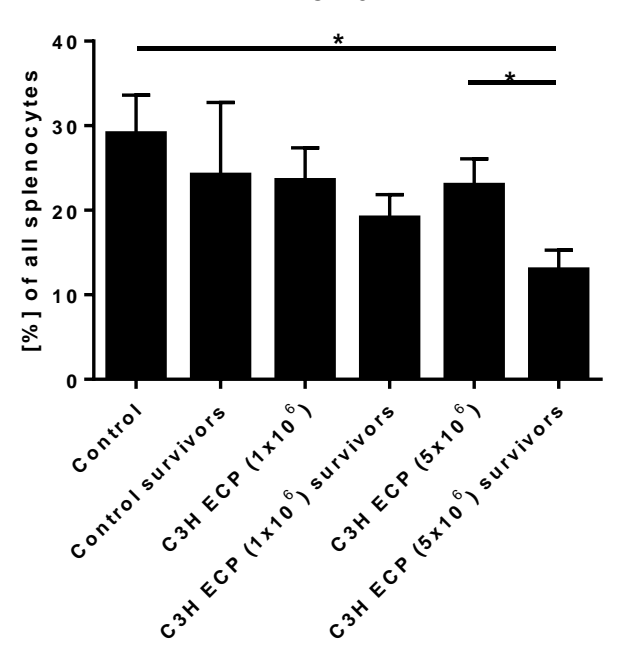

C

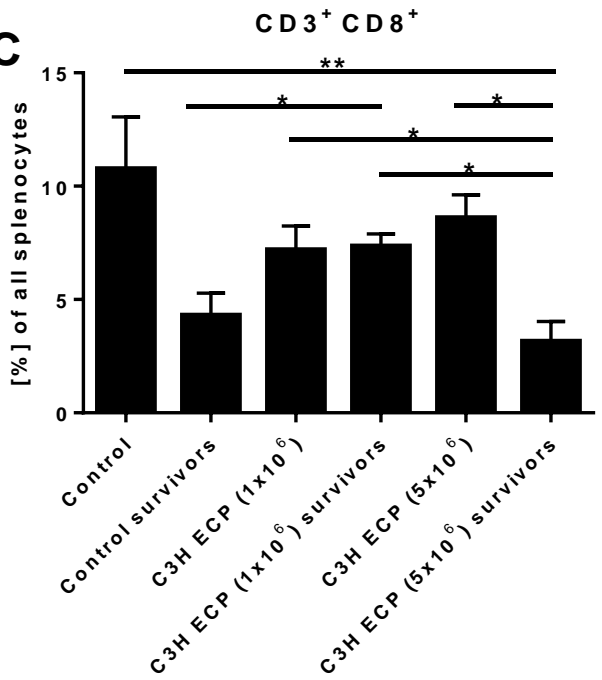

E

E $\quad \mathrm{CD}^{+} \mathrm{CD} 25^{+} \mathrm{FOXP3}^{+}$

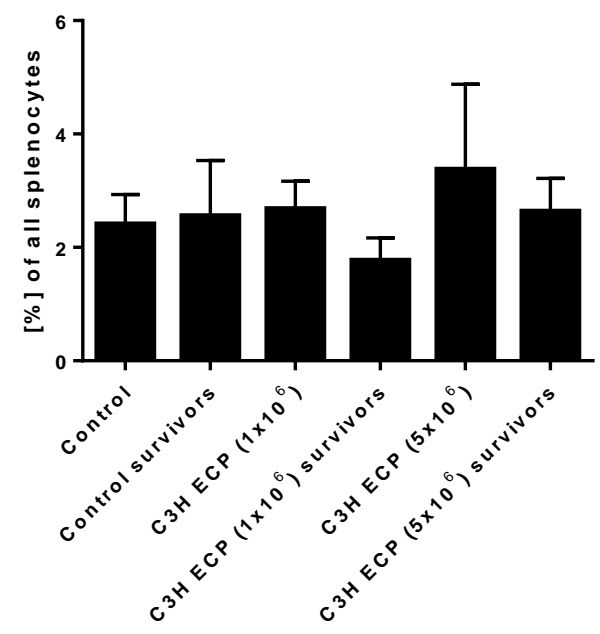

B

CD $4^{+}$

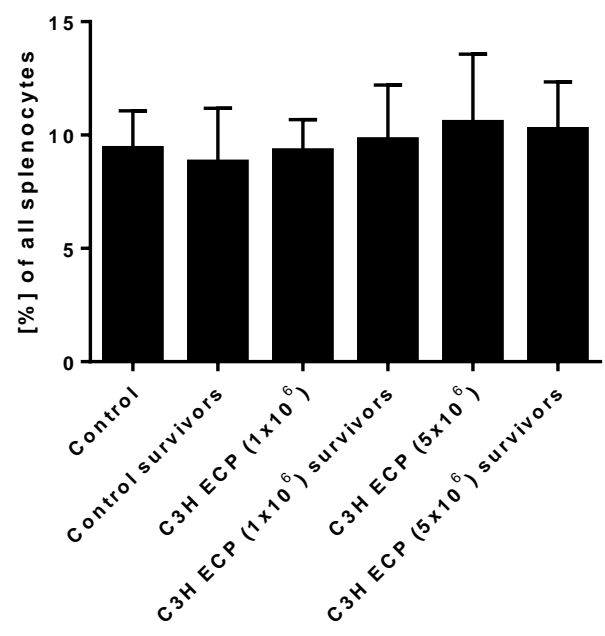

D

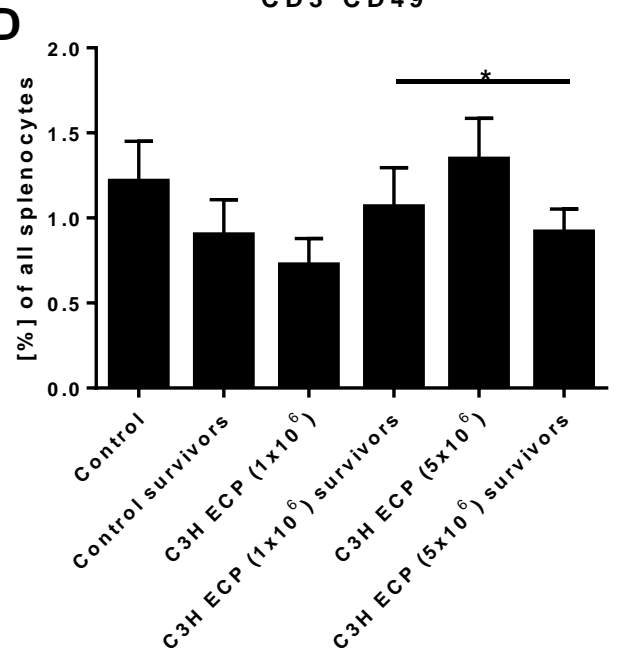

Fig. 11: FACS analysis of splenocytes from aGvHD mice after ECP therapy with cells of C3H origin. ECP therapy was performed four times in weekly intervals starting from day 3 after BMT. To this end, C57BL/6->BALB/c mice were injected with $1 \times 10^{6}$ or $5 \times 10^{6}$ PUVA-treated cells obtained from $\mathrm{C} 3 \mathrm{H}$ spleens. Control mice were treated with PBS only. Percentages of $\mathrm{CD}^{+} \mathrm{T}$ cells (A), $C D 4^{+} T$ cells (B), $C D 3^{+} C D 8^{+} T$ cells $(C)$, $\mathrm{CD}^{-} \mathrm{CD}^{-} \mathrm{bb}^{+} \mathrm{NK}$ cells (D) and $\mathrm{CD}^{+} \mathrm{CD}^{+} 5^{+}$ $\mathrm{FoxP}^{+}$Treg cells (E) amonst all splenocytes. FACS analysis is based on 24 mice treated with $1 \times 10^{6}$ cells, 17 mice injected with $5 \times 10^{6}$ cells and 22 control mice. Animals were sacrificed when reaching a clinical GvHD score of $\geq 6$ or at day 56 post BMT. The data are depicted as means \pm SEM. 


\subsection{Analysis of the first peak in ECP therapy of aGvHD with splenocytes of C3H}

\section{origin}

My previous experiments had revealed that $\mathrm{C} 57 \mathrm{BL} / 6->\mathrm{BALB} / \mathrm{c}$ mice treated with $\mathrm{ECP}$ therapy using cells derived from $\mathrm{C} 3 \mathrm{H}$ strain showed a therapeutic effect. Based on these result it should be examined whether these ECP-treated mice also showed differences on the cytokine or cellular level compared to control mice at the highest peak of aGvHD. To this end, recipient mice were sacrificed at day 7 post BMT when clinical aGvHD were temporarily highest. Afterwards serum, splenocytes and, lymph nodes were isolated and analyzed by ELISA and flow cytometry.

A

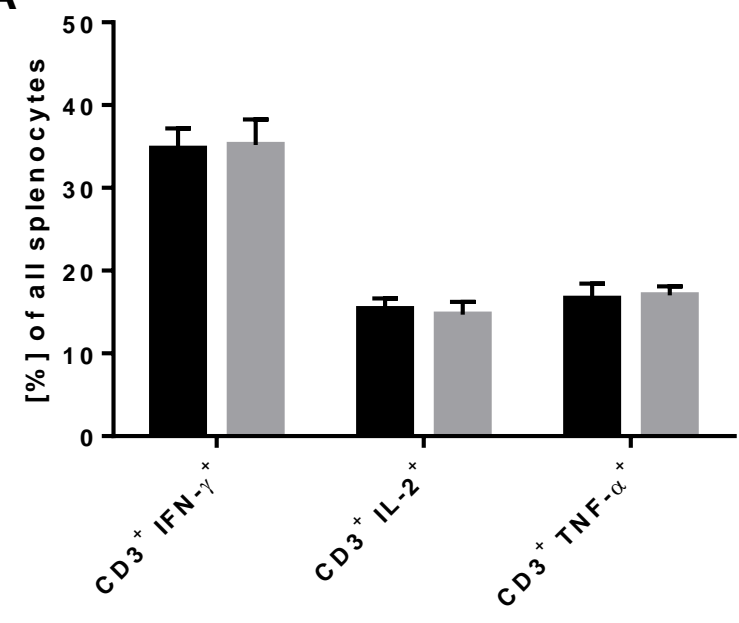

C

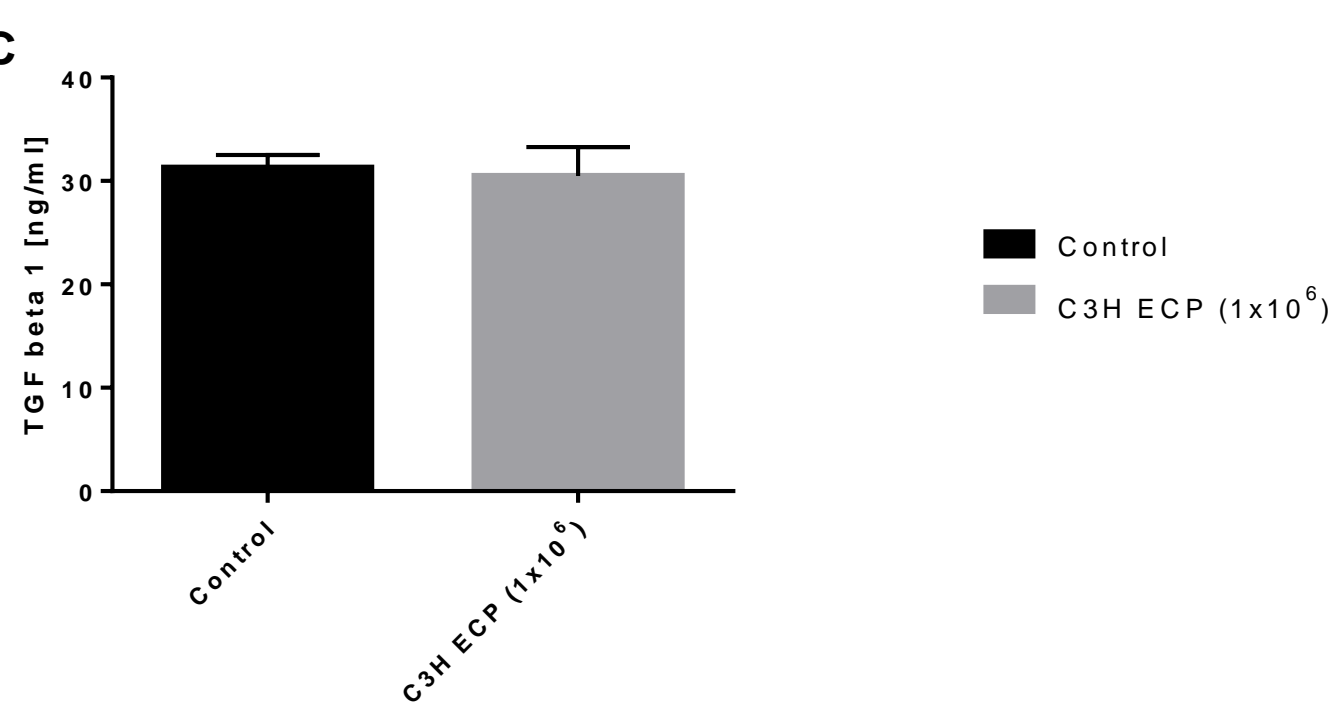

B

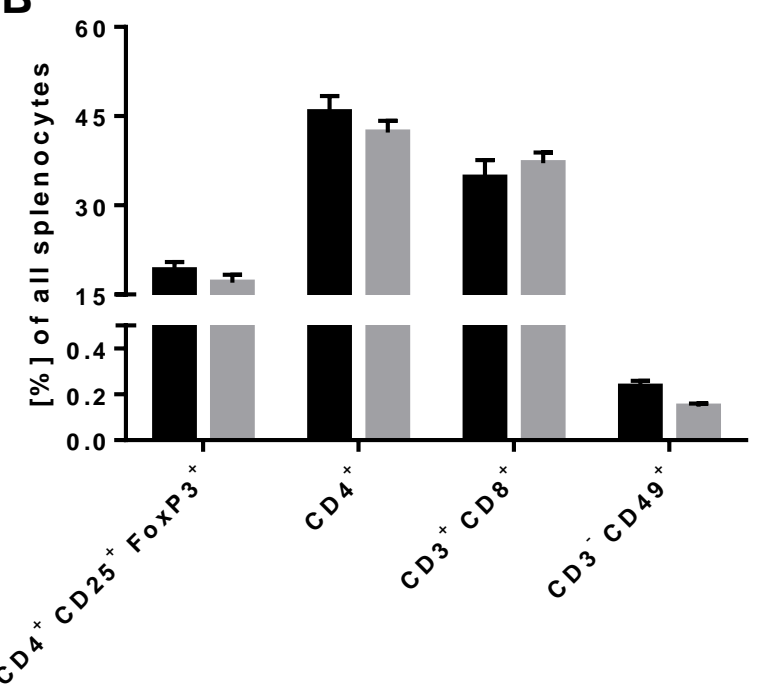


Fig. 12: Analysis of splenocytes and serum from C57BL/6->BALB/c mice injected with PUVAtreated cells of $\mathrm{C} 3 \mathrm{H}$ origin. BALB/C mice received an allogeneic transplant from C57BL/6 donors. Three days post BMT one cohort of 15 C57BL/6->BALB/c mice was intravenously injected with $1 \times 10^{6}$ PUVA-treated splenocytes from $\mathrm{C} 3 \mathrm{H}$ mice. Another group of 15 mice was injected simultaneously with PBS and served as a control. Seven days post BMT when the mice had reached the maximal clinical GvHD score they were sacrificed. Splenocytes were isolated and the percentages of either intracellular cytokines in T cells (A) or of several cellular subpopulations (B) were analyzed using flow cytometry. The serum was isolated using heart puncture and the concentrations of TGF beta 1 were determined by ELISA $(C)$. The data show means \pm SEM and were analyzed with the Mann Whitney $U$ test.

The analyses of intracellular cytokine expressions in T cells $\left(\mathrm{CD}^{+} \mathrm{IFN}-\mathrm{\gamma}^{+}, \mathrm{CD}^{+} \mathrm{IL}-2^{+}, \mathrm{CD}^{+}\right.$ TNF- $\alpha^{+}$) showed no differences between ECP-treated and control mice (Fig. 12A) Furthermore, cellular composition of the splenocytes (Fig. 12B) and the lymph nodes (not shown) also showed no difference in the percentages of $\mathrm{CD}^{+} \mathrm{CD}^{+} 5^{+} \mathrm{FoxP}^{+}, \mathrm{CD}^{+}, \mathrm{CD}^{+}$ $\mathrm{CD}^{+}$and, $\mathrm{CD}^{-} \mathrm{CD}^{-} 9^{+}$cells between ECP-treated and control mice. The concentration of TGF- $\beta 1$ in the serum at day 7 post BMT was similar in C57BL/6->BALB/C mice treated with ECP therapy and PBS-treated control mice (Fig. 12C).

\subsubsection{ECP therapy with cells activated in a mixed lymphocyte reaction}

\subsection{Establishment of a mixed lymphocyte reaction in vitro}

The MLR was established in vitro by first determining the optimal cell density. To this end, MLRs were prepared at different cell densities and counted every day starting on day one after initiation of the culture. Generally, about $26-48 \%$ of the cells died during the first four days of incubation. An MLR with $5 \times 10^{6}$ cells per $\mathrm{ml}$ was chosen as the optimal cell density because here the fewest cells died during incubation.

Next, we wanted to determine the day when proliferation rate reached its peak. Before incubation, MLR cells were labeled with the cell proliferation dye eFlour and the proliferation rate was measured daily using flow cytometry. The highest proliferation rate was reached at day four after the setup of the MLR.

As a final step of the establishment, the percentages of intracellular cytokines were analyzed by flow cytometry. At day six after MLR preparation the percentages of pro-inflammatory TNF- $\alpha^{+}$and IFN- $\gamma^{+}$cells started to increase whereas the percentage of IL-2 ${ }^{+}$cells did not increase during MLR at all.

Based on these results, the MLR was incubated at a density of $5 \times 10^{6}$ cells per $\mathrm{ml}$ for four days before they were used for ECP therapy in the mouse model of aGvHD. 


\subsection{ECP therapy with MLR cells from BALB/C and C57BL/6 donor mice}

After having established MLR in vitro (4.1.1.6.1.), the therapeutic impact of ECP therapy with MLR cells was examined in the mouse model of aGvHD. An MLR setup with splenocytes from BALB/c and C57BL/6 mice was prepared. Additionally, irradiated BALB/c splenocytes were incubated alone and served as control (BALB/c (xRay)). Following four days of incubation MLR cells and irradiated BALB/C cells were treated with 8-MOP/UV-A and were intravenously injected into allogeneic transplanted mice. One cohort of C57BL/6->BALB/C mice received PBS only and served as controls, a second cohort received $1 \times 10^{6} \mathrm{MLR}$ cells and a third cohort $1 \times 10^{6}$ irradiated BALB/c cells (xRay). ECP therapy was performed four times in weekly intervals starting at day three after BMT. The therapeutic impact of PUVAtreated MLR cells was measured by assessing the GvHD clinical score, weight loss and survival rates.

As shown in Fig. 13, no difference in survival rate, the clinical GvHD score and, the weight loss could be found between mice treated with PUVA-treated MLR cells, irradiated BALB/C cells and control mice. Percentages of $\mathrm{CD}^{+}, \mathrm{CD}^{+} \mathrm{CD}^{+}, \mathrm{CD}^{+}, \mathrm{CD}^{+} \mathrm{CD}^{+} 5^{+} \mathrm{FoxP}^{+}$ amongst all splenocytes were not different between controls and MLR-treated mice (Fig. 14). 
A
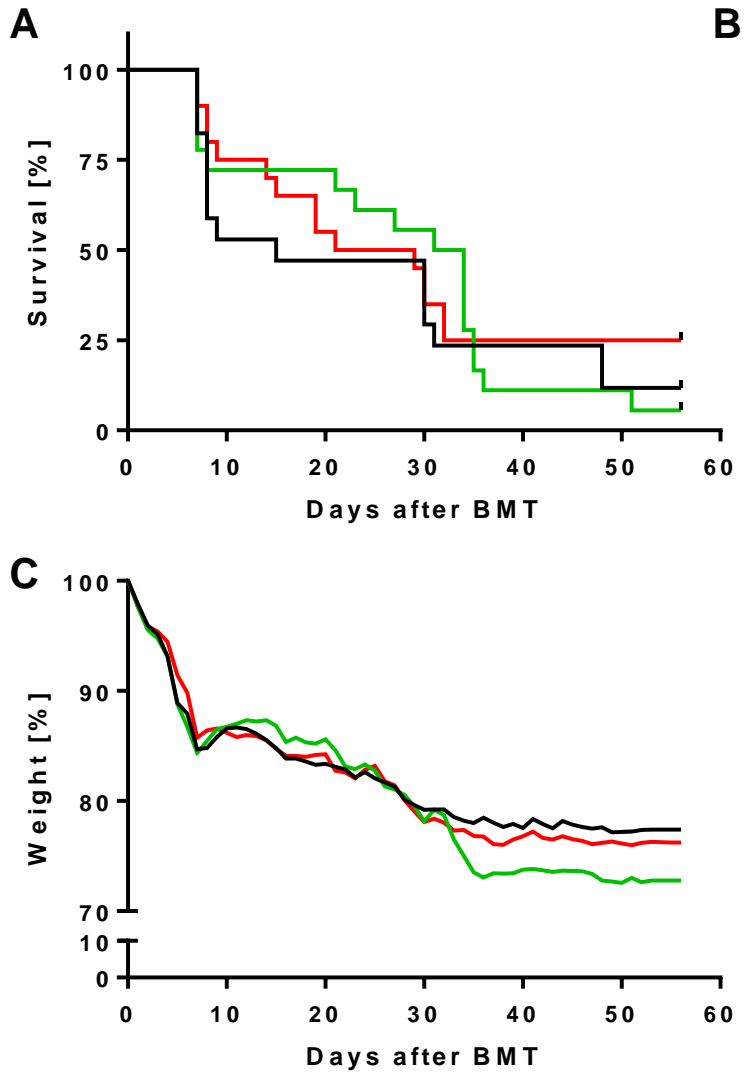

B

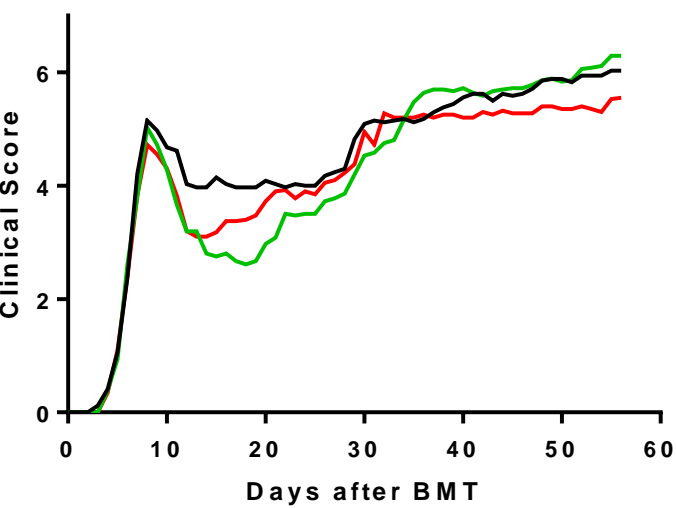

Control

- BALB/C (xRay) ECP $\left(1 \times 10^{6}\right)$

- MLR (C57BL/6 + BALB/c(xRay) ECP $\left.\left(1 \times 10^{6}\right)\right)$

Fig. 13: ECP therapy of aGvHD using cells from MLR of C57BL/6 and BALB/c origin. Irradiated $\mathrm{BALB} / \mathrm{c}$ mice received an allogeneic transplant containing BM and T cells of C57BL/6 mice to induce aGvHD. Treatment of C57BL/6->BALB/c mice was performed four times in weekly intervals and started day one after BMT. Two groups of transplanted mice served as controls and either received PBS (black line, $n=17$ ) or $1 \times 10^{6}$ radiated (30 Gy) PUVA-treated BALB/c splenocytes (red line, $n=18$ ). The third cohort of mice was injected with $1 \times 10^{6}$ PUVA-treated MLR cells (green line, $n=20$ ) which consisted of BALB/c leukocytes irradiated at 30Gy and co-cultured for four days with C57BL/6 leukocytes in an incubator. The Kaplan-Meier plot shows the survival rate $(A)$ and was analyzed using the log-rank test. The clinical GvHD score (B) and weight loss (C) were monitored daily and analyzed using the Mann Whitney $U$ test. The data represent the means and were pooled from three independent experiments. 
A

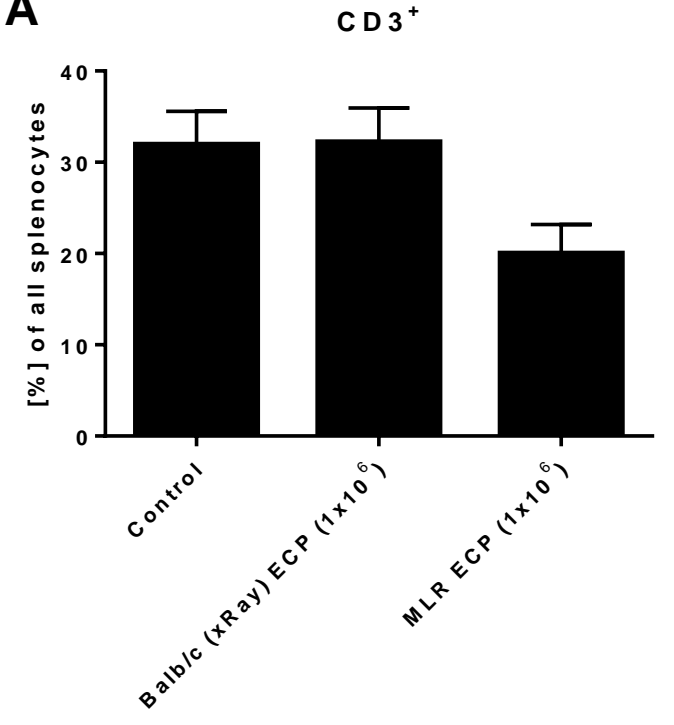

C

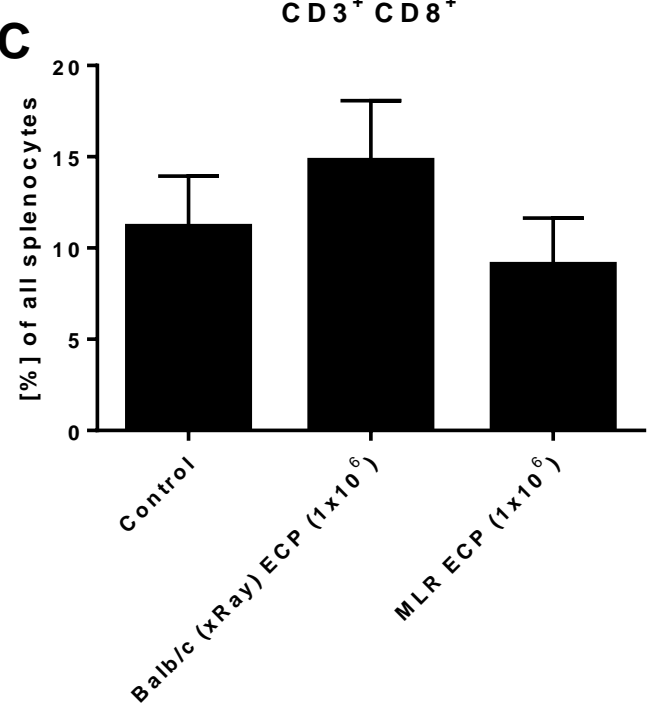

B

C D $4^{+}$

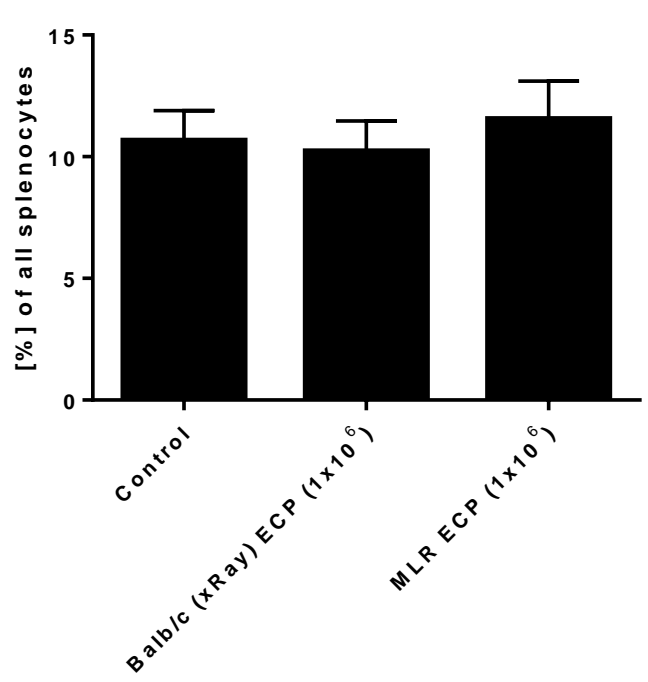

D

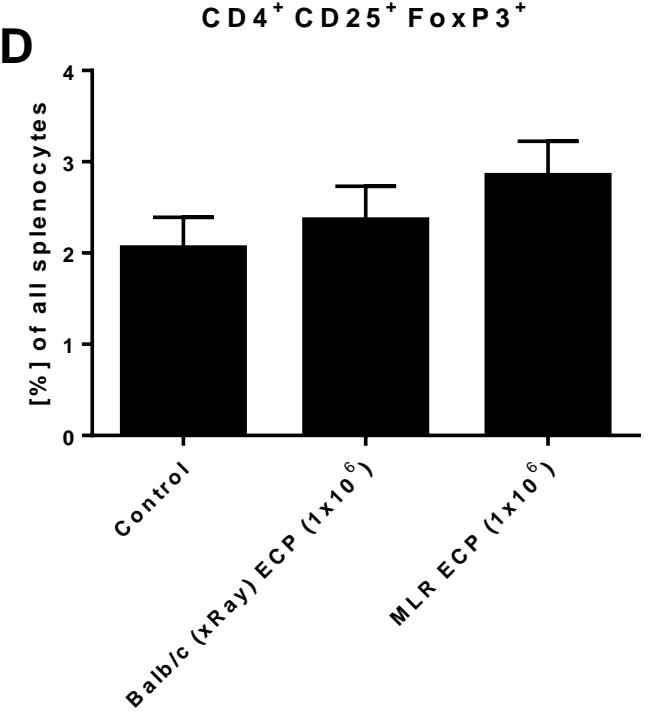

Fig. 14: FACS analysis of aGvHD after ECP therapy with cells derived from an MLR. ECP therapy was performed four times in weekly intervals starting from day 3 after BMT by injecting C57BL/6->BALB/c mice with $1 \times 10^{6} \mathrm{MLR}$ cells. To this end, $5 \times 10^{6} \mathrm{BALB} / \mathrm{c}$ irradiated splenocytes and $5 \times 10^{6} \mathrm{C} 57 \mathrm{BL} / 6$ splenocytes were prepared and co-cultured for four days. Control mice were treated with PBS or $1 \times 10^{6}$ PUVA-treated irradiated (30 Gy) BALB/c splenocytes (Balb/c (xRay). The percentages of $\mathrm{CD}^{+} \mathrm{T}$ cells $(\mathrm{A}), \mathrm{CD} 4^{+} \mathrm{T}$ cells $(\mathrm{B}), \mathrm{CD}^{+} \mathrm{CD}^{+} \mathrm{T}$ cells $(\mathrm{C})$ and $\mathrm{CD} 4^{+} \mathrm{CD} 25^{+} \mathrm{FoxP}^{+} \mathrm{Treg}$ cells (D) amongst all splenocytes are shown. FACS analysis is based on 16 mice treated with $1 \times 10^{6}$ irradiated BALB/c splenocytes, 18 mice injected with $1 \times 10^{6} \mathrm{MLR}$ cells and 15 control mice receiving PBS. Animals were sacrificed when reaching a clinical GvHD score $\geq 6$ or at day 56 post BMT. The data show the means + SEM.

\subsubsection{ECP therapy using cells from MLR of C3H cells activated by irradiated BALB/C splenocytes}


In earlier experiments PUVA-treated splenocytes from unmatched donor mice $(\mathrm{C} 3 \mathrm{H})$ were found exert a significant therapeutic effect in aGvHD (4.1.1.4.). Based on these results it was hypothesized that PUVA-treated MLR cells of $\mathrm{C} 3 \mathrm{H}$ origin might also ameliorate aGvHD.

To test this hypothesis MLR of splenocytes from BALB/c and $\mathrm{C} 3 \mathrm{H}$ was prepared whereas $B A L B / c$ cells were irradiated. The MLR and the irradiated control BALB/c cells were incubated for four days. Following incubation, the MLR and the irradiated BALB/c cells were treated with 8-MOP and UV-A light and injected at a concentration of $1 \times 10^{6}$ into aGvHD mice. A third group of mice received PBS and served as control.

A
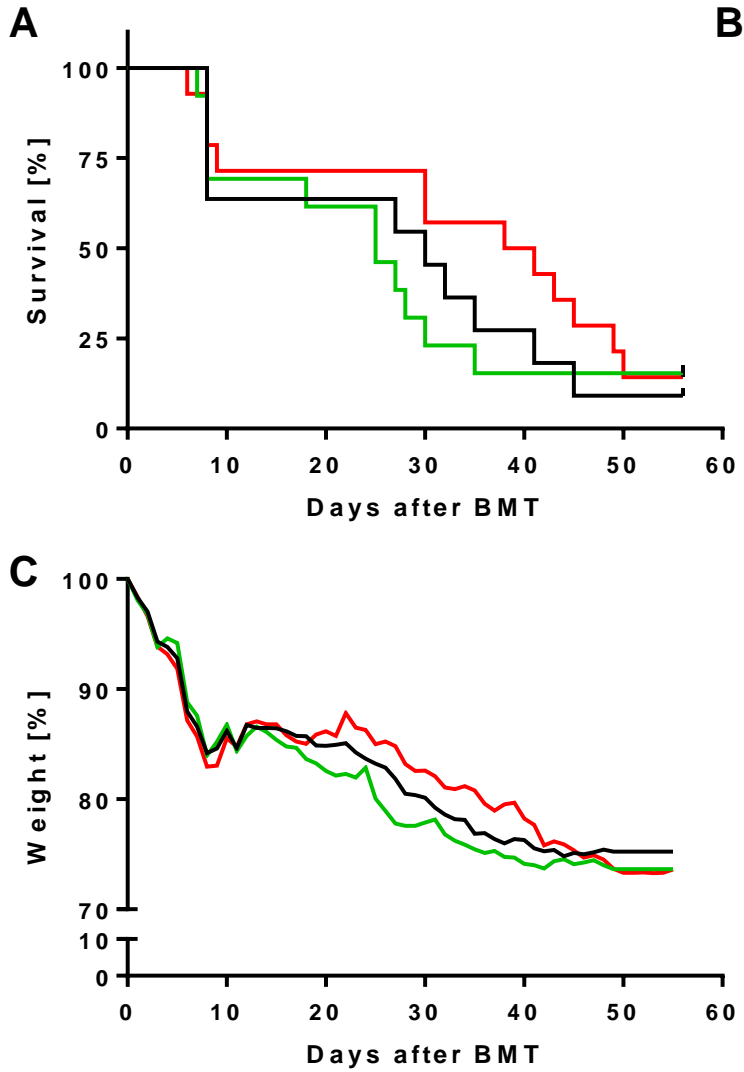

B

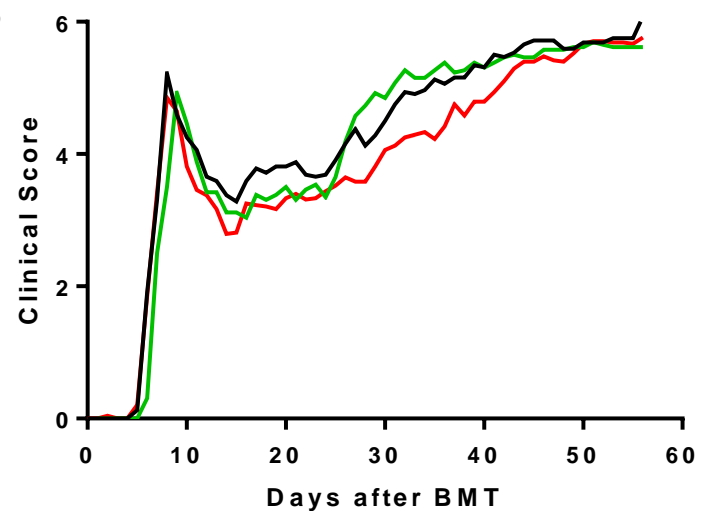

- control

- BALB/C (xRay) ECP $\left(1 \times 10^{6}\right)$

- MLR $\left(C 3 H+B A L B / C(x R a y) E C P\left(1 \times 10^{6}\right)\right)$

Fig. 15: ECP therapy using MLR cells of C3H origin in the mouse model of acute GvHD. In the C57BL/6->BALB/C aGvHD mouse model ECP treatment was performed four times in weekly intervals starting at day 1 after BMT. Two cohorts of transplanted mice served as controls receiving either PBS (black line, $n=11$ ) or $1 \times 10^{6}$ irradiated ( $30 \mathrm{~Gy}$ ) BALB/c PUVA-treated leukocytes (red line, $n=13$ ). The third group of mice was injected with $1 \times 10^{6}$ PUVA-treated MLR cells (green line, $n=14$ ) consisting of $\mathrm{C} 3 \mathrm{H}$ splenocytes co-cultured with 30Gy irradiated BALB/c leukocytes for four days. The Kaplan-Meier plot shows the survival rate $(A)$ and was analyzed using the log-rank test. The clinical GvHD score (B) and the weight changes $(C)$ were monitored daily and analyzed using the Mann Whitney $U$ test. The data show the means and were pooled from three independent experiments. 
Analysis of the survival rate, the clinical aGvHD score or weight loss did not reveal any differences between C57BL/6->BALB/c mice treated with MLR cells, irradiated BALB/c cells or PBS (Fig. 15).

A

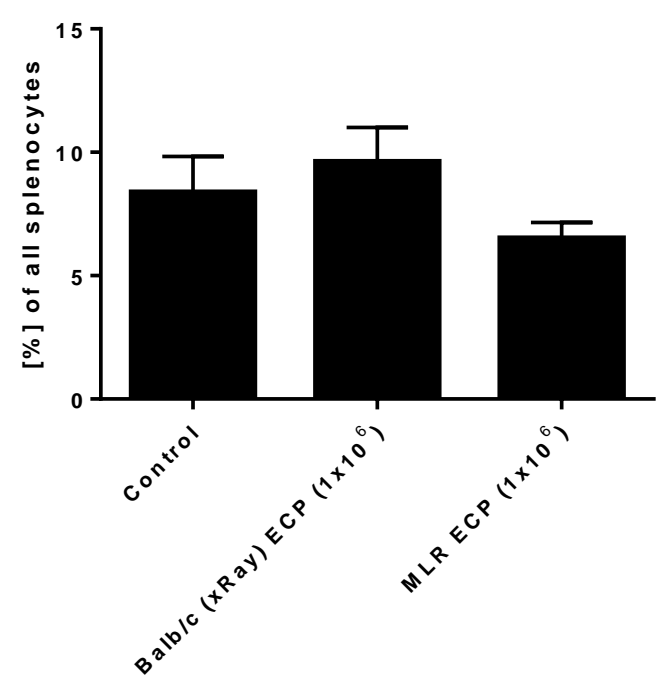

C

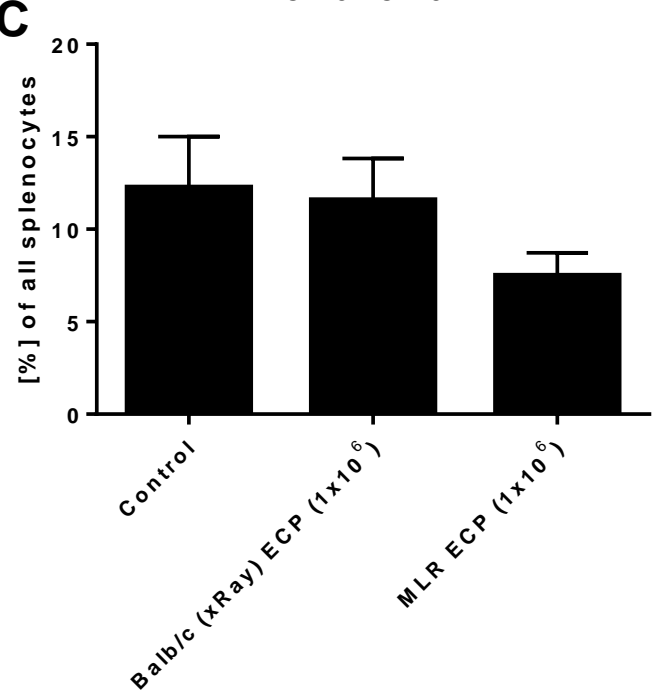

B

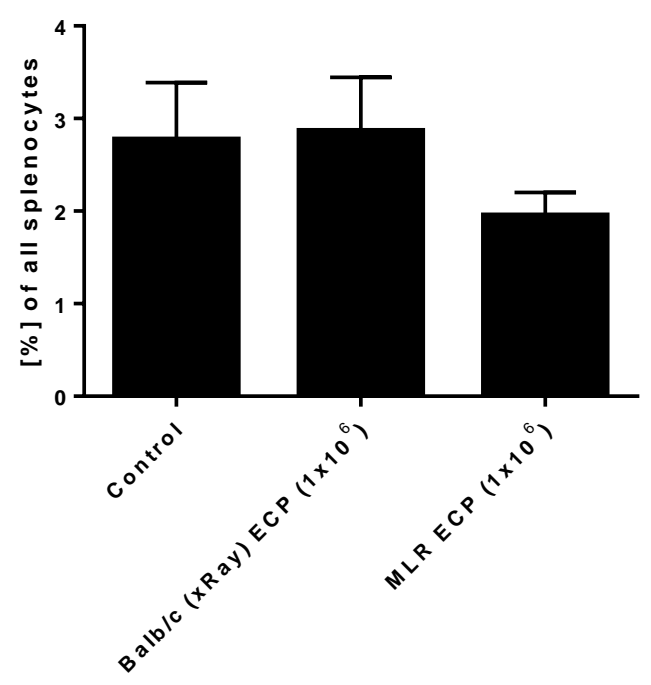

Fig. 16: FACS analysis of splenocytes from aGvHD mice after ECP therapy with cells derived from a MLR of C3H origin. Allogeneic transplanted mice were treated with ECP therapy four times in weekly intervals starting day three after transplantation. ECP therapy was performed with PUVAtreated MLR cells obtained in a similar manner as in Fig. 15. One cohort of C57BL/6->BALB/c mice was injected with $1 \times 10^{6}$ MLR cells $(n=10)$, a second cohort of mice was injected with PBS $(n=8)$ and a third one with $1 \times 10^{6}$ PUVA-treated irradiated (30 Gy) BALB/c splenocytes (Balb/c (xRay)) $(n=11)$. The animals were sacrificed when reaching a clinical GvHD score $\geq 6$ or at day 56 post BMT. The 
percentages of $\mathrm{CD}^{+} \mathrm{T}$ cells (A), $\mathrm{CD}^{+} \mathrm{CD}^{+} 5^{+} \mathrm{FoxP}^{+}$Treg cells (B) and $\mathrm{CD}^{+} \mathrm{CD}^{+} \mathrm{T}$ cells $(\mathrm{C})$ are shown. The data show the means \pm SEM.

The percentages of $\mathrm{CD}^{+} \mathrm{T}$ cells, $\mathrm{CD}^{+} \mathrm{CD}^{+} 5^{+} \mathrm{FoxP}^{+}$Treg cells and, $\mathrm{CD}^{+} \mathrm{CD}^{+} \mathrm{T}$ cells were undistinguishable between both control groups and mice which were injected with $1 \times 10^{6}$ MLR cells from C3H/ BALB/c co-cultures (Fig. 16).

\subsubsection{Tracking ECP cells in the aGvHD mouse model}

Splenocytes incubated with 8-MOP and irradiated with UV-A light are known to undergo apoptosis. These apoptotic cells are believed to increase immune tolerance and mediate the therapeutic effect in ECP-treated human patients (Gatza et al., 2008). Therefore it was investigated for how long infused PUVA-treated, apoptotic cells could be tracked in spleen and lymph nodes of allogeneic C57BL/6->BALB/C mice. Transplanted mice were intravenously injected with splenocytes from CD45-congenic C57BL/6 donor mice (C57BL/6.SJL-Ptprc ${ }^{a}$ Pepc $c^{b}$ BoyJ) carrying the differential Ptrprc ${ }^{a}$ pan (CD45.1) leukocyte marker. In contrast, wildtype C57BL/6 donor mice expressed the Ptprc ${ }^{b}$ (CD45.2) allele and could therefore be easily distinguished from $\mathrm{CD} 45.1^{+}$mice by flow cytometry using monoclonal antibodies.

In the course of this study C57BL/6->BALB/C transplanted mice were injected with $15 \times 10^{6}$ splenocytes from CD45.1+ donor mice. At 1, 24, 48, 72 and 96 hours after ECP therapy, the mice were sacrificed and analyzed concerning the number of CD45. $1^{+}$cells present in spleen and lymph nodes.

A

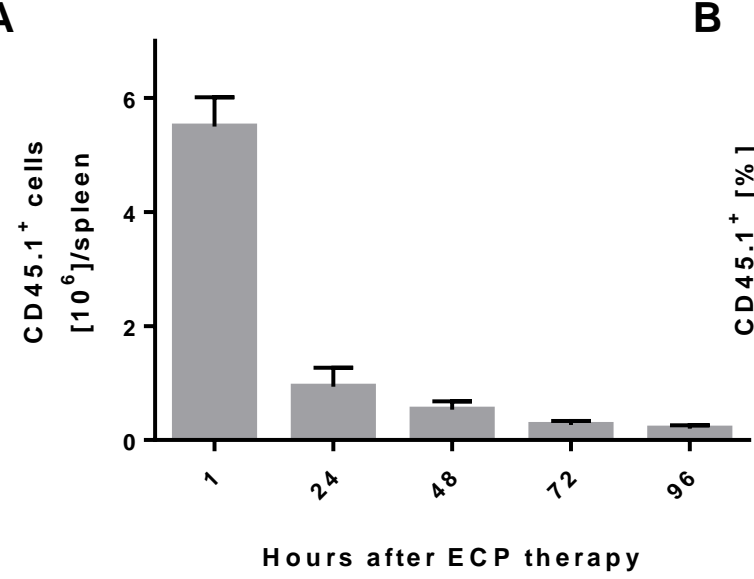

B

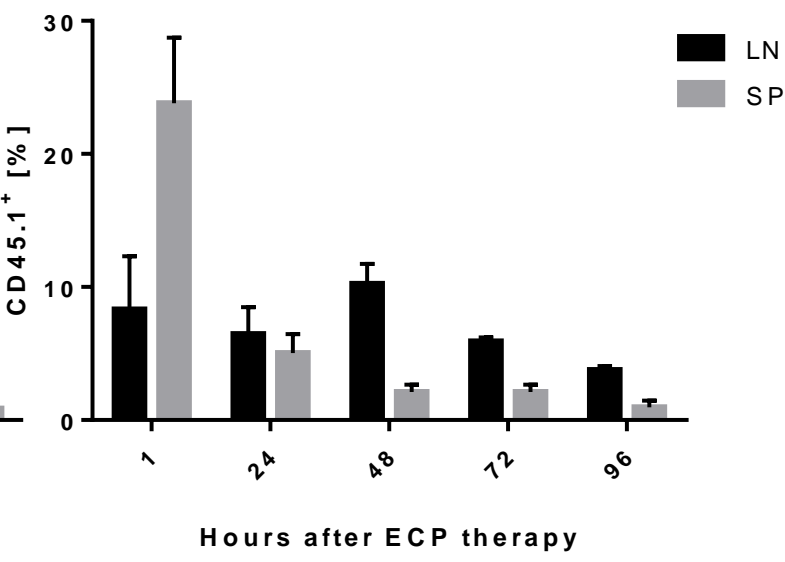


Fig. 17: Tracking of PUVA-treated CD45.1 $1^{+}$splenocytes after ECP therapy of aGvHD mice. C57BL/6->BALB/C mice were injected once with $15 \times 10^{6}$ 8-MOP/UV-A treated splenocytes derived from C57BL/6.SJL-Ptprc ${ }^{a}$ Pepc $/$ BoyJ donor mice. At specific time points (1, 24, 48, 72, 98 hours) after ECP therapy the mice $(n=3)$ were sacrificed. Absolute CD $45.1^{+}$splenocyte numbers $\left[10^{6} /\right.$ spleen] are depicted in (A) whereas the percentages of $C D 45.1^{+}$splenocytes and lymph node cells are shown in (B). The data are shown as means \pm SEM.

CD45. $1^{+}$splenocytes can be tracked up to 96 hours after ECP therapy (Fig. 17A). 24\% splenocytes were found to be CD45.1 positive one hour after ECP therapy whereas 24 hours after ECP therapy only $5 \%$ splenocytes were CD $45.1^{+}$(Fig. 17B). In addition, lymph nodes were analyzed and one hour after ECP therapy $7 \%$ of all lymphocytes were found to be CD45.1 positive. In lymph nodes CD45.1 positive ECP cells were also tracked up to 96 hours after ECP therapy.

\subsection{Potential GvHD and ECP biomarkers in human patients receiving allogeneic BMT and CGvHD patients}

It is not only necessary to optimize ECP therapy but also to forsee whether a patient is going to suffer from GvHD or respond to ECP therapy. Biomarkers could help to predict both of them. To address this issue blood samples from patients were collected to examine the potency of potential biomarkers.

\subsubsection{Description of the employed blood donor groups}

To analyze potential GvHD and ECP biomarkers in allogeneic BMT and GvHD patients, blood samples were collected at defined time points. A scheme of the employed schedule of blood sampling is depicted below (Fig. 18). In total, 25 healthy blood donors served as controls and donated two blood samples with at least three months between the first and the second donation. Before each donation the health status of the blood donors was checked by a physician. To examine potential and already known GvHD biomarkers, 30 patients receiving allogeneic HSCT (HSCT patient) were selected to provide blood samples before transplantation (pre HSCT) and post engraftment. Blood samples from twelve GvHD patients were collected to find biomarkers for predicting response to ECP therapy. To this end, blood samples from GvHD patients were collected directly before the first ECP therapy cycle as well as three and six months afterwards. However due to severity of the disease some GvHD patients could not donate blood samples three and six months after their first ECP therapy anymore. 

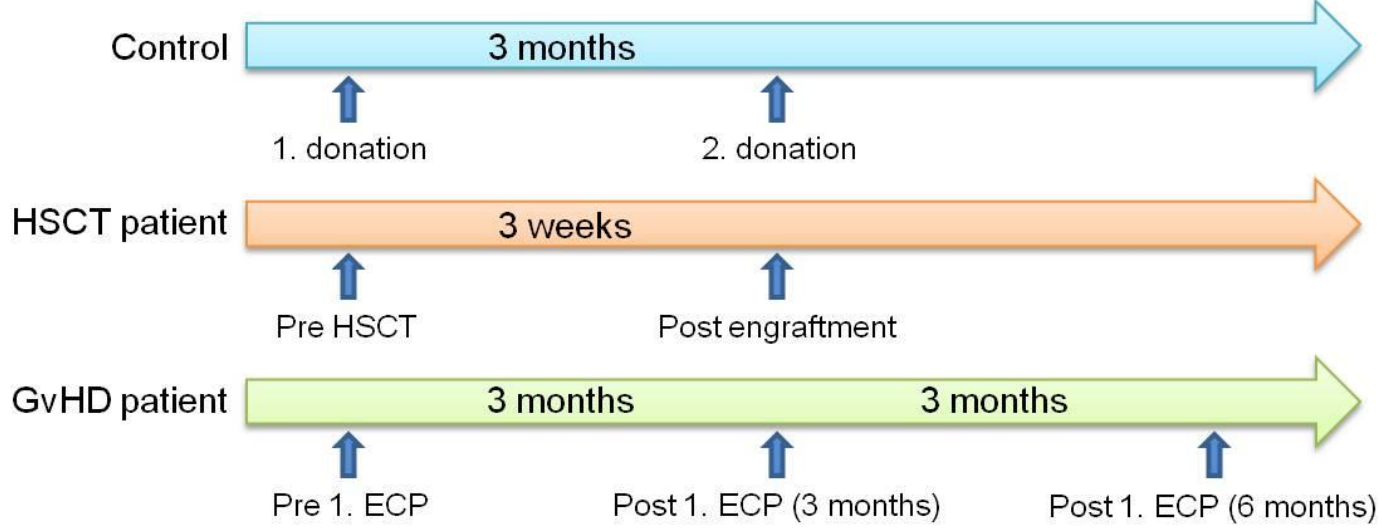

Fig. 18: Scheme of the blood sampling for the analysis of GvHD and ECP biomarkers.

\subsubsection{Flow cytometric analysis of mononuclear cells}

MNCs were isolated from heparin blood by ficoll density centrifugation and were frozen at $80^{\circ} \mathrm{C}$. The samples of each patient or control subject were kept frozen until all samples at a defined time point were collected. Afterwards they were simultaneously analyzed by flow cytometry. On the one hand MNCs were analyzed in terms of percentage of all cells and on the other hand in terms of absolute numbers.

\subsubsection{Reference ranges for potential cellular biomarkers}

The reference values of peripheral blood subpopulations were analyzed in healthy adult blood donors. Percentages and absolute numbers of $\mathrm{CD}^{+} \mathrm{T}$ cells, CD19 ${ }^{+} \mathrm{CD} 21^{-}$immature $\mathrm{B}$ cells, $\mathrm{CD}^{+} \mathrm{CD}^{+}$and $\mathrm{CD}^{+} \mathrm{CD}^{+} \mathrm{T}$ cells, and Lin1 ${ }^{-} \mathrm{CD} 11 \mathrm{c}^{+} \mathrm{HLA}^{-D R^{+}} \mathrm{mDC}$ as well as $\mathrm{CD} 4^{+}$ $\mathrm{CD}^{2} 5^{+} \mathrm{FoxP}^{+}$Treg cells were analyzed by flow cytometry.

Tab. 13: Reference ranges of potential cellular biomarkers in percentages amongst all MNCs. Peripheral blood samples were collected two times from healthy blood donors with at least three months difference between both donations. MNCs were drawn in S-Monovettes with the anticoagulants Lithium/ Heparin and isolated by using ficoll density centrifugation. After a freezing and thawing cycle, MNCs were analyzed by flow cytometry for the percentage of $\mathrm{CD}^{+} \mathrm{T}$ cells, CD19 ${ }^{+}$ CD21 immature B cells, $\mathrm{CD}^{+} \mathrm{CD}^{+}$and $\mathrm{CD}^{+} \mathrm{CD}^{+}{ }^{+}$T cells, and Lin1 ${ }^{-} \mathrm{CD} 11 \mathrm{c}^{+} \mathrm{HLA}^{-D R^{+}} \mathrm{mDCs}$ as well as $\mathrm{CD}^{+} \mathrm{CD}^{+} 5^{+} \mathrm{FoxP}^{+}$Treg cells. The amounts (n) of samples are shown as well as the median, $2.5^{\text {th }}$ to $97.5^{\text {th }}$ percentile, and minimum and maximum.

\begin{tabular}{|l|c|c|c|c|c|}
\hline \multirow{2}{*}{$\begin{array}{c}\text { Potential } \\
\text { cellular biomarkers }\end{array}$} & \multirow{n}{*}{} & \multicolumn{3}{c|}{ [percentages amongst all MNCs] } \\
\cline { 3 - 6 } & median & $\begin{array}{c}\text { 2.5th - 97.5th } \\
\text { percentile }\end{array}$ & min & max \\
\hline CD3 $^{+}$ & 25 & 64 & $48-80$ & 48 & 80 \\
\hline CD19 $^{+}$CD21 $^{-}$ & 24 & 1.1 & $0.7-2.5$ & 0.7 & 2.5 \\
\hline CD3 $^{+}$CD4 $^{+}$ & 25 & 38 & $26-60$ & 26 & 60 \\
\hline
\end{tabular}




\begin{tabular}{|l|c|c|c|c|c|}
\hline CD3 $^{+}$CD8 $^{+}$ & 25 & 17 & $8.9-30$ & 8.9 & 30 \\
\hline CD4 $^{+}$CD25 $^{+}$FoxP3 $^{+}$ & 24 & 2.5 & $1.4-5$ & 1.4 & 5 \\
\hline Lin1 $^{-}$CD11c $^{+}$HLA-DR $^{+}$ & 25 & 1.4 & $0.6-5.5$ & 0.6 & 5.5 \\
\hline
\end{tabular}

The reference ranges percentages from adult healthy blood donors were: CD3 ${ }^{+}(48-80 \%)$, $\mathrm{CD} 9^{+} \mathrm{CD}^{-} 1^{-}(0.7-2.5 \%), \mathrm{CD}^{+} \mathrm{CD}^{+}(26-60 \%), \mathrm{CD}^{+} \mathrm{CD}^{+}(8.9-30 \%)$, and Lin1 ${ }^{-} \mathrm{CD} 11 \mathrm{C}^{+}$ $\mathrm{HLA}_{-\mathrm{DR}}^{+}(0.6-5.5 \%)$, and CD4 ${ }^{+} \mathrm{CD}^{+} 5^{+} \mathrm{FoxP}^{+}(1.4-5 \%)($ Tab. 13).

In addition, the reference ranges absolute cell counts were: $\mathrm{CD}^{+}(2080-8467), \mathrm{CD}^{+} 9^{+} \mathrm{CD} 21^{-}$ (32-151), $\mathrm{CD}^{+} \mathrm{CD}^{+}$(530-3370), $\mathrm{CD}^{+} \mathrm{CD}^{+}$(96-939), and Lin1 ${ }^{-} \mathrm{CD} 11 \mathrm{C}^{+} \mathrm{HLA}^{-D R^{+}}$(34-327), and $\mathrm{CD}^{+} \mathrm{CD}^{+} 5^{+} \mathrm{FoxP}^{+}$cells (34-327) (Tab. 14).

Tab. 14: Reference values as absolute cell counts of potential cellular biomarkers.

Peripheral blood from healthy blood donors were drawn in S-Monovettes with the anticoagulants Lithium/ Heparin. Blood samples were collected two times from with at least three months difference between both donations. MNCs were isolated by using ficoll density centrifugation. After a freezing and thawing cycle, MNCs were analyzed by flow cytometry for the absolute cell counts of $\mathrm{CD}^{+} \mathrm{T}$

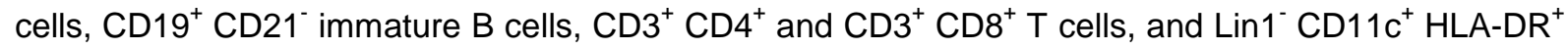
mDCs as well as $\mathrm{CD}^{+} \mathrm{CD}^{+} 5^{+} \mathrm{FoxP}^{+}$Treg cells. $\mathrm{n}$ indicates the number of samples. Cell counts of the indicated cell populations are presented as medians, reference ranges were extracted from the 2.5th to 97.5 th percentile.

\begin{tabular}{|c|c|c|c|c|c|}
\hline \multirow{2}{*}{$\begin{array}{c}\text { Potential } \\
\text { cellular biomarkers }\end{array}$} & \multirow[b]{2}{*}{$\mathbf{n}$} & \multicolumn{4}{|c|}{ [absolute cell count/ $/ \mu l]$} \\
\hline & & median & $\begin{array}{l}\text { 2.5th }-97.5 \text { th } \\
\text { percentile }\end{array}$ & $\min$ & $\max$ \\
\hline $\mathrm{CD3}^{+}$ & 21 & 3655 & $2080-8467$ & 2080 & 8467 \\
\hline $\mathrm{CD} 9^{+} \mathrm{CD}^{-}{ }^{-}$ & 18 & 63 & $32-151$ & 32 & 151 \\
\hline $\mathrm{CD3}^{+} \mathrm{CD}^{+}$ & 21 & 1375 & $530-3370$ & 530 & 3370 \\
\hline $\mathrm{CD}^{+} \mathrm{CD}^{+}$ & 21 & 227 & $96-939$ & 96 & 939 \\
\hline $\mathrm{CD}^{+} \mathrm{CD}^{2} 5^{+} \mathrm{FoxP3}^{+}$ & 21 & 140 & $64-485$ & 64 & 485 \\
\hline Lin1 $^{-}$CD11 $^{+}$HLA-DR ${ }^{+}$ & 21 & 101 & $34-327$ & 34 & 327 \\
\hline
\end{tabular}

\subsubsection{Comparison of both blood donations from control samples for differences in potential biomarkers}

As mentioned above, control subjects donated blood samples twice with a time difference of at least three months between donations. Differences in potential biomarker values between the first and the second donation were neither found in percentages amongst all MNCs nor in absolute numbers of potential cellular biomarkers (Tab. 15). 
Tab.15: Comparison of two donation timepoints from control subjects.

Blood samples were collected two times from healthy blood donors with at least three months difference between both donations. MNCs were isolated from peripheral blood drawn in S-Monovettes with the anticoagulants Lithium/ Heparin by using ficoll density centrifugation. After a freezing and thawing cycle, MNCs were analyzed by flow cytometry for the percentage or absolute numbers of $\mathrm{CD}^{+}{ }^{+}$cells, CD19+ ${ }^{+}$CD21 immature $\mathrm{B}$ cells, $\mathrm{CD}^{+} \mathrm{CD}^{+}$and $\mathrm{CD} 3^{+} \mathrm{CD} 8^{+} \mathrm{T}$ cells, and Lin1 ${ }^{-} \mathrm{CD} 11 \mathrm{c}^{+}$ $\mathrm{HLA}^{-\mathrm{DR}^{+}} \mathrm{mDC}$ as well as $\mathrm{CD} 4^{+} \mathrm{CD} 25^{+}$FoxP3 ${ }^{+}$Treg cells.. The data of controls were analyzed with the paired $t$ test. The amounts $(n)$ of control subjects are listed whereas $p$-values represent the difference between both blood donations of control subjects ( $n s(p \geq 0.05)$ ).

\begin{tabular}{|l|c|c|c|c|}
\hline \multirow{2}{*}{$\begin{array}{c}\text { Potential } \\
\text { cellular biomarkers }\end{array}$} & \multicolumn{2}{c|}{$\begin{array}{c}\text { percentages } \\
\text { amongst all MNCs }\end{array}$} & \multicolumn{2}{c|}{ absolute numbers } \\
\cline { 2 - 5 } & $\mathbf{n}$ & $\mathbf{p}$-value & $\mathbf{n}$ & p-value \\
\hline $\mathrm{CD}^{+}$ & 23 & 0.5 & 18 & 0.42 \\
\hline $\mathrm{CD}^{+} 9^{+} \mathrm{CD}^{-} 1^{-}$ & 22 & 0.9 & 18 & 0.55 \\
\hline $\mathrm{CD}^{+} \mathrm{CD}^{+}$ & 22 & 0.23 & 18 & 0.78 \\
\hline $\mathrm{CD}^{+} \mathrm{CD}^{+}$ & 23 & 0.2 & 18 & 0.26 \\
\hline $\mathrm{CD}^{+}$CD25 $^{+} \mathrm{FoxP3}^{+}$ & 23 & 0.31 & 19 & 0.96 \\
\hline Lin1 $^{-} \mathrm{CD}_{11 c^{+} \mathrm{HLA}^{+} \mathrm{DR}^{+}}$ & 22 & 0.71 & 18 & $>0.99$ \\
\hline
\end{tabular}

\subsubsection{Comparison of cellular subpopulations as potential GvHD and ECP biomarkers}

\subsubsection{1. $T$ cells and immature $B$ cells}

The absolute numbers and percentages of $C D 3^{+} \mathrm{T}$ cells and CD19- $\mathrm{CD} 21^{+}$immature $\mathrm{B}$ were measured by flow cytometry.

The percentage of $\mathrm{CD}^{+} \mathrm{T}$ cells amongst all MNCs (Fig. 19A) was increased in HSCT patients and ECP patients ( $p \leq 0.02)$ compared to controls.

The absolute number of $\mathrm{CD}^{+} \mathrm{T}$ cells per $\mu$ l peripheral blood (Fig. 20A) was reduced in HSCT patients compared to controls $(p \leq 0.001)$. However, before ECP and three months after the first ECP therapy, GvHD patients showed increased T cells numbers compared to controls $(p \leq 0.01)$. The absolute number of T cells was increased in GvHD patient compared to HSCT patients before HSCT ( $p \leq 0.017)$ and post engraftment $(p \leq 0.001)$.

The percentages of immature B cells amongst all MNCs (Fig. 19B) were increased in HSCT patients $(p \leq 0.02)$ and GvHD patients before the first ECP therapy $(p<0.001)$ compared to the control group. Furthermore, the percentages of immature B cells were increased in HSCT patients post engraftment $(p=0.001)$ and GvHD patients before the first ECP therapy $(p=$ $0.0015)$ compared to the pre HSCT condition.

The absolute number of immature B cells (Fig. 20B) was reduced before HSCT $(p=0.004)$ but increased before the first ECP therapy $(p=0.001)$ compared to controls. Significantly increased numbers of immature B cells were found in GvHD patients before and three 
months after the first ECP therapy compared to HSCT patients before transplantation ( $p \leq$ 0.01). Additionally, GvHD patients had significantly increased immature B cell numbers before the first ECP therapy compared to post engraftment in HSCT patients $(p=0.0002)$. 
A

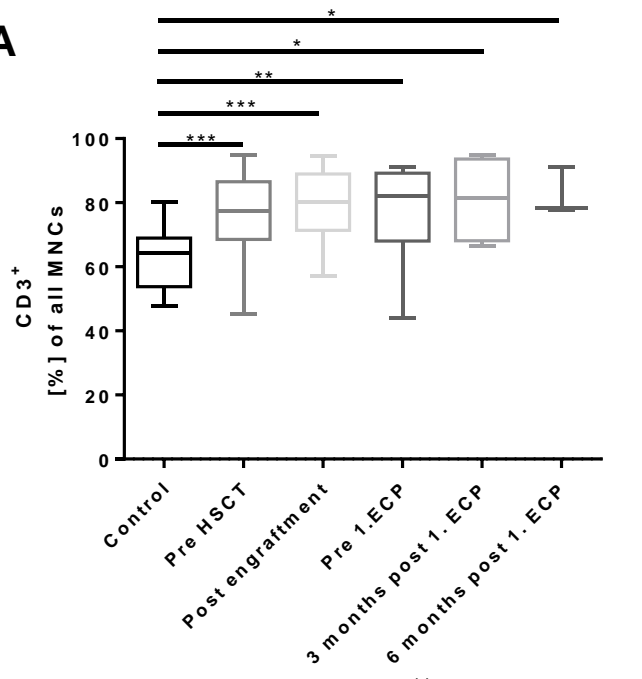

C

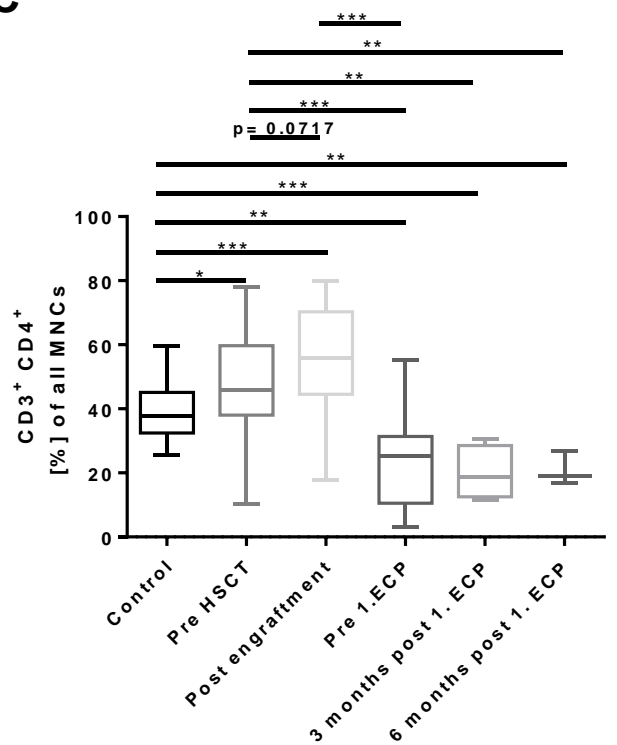

$\mathbf{E}$

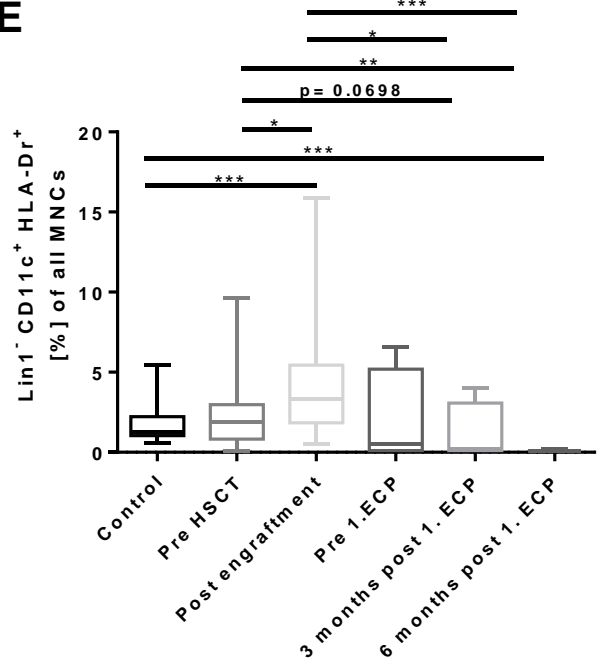

B

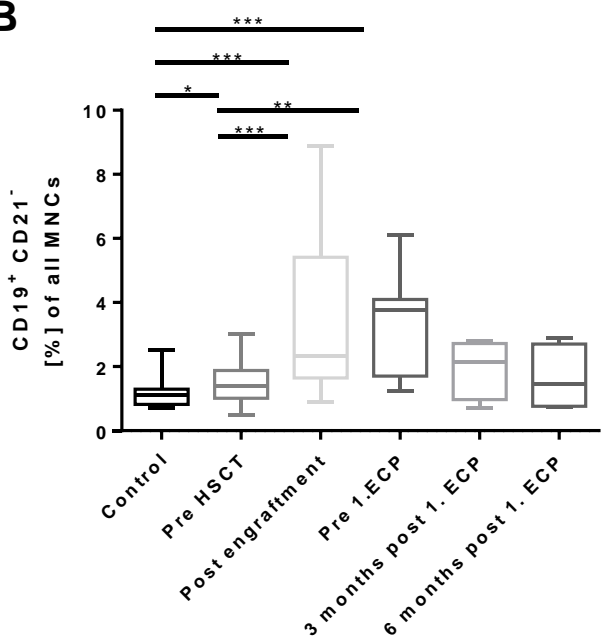

D

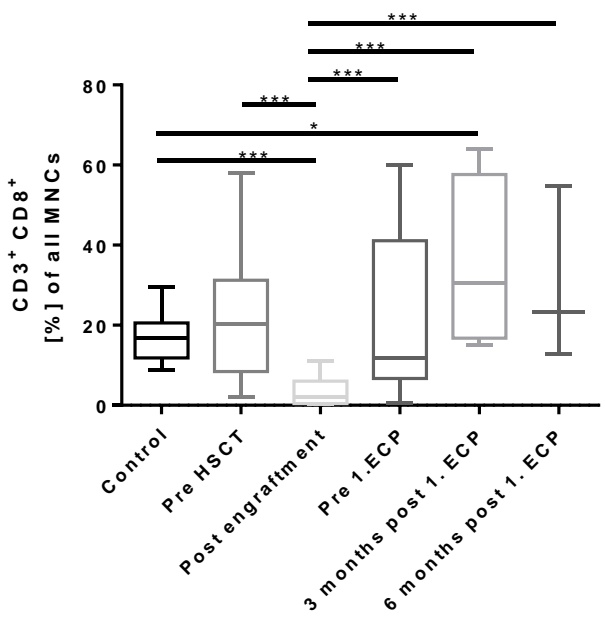

$\mathbf{F}$

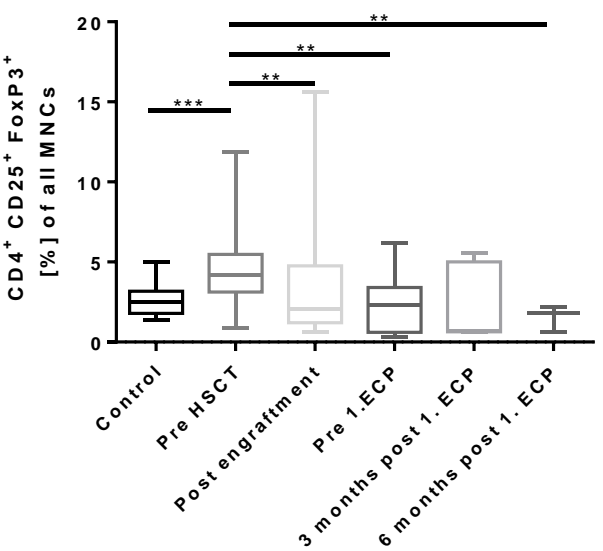

Fig. 19: Flow cytometric analysis of potential GvHD and ECP biomarkers measured in the blood of HSCT and GvHD patients. Peripheral blood was collected from healthy blood donors (controls $n=$ 24), patients receiving allogeneic HSCT (pre and after HSCT; $n=30$ ) and GvHD patients before the 
first ECP therapy (pre 1.ECP, $n=12$ ) as well as three and six months afterwards (three $(n=6)$ \& six $(n=3)$ months post 1.ECP). MNCs were isolated from peripheral blood drawn in S-Monovettes with the anticoagulants Lithium/ Heparin by using ficoll density centrifugation. After a freezing and thawing cycle, MNCs were analyzed for the percentage of $C D 3^{+} T$ cells $(A), C D 19^{+} C D 21^{-}$immature $B$ cells (B), $\mathrm{CD}^{+} \mathrm{CD}^{+}(\mathrm{C})$ and $\mathrm{CD}^{+} \mathrm{CD}^{+}{ }^{\mathrm{T}}$ cells (D), Lin1 ${ }^{-} \mathrm{CD} 11 \mathrm{c}^{+} \mathrm{HLA}^{-\mathrm{DR}^{+}} \mathrm{mDCs}(\mathrm{E})$ as well as $\mathrm{CD} 4^{+}$ $\mathrm{CD}^{+} 5^{+} \mathrm{FoxP}^{+}$Treg cells (F). MNCs were gated based on the FSC and the SSC. The box-andwhisker plots represent the median with 25 to 75 th percentile and $\min / \mathrm{max}$ values. The data of controls were analyzed with the paired t test whereas all other data was analyzed with the Mann Whitney U test (ns $\left.(p \geq 0.05),{ }^{*}(p<0.05),{ }^{* *}(p \leq 0.01),{ }^{* * *}(p \leq 0.001)\right)$.

\subsubsection{2. $T$ cell subsets}

The different subsets of T cells were further analyzed in detail (Fig. 19 and 20). Compared to controls, the percentages of $\mathrm{CD}^{+} \mathrm{CD}^{+}$cells amongst all MNCs were increased in all HSCT patients ( $p \leq 0.01$ ). GvHD patients had significantly lower percentages of $C D 3^{+} \mathrm{CD} 4^{+} \mathrm{T}$ cells compared to controls ( $p \leq 0.003$ ) and compared to HSCT patients $(p \leq 0.004)$. The absolute numbers of $\mathrm{CD}^{+} \mathrm{CD}^{+} \mathrm{T}$ cells per $\mu$ l were decreased in HSCT patients compared to healthy blood donors ( $p \leq 0.001)$.

Furthermore, the percentages of $\mathrm{CD}^{+} \mathrm{CD}^{+} \mathrm{T}$ cells amongst all MNCs were significantly lower in HSCT patients post engraftment compared to controls $(p \leq 0.001)$ and compared to HSCT patients before transplantation (Fig. 19; $p<0.001$ ). However, after engraftment HSCT patients had lower percentages of $\mathrm{CD}^{+} \mathrm{CD}^{+} \mathrm{T}$ cells than GvHD patients before and after the first ECP therapy ( $p \leq 0.001$ ). Additionally, the absolute numbers of $\mathrm{CD}^{+} \mathrm{CD} 8^{+} \mathrm{T}$ cells in HSCT patients post engraftment was reduced compared to controls $(p<0.001)$ and patients before HSCT (Fig. 20; $p<0.001$ ). Furthermore, significantly more $\mathrm{CD}^{+} \mathrm{CD}^{+}$cells were found in ECP patients before $(p=0.001)$ and after the first ECP therapy $(p=0.001)$. 
A

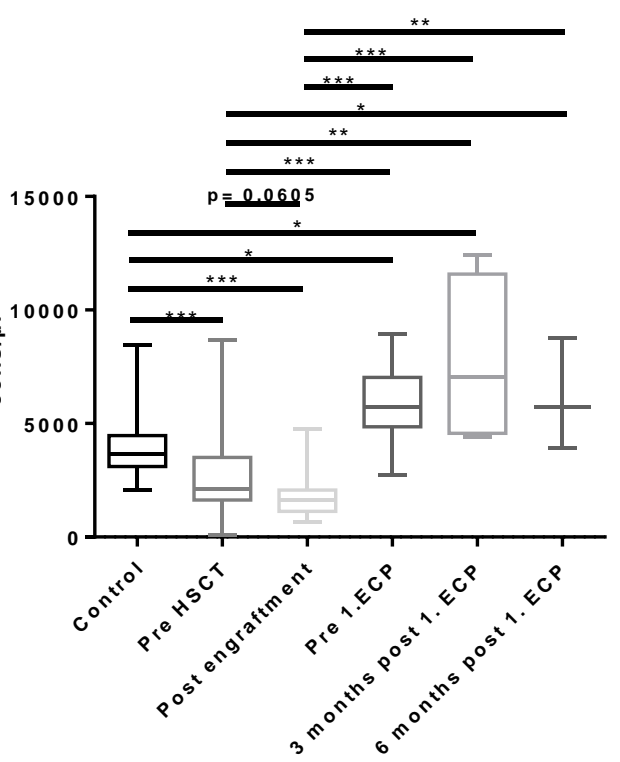

C

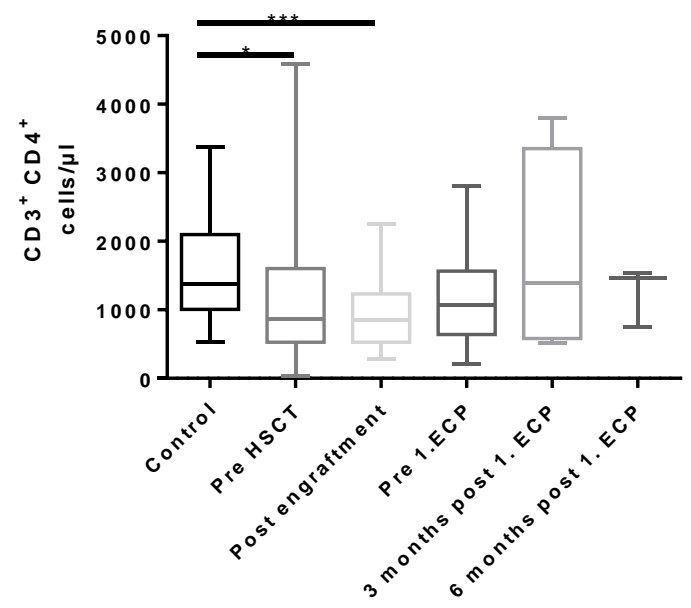

$\mathbf{E}$

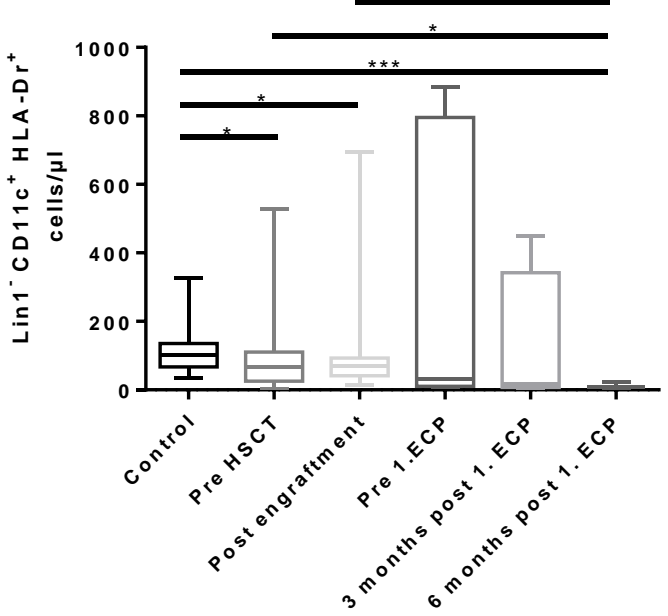

B
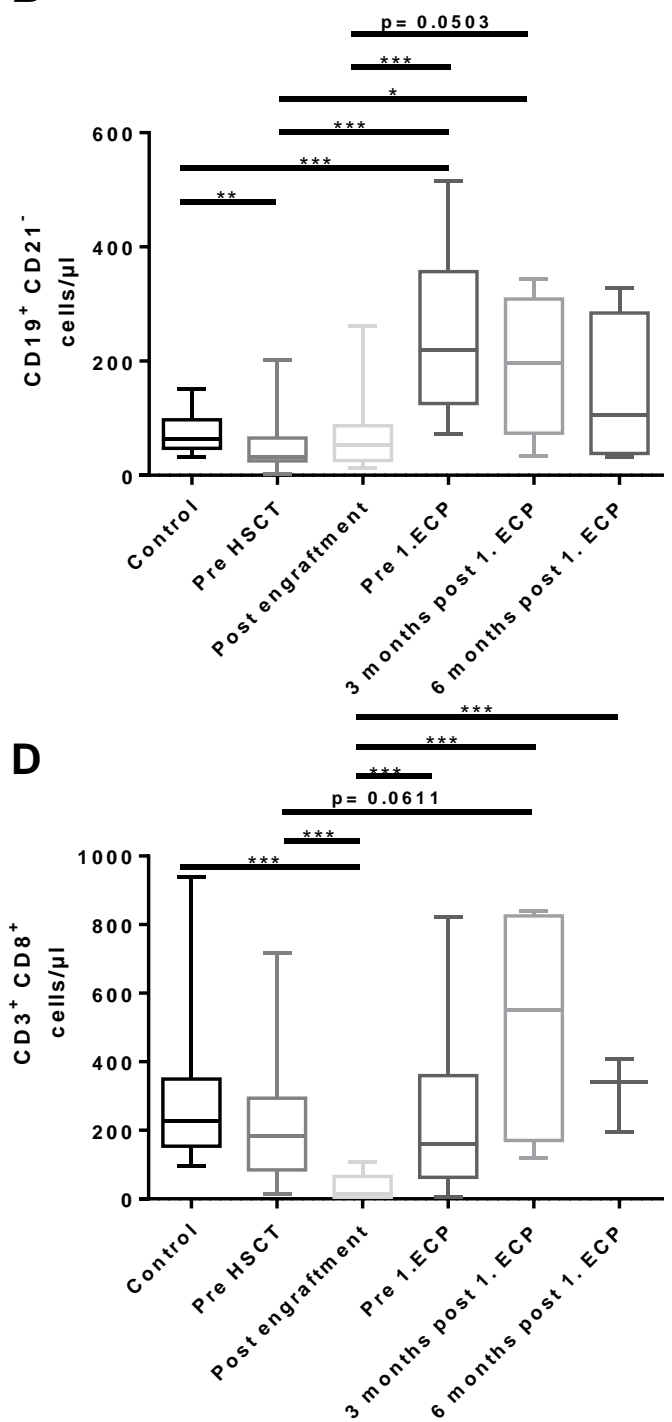

$\mathbf{F}$

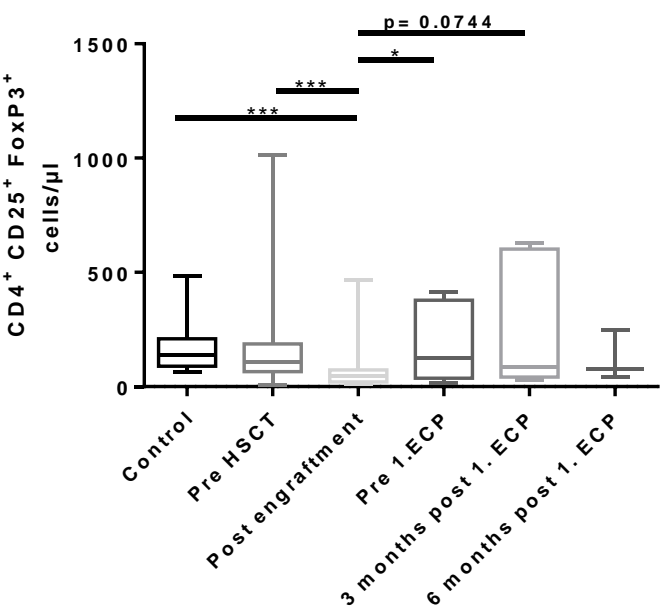

Fig. 20: Flow cytometric analysis of potential GvHD and ECP biomarkers as absolute cell number in the blood of HSCT and GvHD patients. Heparin blood was collected from healthy blood donors (controls $n=24-25$ ), patients receiving allogeneic HSCT before transplantation (pre HSCT, $n=$ 
30) and after engraftment (post engraftment, $n=30$ ) and GvHD patients before the first ECP therapy (pre 1.ECP, $n=12)$ as well as three and six months after the first ECP therapy (three $(n=6)$ \& six $(n=$ 3) months post 1.ECP). Peripheral blood was collected in S-Monovettes with anticoagulants Lithium/Heparin and MNCs were isolated by using ficoll density centrifugation. After freezing and thawing MNCs the absolute cell number of $\mathrm{CD}^{+} \mathrm{T}$ cells (A), CD19+ $\mathrm{CD} 21^{-}$immature $\mathrm{B}$ cells (B), $\mathrm{CD} 3^{+}$ $\mathrm{CD}^{+} \mathrm{T}$ cells (C), $\mathrm{CD}^{+} \mathrm{CD}^{+} \mathrm{T}$ cells (D), Lin1 ${ }^{-} \mathrm{CD} 11 \mathrm{c}^{+} \mathrm{HLA}^{-D R^{+}} \mathrm{mDCs}(\mathrm{E})$ as well as $\mathrm{CD} 4^{+} \mathrm{CD} 25^{+}$ FoxP $3^{+}$Treg cells (F) per $\mu$ l was analyzed using FACS. MNCs were gated in FSC and SSC. The boxand-whisker plots represent the median, 25 to 75 th percentile and $\min / \mathrm{max}$ values. The data of controls were analyzed with paired $t$ test whereas all other groups were analyzed with Mann Whitney $U$ test (ns $\left.(p \geq 0.05),{ }^{*}(p<0.05),{ }^{* *}(p \leq 0.01),{ }^{* * *}(p \leq 0.001)\right)$.

\subsection{Myeloid dendritic cells and regulatory $T$ cells}

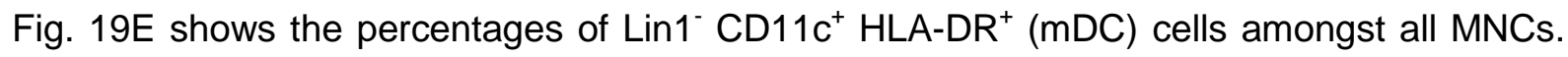
The percentages of mDCs were increased in HSCT patients after engraftment compared to controls $(p<0.001)$ or HSCT patients before HSCT $(p=0.01)$. However, GvHD patients after ECP therapy had lower percentages of mDCs compared to patients before HSCT ( $p \leq$ $0.0018)$ and after engraftment $(p \leq 0.0230)$. Analysis of the absolute cell number of mDCs revealed that there were less mDCs in GvHD patients six months after the first ECP therapy compared to controls $(p=0.001)$, HSCT patients before transplantation $(p=0.025)$ and after engraftment $(p=0.0054)$.

The percentages of $\mathrm{CD}^{+} \mathrm{CD}^{2} 5^{+} \mathrm{FoxP}^{+}$Treg cells are depicted in Fig. 19F and were increased before HSCT compared to controls $(p<0.0001)$. However, after engraftment $(p=$ $0.0086)$ and in ECP patients ( $p \leq 0.007)$ the percentages of Treg cells were lower than in HSCT patients before transplantation. With regard to the absolute cell numbers, Treg cells were reduced in HSCT patients after engraftment compared to controls ( $p \leq 0.001)$ and HSCT patients before transplantation $(p<0.001)$. In contrast, Treg cell numbers were elevated in GvHD patients before the first ECP therapy compared to patients after engraftment $(p=0.03)$.

\subsubsection{ELISA analyses of serum samples}

Serum concentrations of sIL-2R, sTNF-R and HGF were measured in healthy controls as well as in HSCT and cGvHD patients by ELISA.

\subsubsection{Cytokine levels in the serum of healthy subjects}

In serum of healthy control subjects several cytokines were analyzed for their reference ranges: sIL-2R: 4-8.6 ng/ml, HGF: 0.05-1.2 ng/ml, sTNF-R: 0.1-3.5 ng/ml (Tab. 16). 
Tab. 16: Reference ranges for serological cytokines.

Serum samples were collected two times from healthy control subjects with at least three months difference between both donations. After a freezing and thawing cycle, serum was analyzed by ELISA for investigation cytokine levels.n indicates the amount of serum samples. Serological cytokine levels are presented as medians, reference ranges were extracted from the 2.5th to 97.5 th percentile.The amount of investigated samples is shown ( $\mathrm{n}$ ) and the minimum and the maximum is shown.

\begin{tabular}{|l|c|c|c|c|c|}
\hline \multirow{2}{*}{$\begin{array}{c}\text { Potential } \\
\text { cytokine biomarkers }\end{array}$} & \multicolumn{5}{|c|}{ [ng/ml] } \\
\cline { 2 - 7 } & $\mathbf{n}$ & median & $\begin{array}{c}\text { 2.5th - 97.5th } \\
\text { percentile }\end{array}$ & min & max \\
\hline sIL-2R & 25 & 6.1 & $4-8.6$ & 4 & 8.6 \\
\hline sTNF-R & 24 & 1.1 & $0.1-3.5$ & 0.1 & 3.5 \\
\hline HGF & 25 & 0.37 & $0.05-1.2$ & 0.05 & 1.2 \\
\hline
\end{tabular}

\subsubsection{Comparison of two blood donations from control subjects for the identification of differences in cytokine levels}

Peripheral blood samples were collected from healthy subjects at two timepoints with at least three months between both donations. It was investigated whether differences in cellular subpopulations occur between both donations. However, no differences in serological cytokine levels between both timepoints were found (Tab. 17).

Tab. 17: Comparison of differences in serological cytokine levels between two timepoints of blood donations. Serum from healthy blood donors collected at different time points (1. donation $(n=$ 25 ) and 2. donation $(n=24)$ ). ELISA was performed for the quantitative detection sIL-2R, sTNF-R and HGF. $n$ indicates the number of analyzed pairs of control subjects. The data of both timepoints of blood donations were analyzed with the paired test ( $n s(p \geq 0.05))$.

\begin{tabular}{|l|c|c|}
\hline $\begin{array}{c}\text { Potential } \\
\text { cytokine biomarkers }\end{array}$ & n & p-value \\
\hline sIL-2R & 24 & 0.49 \\
\hline sTNF-R & 23 & 0.37 \\
\hline HGF & 19 & 0.32 \\
\hline
\end{tabular}

\subsubsection{Comparison of cellular subpopulations as potential GvHD and ECP biomarkers}

Compared to healthy controls, HSCT patients had elevated sIL-2R levels ( $p \leq 0.0199)$. Serum levels of sIL-2R were also increased in HSCT patients post engraftment compared to patients before HSCT $(p=0.0009)$. ECP patients had elevated SIL-2R levels compared to controls $(p \leq 0.0006)$. 

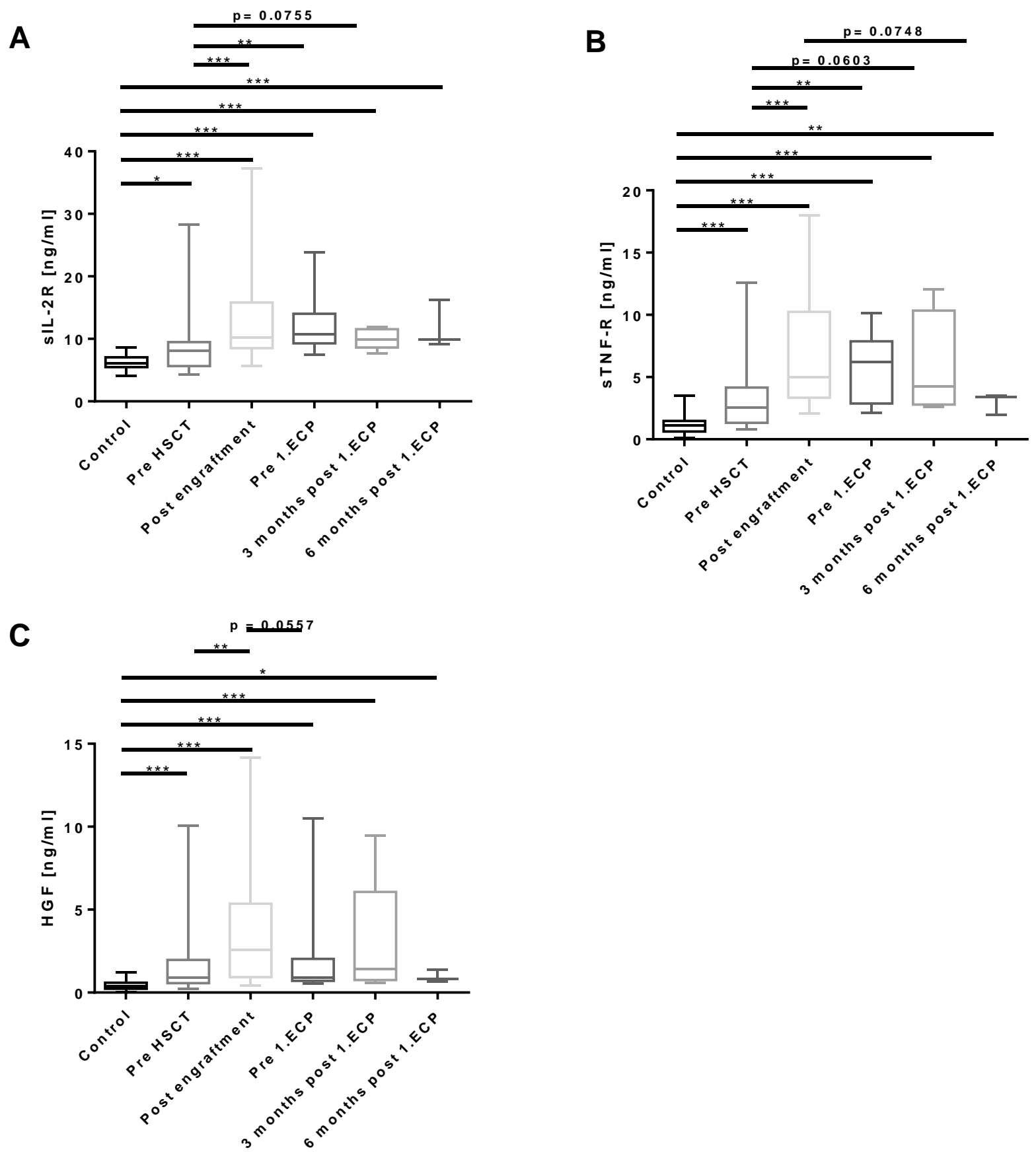

Fig. 21: Analysis of serum samples from HSCT and GvHD patients by ELISA for the detection of potential GvHD and ECP biomarkers. Peripheral blood samples were collected from patients before allogeneic HSCT (pre HSCT, $n=30$ ) and after engraftment (post engraftment, $n=30$ ). Furthermore, GvHD patients donated blood before the first ECP therapy $(n=12)$ and, three $(n=6)$ and six $(n=3)$ months afterwards. Serum from healthy blood donors collected at different time points (1. $(n=25)$ and 2. ( $n=24)$ donation) served as controls. ELISA was performed for the quantitative detection of human soluble interleukin-2 receptor alpha (sIL-2R) (A), soluble human tumor necrosis factor-receptor (sTNF-R) (B) and hepatocyte growth factor (HGF) (C). The box-and-whisker plots represent the median with 25 to 75 th percentile and $\mathrm{min} / \mathrm{max}$ values. The data of controls were analyzed with paired $t$ test whereas all others by using Mann Whitney $U$ test $\left(n s(p \geq 0.05),{ }^{*}(p<0.05)\right.$, $\left.{ }^{* *}(p \leq 0.01),{ }^{* * *}(p \leq 0.001)\right)$. 
Serum sTNF-R concentrations (Fig. 21B) were increased in HSCT patients $(p<0.0001)$ compared to healthy controls. sTNF-R values increased after engraftment compared to pre HSCT $(p<0.0001)$. Furthermore, GvHD patients showed elevated sTNF-R levels compared to controls ( $p \leq 0.004$ ). sTNF-R serum levels were still elevated in GvHD patients before the first ECP therapy but seemed to decrease during ECP therapy.

HGF concentrations in HSCT and ECP patients were elevated compared to healthy controls $(p<0.0001)$ (Fig. 21C). Additionally, HGF levels were increased after HSCT compared to before HSCT $(p=0.0037)$. 


\section{Discussion}

\subsection{ECP therapy of GvHD in mice using cells of different genetic origin}

In the course of this PhD project the therapeutic effect of ECP therapy on GvHD in vivo has been investigated. To this end, the C57BL/6->BALB/c total MHC mismatch mouse model of aGvHD known for its severe clinical GvHD symptoms and the poor survival rate has been used (Reddy et al., 2008). The protocol of ECP therapy was transferred from the clinical setting to the mouse model and was previously described in 2008 (Gatza et al., 2008). Here, Gatza and colleagues had treated a cohort of GvHD mice with ECP cells derived from another cohort of GvHD mice having undergone allogeneic transplantation. This protocol resembles the ECP procedure performed in the clinic and led to a therapeutic effect in a miHA mismatch mouse model of GvHD. In 2014, Budde and colleagues transferred this ECP setup in the C57BL/6->BALB/c mouse model of aGvHD and showed for the first time that it had a significant therapeutic effect when MHC class I and II molecules were mismatched (Budde et al., 2014). Furthermore, Capitini and co-workers had found in 2011 that ECP therapy with splenocytes from a wildtype BMT donor strain into MHC matched but miHA mismatch GvHD mouse model led to reduced weight loss. From this finding they concluded that the source of splenocytes for EPC treatment does not have to be same as the recipient itself, but instead can be from a third party donor (Capitini et al., 2011).

Based on these previous findings, the aim of this PhD study was to modify ECP therapy in such a way that the exhausting apheresis procedure in GvHD patients could be replaced. Hence, a modified ECP setup using PUVA-treated splenocytes derived from different healthy donor strains was established and applied to C57BL/6->BALB/c transplanted mice suffering from aGvHD. Two different numbers of splenocytes were tested based on the idea that they should be close to or higher than clinical ECP protocols where $5-10 \%$ of the patients circulating MNCs are treated with PUVA and reinfused (Flowers et al., 2008). ECP therapy was performed four times in weekly intervals since it is well known that ECP therapy has to be frequently repeated to achieve a positive outcome in patients (Greinix et al., 2006b).

In the first modified ECP setup PUVA-treated splenocytes from the C57BL/6 mice were investigated. However, there was no therapeutic effect on the survival rate, the clinical score and weight loss. There was also no difference between mice injected with a low or a high dose of ECP cells. Noteworthy, our findings are in contrast to those by Capitini and colleagues who had found that ECP therapy with splenocytes derived from the BMT donor origin caused a reduced weight loss in a MHC match and miHA mismatch GvHD mouse model (Capitini et al., 2011). It should be mentioned that these authors did not show any survival rates or clinical GvHD scores, and that the mouse model was a different one. 
PUVA-treated splenocytes sourced from wildtype BMT donor strain led to a therapeutic effect in Captini's MHC matche and miHA mismatched whereas in our full MHC mismatched aGvHD mouse model there was no therapeutic effect. Subsequently, we tested our ECP setup in the B10D2->BALB/c mouse model of CGvHD which is based on a MHC matched but miHA mismatched graft. This model was used to investigate whether ECP therapy with splenocytes from the same strain as the BMT donor has a therapeutic effect on the course and severity of the disease. Interestingly, low dose ECP treatment showed a beneficial effect on cGvHD symptoms and weight loss compared to untreated allogeneic transplanted mice suffering cGvHD. The reduced weight loss is in concordance with the previously mentioned findings by Capitini and colleagues. PUVA treatment induces apoptosis within 24-48 hours after ECP treatment (Greinix et al., 2006b). APCs including dendritic cells and macrophages then begin to phagocytose these cells thereby inducing immune tolerance (Steinman et al., 2000). Our findings thus indicate that apoptotic splenocytes that are genetically identical with the BMT donor strain may induce ECP-mediated tolerance in the cGvHD but not in the severe aGvHD mouse model.

In a third approach it was analyzed whether ECP therapy with splenocytes derived from the same strain as the BMT recipient (BALB/C) would have a therapeutic effect on the course and clinical symptoms in the C57BL/6->BALB/C mouse model. Interestingly, compared to control mice the clinical score of ECP-treated mice was increased and additionally these mice even lost more weight. This suggests that aGvHD was unexpectedly aggravated in ECP-treated mice in this setup.

As a next step C57BL/6->BALB/c mice received either low or high doses of PUVA-treated splenocytes from a third party strain $(\mathrm{C} 3 \mathrm{H})$. In comparison to control animals, ECP-treated mice showed a therapeutic effect on clinical scores and a reduced weight loss. In addition, mice treated with a low dose of apoptotic splenocytes had increased survival rates compared to controls. These findings are in concordance with those made by Bittencourt and coworkers (Bittencourt et al., 2001). These authors had observed that no GvHD symptoms occurred when sublethally irradiated mice received a BM graft simultaneously with the apoptotic leukocytes regardless of the genetic source including a completely unrelated mouse strain. These findings were completed by data revealing that DCs pulsed with allogeneic apoptotic cells led to Treg cell expansion (da Costa et al., 2011).

In summary, ECP therapy of aGvHD using apoptotic splenocytes from the BMT donor strain has no beneficial impact on the disease. Mice treated with apoptotic splenocytes derived from the recipient strain itself even struggled with aggravated clinical symptoms and lower survival rates. The only exception was when mice received PUVA-treated splenocytes from a third party donor as they had a better GvHD outcome than controls. This part of the study 
thus shows that the therapeutic effect of ECP is dependent on the source of the PUVAtreated splenocytes.

\subsection{Differential impact of ECP cells on splenocyte subpopulations in GvHD mice depending on their genetic background}

Although the mechanism of action of ECP therapy has not yet been fully understood, several investigators suggested that modulation of APCs and the induction of Treg cells may contribute to the immunoregulatory properties of ECP therapy (Greinix et al., 2006b; Marshall, 2006). It has been shown that DCs engulf apoptotic cells within 24 to 48 hours after treatment (Lamioni et al., 2005). Following uptake of apoptotic cells by DCs they develop a tolerogenic phenotype characterized by increased secretion of anti-inflammatory cytokines such as TGF- $\beta 1$ (Fadok et al., 1998; Lucas et al., 2003). Subsequently tolerogenic DCs foster increased numbers and enhanced functions of Treg cells. Furthermore Tawara et al found that suppression of GvHD is based on the interaction between host APCs and donor Treg cells (Tawara et al., 2010).

Since several T cell subpopulations are key mediators of GvHD on the one hand (CD4 ${ }^{+}$; $\mathrm{CD}^{+}$) and ECP therapy on the other hand (Treg cells) it should be studied whether $\mathrm{T}$ cell subpopulations in the different ECP setups were characteristically altered. Splenocytes were isolated from GvHD mice that were sacrificed either because they had reached an ethical end point during the experiment or after 56 days at the end of the experiment. Analysis of splenocytes was performed by flow cytometry.

Treg cells were analyzed because they have been shown to be key players in modulating immune tolerance. In 2014, Budde et al. showed that the percentages of Treg cells in GvHD mice were significantly decreased compared to control mice which received syngeneic BMT without developing GvHD (Budde et al., 2014). In the study at hand, however there was no difference between control or ECP-treated mice no matter whether GvHD mice received splenocytes derived from $\mathrm{C} 57 \mathrm{BL} / 6, \mathrm{BALB} / \mathrm{C}$ or $\mathrm{C} 3 \mathrm{H}$ mice. It is noteworthy that this observation is in contrast to the findings of Gatza and colleagues who had found that the numbers of Treg cells in thymus and spleen were increased and that the beneficial effect of ECP therapy was lost when mice additionally received an anti-CD25 antibody for depletion of Treg cells (Gatza et al., 2008). It should also be mentioned that Treg cell numbers were found to be increased in ECP-treated patients compared to baseline (Biagi et al., 2007; Tsirigotis et al., 2012).

$\mathrm{CD}^{+} \mathrm{T}$ cells were analyzed because they play an important role in the pathogenesis of GvHD but in none of the modified ECP settings differences between control mice and ECP. 
treated aGvHD or cGvHD mice were found. Furthermore there was also no difference between ECP-treated mice that responded to the therapy compared to those which did not survive. In contrast to our results ECP-treated cGvHD patients responding to this therapy were found to have increased numbers of circulating CD4 ${ }^{+}$T cells (Akhtari et al., 2010).

Besides Treg cells and Th cells, also the percentages of $\mathrm{CD}^{+} \mathrm{T}$ cells in spleen were analyzed in the aGvHD mouse model. Those mice which received a high dose of PUVAtreated splenocytes from an allogeneic third party donor strain and survived the experiment showed decreased percentages of $\mathrm{CD}^{+} \mathrm{T}$ cells compared to those mice that had to be sacrificed for ethical reasons. This result corresponds to the higher survival rates of mice treated with ECP cells from a third party donor (C3H). aGvHD mice injected with PUVAtreated splenocytes from the BMT donor (C57BL/6) or recipient strain (BALB/c) showed no differences in the percentages of $\mathrm{CD}^{+} \mathrm{T}$ cells compared to control mice. Mice treated with high-dose PUVA-treated splenocytes showed less clinical GvHD symptoms than controls, and mice that responded to therapy had reduced percentages of $\mathrm{CD}^{+} \mathrm{T}$ cells in spleens compared to non responding mice. This observation is in accordance with the finding that $\mathrm{CD}^{+} \mathrm{T}$ cell numbers are increased in GvHD patients (Abrahamsen et al., 2005), and that administration of an anti-CD3 antibody was paralleled by an improvement of clinical GVHD symptoms. Thus, the less severity of GvHD correlates with the percentages of $\mathrm{CD}^{+} \mathrm{T}$ cells (Anasetti et al., 1992).

In the model receiving third party ECP cells, the percentages of CD3 ${ }^{-}$CD49 ${ }^{+} \mathrm{NK}$ cells had been found to be decreased in responder mice which received the high dose compared to those injected with low dose PUVA-treated splenocytes. NK cells belong to the innate immune system and have the capacity to kill target cells lacking MHC class I molecule and secrete cytokines. With regards to GVHD NK cells are able to reduce disease severity by inhibiting and lysing autologous donor $T$ cells which had previously been activated by the initiation of GvHD (Olson et al., 2010).

Finally, percentages of $\mathrm{CD}^{+} \mathrm{CD}^{+} \mathrm{T}$ cells were analyzed in the aGvHD mouse model treated with ECP cells from a third party donor strain. Compared to controls and low dose ECP. treated mice there were significantly less $\mathrm{CD} 3^{+} \mathrm{CD}^{+} \mathrm{T}$ cells in high dose ECP-treated mice which survived the whole duration of the experiment.

Another aim of this study was to find out whether ECP therapy altered cytokine production by $\mathrm{T}$ cells (TGF- $\beta 1$; $\mathrm{CD}^{+} \mathrm{IFN}^{-\gamma^{+}}$; $\mathrm{CD}^{+} \mathrm{IL}^{+} 2^{+}$; $\mathrm{CD} 3^{+} \mathrm{TNF}-\alpha^{+}$) or the frequency of various lymphocyte subpopulations (CD3 ${ }^{+} \mathrm{CD}^{+}$; $\mathrm{CD}^{-} \mathrm{CD}^{+} 9^{+}$; $\mathrm{CD}^{+}$; $\mathrm{CD}^{+} \mathrm{CD}^{+} 5^{+} \mathrm{FoxP}^{+}$) at day 7 after BMT corresponds to the first peak of severe GvHD symptoms. The cytokine TGF- $\beta 1$ is essential for inducing the differentiation of naive $\mathrm{CD} 4^{+} \mathrm{T}$ cell into $\mathrm{CD} 4^{+} \mathrm{CD}^{2} 5^{+} \mathrm{FoxP}^{+}$Treg 
cells (Sakaguchi et al., 2008), and intravenous infusion of apoptotic cells causes an expansion of Treg cells in a TGF- $\beta 1$ dependent manner (Kleinclauss et al., 2006). IL-2, IFN$\mathrm{Y}$, and TNF- $\alpha$ are pro-inflammatory cytokines produced by $\mathrm{T}$ cells. Hence, analysis of these mediators could provide insight whether ECP therapy fostered T cell immunity or rather immune suppression. Analysis of splenocytes revealed that there were no differences between ECP-treated mice and controls in any of these parameters. This result coincides with the previously mentioned investigations that steady-state administration of apoptotic cells was needed to induce immune tolerance. Therefore it can not be excluded that differences could be observed if a similar analysis would be performed at several timepoints during ECP therapy.

Another study was also conducted to verify for how long injected PUVA-treated splenocytes were detectable in the aGvHD mouse model. This was achieved by using ECP cells derived from CD45.1-congenic C57BL/6 mice allowing to easily detect the transferred cells with antibodies by flow cytometry. Spleen and lymph nodes of ECP-treated GvHD mice were studied at different time points based on the assumption that in these locations host APC population remove apoptotic cells (Morelli et al., 2003). Interestingly, more than $20 \%$ of CD $45^{+}$cells in the spleen disappeared within 24 hours, possibly due to the fact that APCs engulf apoptotic cells very fast. Previously, Wang and colleagues had monitored the transfer of apoptotic lymphocytes labeled by CFSE and found that the majority of labeled cells accumulates in the liver of mice and that those cells disappeared within twelve hours (Wang et al., 2006).

\subsection{Effects of pre-activated ECP cells on the course and severity of GvHD in a mouse model}

Edelson hypothesized that apoptotic cells have to be alloreactive to be effective in an ECP procedure (Edelson, 2014). In agreement with this hypothesis mice suffering aGvHD showed a therapeutic effect when being injected with EPC-treated splenocytes from another cohort of aGvHD suffering mice (Budde et al., 2014).

In addition, Hannani et al. showed that activated $T$ cells die more rapidly than resting $T$ cells after ECP therapy (Hannani et al., 2010). This indicates that only pre-activated T cells may undergo cell death during the first hours after ECP therapy. Consequently, the time between induction of APCs and actual phagocytosis of dying T cells would be shortened.

Based on these observations the impact of alloreactive ECP cells should be investigated in the mouse model of aGvHD by activating lymphocytes in vitro using MLR before applying them to the PUVA regimen for ECP therapy. In the first setup splenocytes from C57BL/6 
mice were activated by irradiated BALB/c splenocytes followed by PUVA treatment and transfer into GvHD mice. No differences in the survival rate, the clinical GvHD score or weight loss between control mice or ECP-treated mice were observed. In a second setup splenocytes from $\mathrm{C} 3 \mathrm{H}$ instead of $\mathrm{C} 57 \mathrm{BL} / 6$ were activated by irradiated BALB/c splenocytes and tested for the therapeutic efficacy. However, also here no differences regarding survival rate, clinical score or weight loss were found between controls and ECP-treated mice. There were also no differences in the percentages of $\mathrm{CD}^{+}, \mathrm{CD}^{+}, \mathrm{CD}^{+} \mathrm{CD}^{+} 5^{+} \mathrm{FoxP}^{+}$, and $\mathrm{CD} 3^{+}$ $\mathrm{CD}^{+} \mathrm{T}$ cells between control and ECP-treated mice found. These findings indicate that the MLR cells were either sufficiently alloreactive or that alloreactivity is not necessary for apoptotic $T$ cells to generate a tolerogenic immune status.

\subsection{Search for novel GvHD and ECP biomarkers}

Biomarkers serve as indicators of normal biologic or pathogenic processes or, of response to treatment modalities. With regard to GvHD, biomarkers should allow assessing the risk of developing GvHD after HSCT, and the prognosis of disease. Several types of biomarkers have already been investigated as potential GvHD markers. However, biomarkers predicting the response to ECP therapy are also highly needed in view of the logistic challenges, the high costs, and the exhausting apheresis procedure. The aim of our group is therefore to identify biomarkers as indicators of the responsiveness to ECP treatment. Thereby physicians might be able to subdivide patients into low-response and high-response groups and thereby predict the patients' response to ECP therapy. In the course of this study several putative GvHD and ECP biomarkers have been tested, all of which were associated with GvHD in previous studies.

As a first step whole blood was collected from several healthy blood donors for determining the reference values of selected putative biomarkers. Subsequently, potential cellular and cytokine biomarkers were measured and reference values calculated. When comparing reference values of this study with those of other investigators, it has to be taken into account that differences can be due to blood sample preparation techniques (Vuckovic et al., 2004). Furthermore, potential biomarkers were also studied in the blood and serum from healthy controls, HSCT and cGvHD patients.

\subsubsection{Suitability of cellular subpopulations as potential biomarkers}

The development of GvHD goes along with an elevation in the proportion of $\mathrm{CD} 3^{+} \mathrm{CD} 4^{+} \mathrm{CD} 8^{+}$ cells within the first 7-21 days post-transplant (Brinkman et al., 2007). Furthermore increased percentages of $\mathrm{CD}^{+}$and $\mathrm{CD}^{+}$effector memory cells were found to be associated with 
cGvHD whereas percentages of naïve $\mathrm{CD}^{+} \mathrm{T}$ cells were decreased (D'Asaro et al., 2006; Yamashita et al., 2004). In contrast to cGvHD, August and coworkers found that CD8 ${ }^{+}$T cells were increased in patients suffering aGvHD (August et al., 2011).

Based on all the aforementioned findings and the fact that $T$ cell subsets are associated with the development of GvHD their analysis was in focus of this study. The reference value for the frequency of $\mathrm{CD}^{+} \mathrm{T}$ cells in peripheral blood was $48-80 \%$ whereas absolute cells count had a median of 3655 cells per $\mu$ l. The percentages of $\mathrm{CD}^{+} \mathrm{T}$ cells amongst all MNCs were increased in HSCT before transplantation and after engraftment as well as in cGvHD patients before and during ECP treatment. We found a decrease of total $\mathrm{CD}^{+}$cells in patients before and after transplantation which can be based on the common occurrence of leukopenia. Furthermore, increased $\mathrm{CD}^{+}$cells were found in cGvHD patients before and three months after initiation of ECP therapy. Groups like Abrahmsen and coworkers also showed that cGvHD was associated with higher counts of $\mathrm{CD}^{+} \mathrm{T}$ cells compared to those patients with no GvHD (Abrahamsen et al., 2005).

$\mathrm{CD}^{+} \mathrm{CD}^{+} \mathrm{T}$ cells in peripheral blood from healthy control subjects had a reference range of 530-3370 cells per $\mu \mathrm{l}$ and $26-60 \%$ amongst all MNCs. In our study, CD3 ${ }^{+}$CD4 ${ }^{+} T$ cells counts were decreased in HSCT patients before and after transplantation. The large range of the $\mathrm{CD}^{+} \mathrm{CD}^{+}$values indicates that HSCT patients could be differentiated into two groups. It would be possible that these two groups differ in the incidence and severity of GvHD and therefore have to be studied separately in the future. Furthermore, we found that the percentages of $\mathrm{CD}^{+} \mathrm{CD} 4^{+} \mathrm{T}$ cell were increased in HSCT patients but decreased in cGvHD patients compared to HSCT patients and controls. However during ECP treatment the frequency of this subpopulation stays on this plateau.

The reference values of the $\mathrm{CD}^{+} \mathrm{CD}^{+} \mathrm{T}$ cell subset in healthy controls were $8.9-30 \%$ or 96 939 cells/ $\mu$ l. In our study, HSCT patients analyzed shortly after engraftment showed decreased frequencies and cell counts of $\mathrm{CD}^{+} \mathrm{CD}^{+} \mathrm{T}$ cells compared to controls, whereas during ECP therapy these values increased in cGvHD patients. This observation is in accordance with the findings of Abrahamsen because these authors found that cell counts of $\mathrm{CD8}^{+} \mathrm{T}$ cells were increased in cGvHD patients (Abrahamsen et al., 2005).

The reference values of the percentages of Treg cells measured in this study are in agreement with those described by Watanbe and colleagues (Watanabe et al., 2011). Namely, healthy subjects and cGvHD patients had a median of $2 \%$ Treg cells in peripheral blood. In contrast, aGvHD patients had around 5\% Treg cells. Watanbe et al. further reported that 6-25 Treg cell/ $\mu \mathrm{l}$ were the normal range in healthy subjects. This in fact is different to the reference value of this study where a median of 64-485 Treg cells per $\mu$ l was measured. 
Interestingly, Watanbe and colleagues also described that compared to healthy control subjects, cGvHD patients had 3-fold higher Treg cell counts whereas this values was similar in aGvHD patients and healthy controls. In our study, the percentages of Treg cells in patients after engraftment and in cGvHD were not altered compared to healthy controls and did also not change three and six months after initiation of ECP treatment. It is noteworthy that this result is in contrast to Di Biaso's findings showing that ECP-responding patients have significantly increased numbers of circulating Treg cells (Di Biaso et al., 2009). Treg cell counts in HSCT patients after engraftment were reduced compared to those patients before allogeneic HSCT. cGvHD patients seem to have almost unaltered Treg cell counts compared to controls.

CD21- B cells were previously found to be increased in rheumatoid arthritis and common variable immunodeficiency (Isnardi et al., 2010). In our study the reference values for these immature B cells were $0.6-5.5 \%$ amongst all MNCs and 34-327 cells/ $\mu$ l. When compared to healthy controls CGvHD patients had elevated numbers and percentages of immature CD21 $B$ cells. This result is in agreement with those of Greinix and colleagues (Greinix et al., 2008). Interestingly, Kuzmina and coworkers found that GvHD patients had about $22 \%$ immature B cells in peripheral blood before ECP therapy was applied. They also reported that patients responding to ECP therapy had decreased percentages ( $5 \%)$ of immature $B$ cells whereas ECP non responders did not have increased percentages of the same (Kuzmina et al., 2009).

Reference values of mDCs were $0.6-5.5 \%$ and $34-327$ cells/ $\mu$. Heinze and colleagues had previously measured reference ranges from children and found that $\mathrm{mDC}$ values strongly correlated with age (Heinze et al., 2013). Compared to healthy controls in this study, percentages of $\mathrm{mDCs}$ amongst all MNCs were increased in engrafted patients whereas percentages of mDCs were decreased in cGvHD patients six months after their first ECP therapy. The $\mathrm{mDC}$ cell counts in cGvHD patients six months after the initiation of ECP therapy were also decreased compared to controls. According to these results, mDCs should be investigated in more patients in order to determine if this is a potential biomarker for predicting responsiveness to ECP therapy.

\subsubsection{Potential cytokine biomarker}

In addition to cellular biomarkers in peripheral blood, cytokine levels were studied in the serum from healthy controls, HSCT and CGvHD patients. Paczesny and colleagues had suggested that IL-2Ra, TNF-R1, HGF, and IL-8 might be most suitable for predicting the occurrence of aGvHD (Paczesny et al., 2009a). Therefore sIL-2Ra, sTNF-R and HGF were 
considered as promising biomarkers also for cGvHD patients and may also allow predicting the responsiveness to ECP therapy.

slL-2R is a well known marker of $T$ cell activation and suppression of donor $T$ cell responses in GvHD prophylaxis. In serum the measured reference range of sIL-2R levels is approximatelly $6 \mathrm{ng} / \mu \mathrm{l}$. Consistent with the results of Kami and co-workers, serum sIL-2R levels were elevated in HSCT and aGvHD patients in our study. Kami and colleagues also found a correlation between the grade of aGvHD and sIL-2R levels (Kami et al., 2000). In our study the levels were elevated during ECP therapy but did not decrease.

In this study, serum levels of sTNF-R were found to be increased in patients suffering from a hematopoietic disease whereas these levels increased after allogeneic HSCT. cGvHD patients still had elevated levels of sTNF-R whereas during ECP therapy these levels seemed to go back to baseline. As known from literature sTNF-R is mostly released from TNF- $\alpha$-secreting monocytes. Animals models showed that the inflammatory cytokine TNF- $\alpha$ is a mediator of GvHD (Reddy and Ferrara, 2003). Furthermore when a soluble inhibitor of TNF- $\alpha$ was added to steroids as first-line treatment of GvHD high percentages of response rates were observed (Levine et al., 2008).

It was discovered that HGF is secreted by target organs which have been impaired by GvHD (Paczesny et .al., 2009b). Therefore HGF was discussed as potential biomarker for GvHD. Okamoto and colleagues found that 18 normal persons had HGF levels of approximately 4 $\mathrm{ng} / \mathrm{ml}$ in their serum (Okamoto et al., 2001). In contrast to their results, 25 healthy blood donors measured in the course of this study had around $0.4 \mathrm{ng} / \mathrm{ml}$. In addition, HGF levels were elevated in patients before transplantation and further increased after engraftment in our study. In the serum of cGvHD patients involved in this study, higher HGF levels were found compared to healthy controls. Also in serum of aGvHD patients higher HGF levels were found and additionally higher levels of HGF were correlated with the grade of aGvHD (Okamoto et al., 2001).

To sum up, all potential biomarkers tested were found to be associated with the pathophysiology of GvHD. The question whether these putative markers could also predict the responsiveness of ECP therapy remains unclear. However this question can probably be solved in the future when the number of samples from GvHD patients is increased, and most importantly when it is clear which patients responded to the ECP treatment.

\subsection{Future perspectives}


The results obtained in ECP-treated mouse models of GvHD feed the hope that it might be possible that the exhausting apheresis procedure is exchanged by leukocytes derived from third party donors. However, when donor-derived leukocytes were used for ECP therapy in mouse models of cGvHD and aGvHD not all tested ECP-treated leukocytes had an effect on the course and severity of GvHD. The most obvious explanation for the observed differences are the disparate MHC antigens of the mouse strains used as donors for allogeneic grafts and the isolation of leukocytes for ECP treatment. Mouse strains used as donors for ECP were BALB/C $\left(\mathrm{H}-2 \mathrm{D}^{\mathrm{d}}\right), \mathrm{C} 57 \mathrm{BL} / 6\left(\mathrm{H}-2 \mathrm{D}^{\mathrm{b}}\right)$, and $\mathrm{C} 3 \mathrm{H}\left(\mathrm{H}-\mathrm{D} 2^{\mathrm{k}}\right)$, whereas B10.D2 $\left(\mathrm{H}-2 \mathrm{D}^{\mathrm{d}}\right)$ or C57BL/6 were used as donors for the induction of cGvHD or aGvHD. BALB/c served as recipients of allogeneic transplantation in all cases. As a next step to further prove the efficacy of third party donors as a source of leukocytes for ECP treatment several other mouse strains should be tested as donors for ECP cells. In the context of the already used cGvHD or aGvHD mouse models several mouse strains could serve as ECP cell donors, including DBA/1 $\left(\mathrm{H}-2 \mathrm{D}^{\mathrm{q}}\right)$, BDP/J $\left(\mathrm{H}-\mathrm{D} 2^{\mathrm{p}}\right)$, or $\mathrm{I} / \mathrm{LnJ}\left(\mathrm{H}-2 \mathrm{D}^{\mathrm{j}}\right)$. If these third party donors would also show a therapeutic effect on the course and severity of GvHD one could think about applying this modified ECP therapy in a clinical study.

Regarding the search for potential biomarker for predicting the responsiveness of ECP therapy further evaluation is necessary. Based on the fact that the collection of many blood samples from HSCT patients was completed only a few months ago we are not yet completely informed about the health status of every single patient enrolled in this study. This information, however, is of great importance since based on these informations patients could be divided into several subgroups to further evaluate our flow cytometric and serological data. The ability to divide patients into different groups would probably reduce the observed broad distribution of cellular values. In addition the amount of blood samples from cGvHD patients with ECP treatment needs to be increased to assess whether ECP-treated cGvHD patients respond to ECP therapy or not. 


\section{References}

Abrahamsen, I.W., Sømme, S., Heldal, D., Egeland, T., Kvale, D., and Tjønnfjord, G.E. (2005). Immune reconstitution after allogeneic stem cell transplantation: the impact of stem cell source and graft-versus-host disease. Haematologica 90, 86-93.

Akhtari, M., Giver, C.R., Ali, Z., Flowers, C.R., Gleason, C.L., Hillyer, C.D., Kaufman, J., Khoury, H.J., Langston, A.A., Lechowicz, M.J., et al. (2010). Receiver operating characteristic curve analysis of circulating blood dendritic cell immatures and $T$ cells predicts response to extracorporeal photopheresis in patients with chronic graft-versus-host disease. Transfusion (Paris) 50, 2424-2431.

Anasetti, C., Martin, P.J., Storb, R., Appelbaum, F.R., Beatty, P.G., Davis, J., Doney, K., Hill, H.F., Stewart, P., and Sullivan, K.M. (1992). Treatment of acute graft-versus-host disease with a nonmitogenic anti-CD3 monoclonal antibody. Transplantation 54, 844-851.

Antin, J.H. (2011). T-cell depletion in GVHD: less is more? Blood 117, 6061-6062.

August, K.J., Chiang, K.-Y., Bostick, R.M., Flanders, W.D., Waller, E.K., Langston, A., Worthington-White, D., Rowland, P., Moore, K.F., Khoury, H.J., et al. (2011). Biomarkers of immune activation to screen for severe, acute GVHD. Bone Marrow Transplant. 46, 601604.

Barr, M.L., Meiser, B.M., Eisen, H.J., Roberts, R.F., Livi, U., Dall'Amico, R., Dorent, R., Rogers, J.G., Radovancević, B., Taylor, D.O., et al. (1998). Photopheresis for the prevention of rejection in cardiac transplantation. Photopheresis Transplantation Study Group. N. Engl. J. Med. 339, 1744-1751.

Beatty, P.G., Clift, R.A., Mickelson, E.M., Nisperos, B.B., Flournoy, N., Martin, P.J., Sanders, J.E., Stewart, P., Buckner, C.D., and Storb, R. (1985). Marrow transplantation from related donors other than HLA-identical siblings. N. Engl. J. Med. 313, 765-771.

Biagi, E., Di Biaso, I., Leoni, V., Gaipa, G., Rossi, V., Bugarin, C., Renoldi, G., Parma, M., Balduzzi, A., Perseghin, P., et al. (2007). Extracorporeal photochemotherapy is accompanied by increasing levels of circulating CD4+CD25+GITR+Foxp3+CD62L+ functional regulatory $\mathrm{T}$ cells in patients with graft-versus-host disease. Transplantation 84, 31-39.

Billingham, R.E. (1966). The biology of graft-versus-host reactions. Harvey Lect. 62, 21-78.

Bittencourt, M.C., Perruche, S., Contassot, E., Fresnay, S., Baron, M.H., Angonin, R., Aubin, F., Hervé, P., Tiberghien, P., and Saas, P. (2001). Intravenous injection of apoptotic leukocytes enhances bone marrow engraftment across major histocompatibility barriers. Blood 98, 224-230.

Bladon, J., and Taylor, P.C. (1999). Extracorporeal photopheresis induces apoptosis in the lymphocytes of cutaneous T-cell lymphoma and graft-versus-host disease patients. Br. J. Haematol. 107, 707-711.

Bladon, J., and Taylor, P.C. (2006). Extracorporeal photopheresis: a focus on apoptosis and cytokines. J. Dermatol. Sci. 43, 85-94. 
Bornhäuser, M., Schuler, U., Pörksen, G., Naumann, R., Geissler, G., Thiede, C., Schwerdtfeger, R., Ehninger, G., and Thiede, H.M. (1999). Mycophenolate mofetil and cyclosporine as graft-versus-host disease prophylaxis after allogeneic blood stem cell transplantation. Transplantation 67, 499-504.

Bortin, M.M., Horowitz, M.M., Mrsic, M., Rimm, A.A., and Sobocinski, K.A. (1991). Progress in bone marrow transplantation for leukemia: a preliminary report from the Advisory Committee of the International Bone Marrow Transplant Registry. Transplant. Proc. 23, 6162.

Brinkman, R.R., Gasparetto, M., Lee, S.-J.J., Ribickas, A.J., Perkins, J., Janssen, W., Smiley, R., and Smith, C. (2007). High-content flow cytometry and temporal data analysis for defining a cellular signature of graft-versus-host disease. Biol. Blood Marrow Transplant. J. Am. Soc. Blood Marrow Transplant. 13, 691-700.

Brown, G.R., Lee, E., and Thiele, D.L. (2002). TNF-TNFR2 interactions are critical for the development of intestinal graft-versus-host disease in MHC class II-disparate (C57BL/6J->C57BL/6J x bm12)F1 mice. J. Immunol. Baltim. Md 1950 168, 3065-3071.

Budde, H., Kolb, S., Salinas Tejedor, L., Wulf, G., Reichardt, H.M., Riggert, J., and Legler, T.J. (2014). Modified extracorporeal photopheresis with cells from a healthy donor for acute graft-versus-host disease in a mouse model. PloS One 9, e105896.

Capitini, C.M., Davis, J.P.E., Larabee, S.M., Herby, S., Nasholm, N.M., and Fry, T.J. (2011). Extracorporeal photopheresis attenuates murine GVHD via bone marrow-derived IL-10 and preserves responses to dendritic cell vaccination. Biol. Blood Marrow Transplant. J. Am. Soc. Blood Marrow Transplant. 17, 790-799.

Clift, R.A., Buckner, C.D., Appelbaum, F.R., Bearman, S.I., Petersen, F.B., Fisher, L.D., Anasetti, C., Beatty, P., Bensinger, W.I., and Doney, K. (1990). Allogeneic marrow transplantation in patients with acute myeloid leukemia in first remission: a randomized trial of two irradiation regimens. Blood 76, 1867-1871.

da Costa, T.B., Sardinha, L.R., Larocca, R., Peron, J.P.S., and Rizzo, L.V. (2011). Allogeneic apoptotic thymocyte-stimulated dendritic cells expand functional regulatory $\mathrm{T}$ cells. Immunology 133, 123-132.

Costanzo-Nordin, M.R., Hubbell, E.A., O'Sullivan, E.J., Johnson, M.R., Mullen, G.M., Heroux, A.L., Kao, W.G., McManus, B.M., Pifarre, R., and Robinson, J.A. (1992). Successful treatment of heart transplant rejection with photopheresis. Transplantation 53, 808-815.

Couriel, D.R., Saliba, R., de Lima, M., Giralt, S., Andersson, B., Khouri, I., Hosing, C., Ippoliti, C., Shpall, E.J., Champlin, R., et al. (2009). A phase III study of infliximab and corticosteroids for the initial treatment of acute graft-versus-host disease. Biol. Blood Marrow Transplant. J. Am. Soc. Blood Marrow Transplant. 15, 1555-1562.

Cutler, C., Giri, S., Jeyapalan, S., Paniagua, D., Viswanathan, A., and Antin, J.H. (2001). Acute and chronic graft-versus-host disease after allogeneic peripheral-blood stem-cell and bone marrow transplantation: a meta-analysis. J. Clin. Oncol. Off. J. Am. Soc. Clin. Oncol. 19, 3685-3691. 
Dale, D.C. (1998). The discovery, development and clinical applications of granulocyte colony-stimulating factor. Trans. Am. Clin. Climatol. Assoc. 109, 27-36; discussion 36-38.

D'Asaro, M., Dieli, F., Caccamo, N., Musso, M., Porretto, F., and Salerno, A. (2006). Increase of CCR7- CD45RA+ CD8 T cells (T(EMRA)) in chronic graft-versus-host disease. Leukemia $20,545-547$.

Das-Gupta, E., Dignan, F., Shaw, B., Raj, K., Malladi, R., Gennery, A., Bonney, D., Taylor, P., and Scarisbrick, J. (2014). Extracorporeal photopheresis for treatment of adults and children with acute GVHD: UK consensus statement and review of published literature. Bone Marrow Transplant. 49, 1251-1258.

Di Biaso, I., Di Maio, L., Bugarin, C., Gaipa, G., Dander, E., Balduzzi, A., Parma, M., D'Amico, G., Perseghin, P., Biondi, A., et al. (2009). Regulatory T cells and extracorporeal photochemotherapy: correlation with clinical response and decreased frequency of proinflammatory T cells. Transplantation 87, 1422-1425.

Dignan, F.L., Greenblatt, D., Cox, M., Cavenagh, J., Oakervee, H., Apperley, J.F., Fielding, A.K., Pagliuca, A., Mufti, G., Raj, K., et al. (2012). Efficacy of bimonthly extracorporeal photopheresis in refractory chronic mucocutaneous GVHD. Bone Marrow Transplant. 47, 824-830.

Edelson, R.L. (2014). Mechanistic insights into extracorporeal photochemotherapy: efficient induction of monocyte-to-dendritic cell maturation. Transfus. Apher. Sci. Off. J. World Apher. Assoc. Off. J. Eur. Soc. Haemapheresis 50, 322-329.

Edelson, R., Berger, C., Gasparro, F., Jegasothy, B., Heald, P., Wintroub, B., Vonderheid, E., Knobler, R., Wolff, K., and Plewig, G. (1987). Treatment of cutaneous T-cell lymphoma by extracorporeal photochemotherapy. Preliminary results. N. Engl. J. Med. 316, 297-303.

Fadok, V.A., Bratton, D.L., Konowal, A., Freed, P.W., Westcott, J.Y., and Henson, P.M. (1998). Macrophages that have ingested apoptotic cells in vitro inhibit proinflammatory cytokine production through autocrine/paracrine mechanisms involving TGF-beta, PGE2, and PAF. J. Clin. Invest. 101, 890-898.

Falkenburg, J.H.F., van de Corput, L., Marijt, E.W.A., and Willemze, R. (2003). Minor histocompatibility antigens in human stem cell transplantation. Exp. Hematol. 31, 743-751.

Ferrara, J.L., and Deeg, H.J. (1991). Graft-versus-host disease. N. Engl. J. Med. 324, 667674.

Ferrara, J.L.M., Levine, J.E., Reddy, P., and Holler, E. (2009). Graft-versus-host disease. Lancet Lond. Engl. 373, 1550-1561.

Filipovich, A.H., Weisdorf, D., Pavletic, S., Socie, G., Wingard, J.R., Lee, S.J., Martin, P., Chien, J., Przepiorka, D., Couriel, D., et al. (2005). National Institutes of Health consensus development project on criteria for clinical trials in chronic graft-versus-host disease: I. Diagnosis and staging working group report. Biol. Blood Marrow Transplant. J. Am. Soc. Blood Marrow Transplant. 11, 945-956. 
Fimiani, M., Rubegni, P., Pimpinelli, N., Mori, M., De Aloe, G., and Andreassi, L. (1997). Extracorporeal photochemotherapy induces a significant increase in CD36+ circulating monocytes in patients with mycosis fungoides. Dermatol. Basel Switz. 194, 107-110.

Flowers, M.E., Pepe, M.S., Longton, G., Doney, K.C., Monroe, D., Witherspoon, R.P., Sullivan, K.M., and Storb, R. (1990). Previous donor pregnancy as a risk factor for acute graft-versus-host disease in patients with aplastic anaemia treated by allogeneic marrow transplantation. Br. J. Haematol. 74, 492-496.

Flowers, M.E.D., Apperley, J.F., van Besien, K., Elmaagacli, A., Grigg, A., Reddy, V., Bacigalupo, A., Kolb, H.-J., Bouzas, L., Michallet, M., et al. (2008). A multicenter prospective phase 2 randomized study of extracorporeal photopheresis for treatment of chronic graftversus-host disease. Blood 112, 2667-2674.

Foley, R., Couban, S., Walker, I., Greene, K., Chen, C.S., Messner, H., and Gauldie, J. (1998). Monitoring soluble interleukin-2 receptor levels in related and unrelated donor allogenic bone marrow transplantation. Bone Marrow Transplant. 21, 769-773.

Gatti, R.A., Meuwissen, H.J., Allen, H.D., Hong, R., and Good, R.A. (1968). Immunological reconstitution of sex-linked lymphopenic immunological deficiency. Lancet Lond. Engl. 2, 1366-1369.

Gatza, E., Rogers, C.E., Clouthier, S.G., Lowler, K.P., Tawara, I., Liu, C., Reddy, P., and Ferrara, J.L.M. (2008). Extracorporeal photopheresis reverses experimental graft-versushost disease through regulatory T cells. Blood 112, 1515-1521.

Gerber, A., Bohne, M., Rasch, J., Struy, H., Ansorge, S., and Gollnick, H. (2000). Investigation of annexin $\mathrm{V}$ binding to lymphocytes after extracorporeal photoimmunotherapy as an early marker of apoptosis. Dermatol. Basel Switz. 201, 111-117.

Goulmy, E., Schipper, R., Pool, J., Blokland, E., Falkenburg, J.H., Vossen, J., Gratwohl, A., Vogelsang, G.B., van Houwelingen, H.C., and van Rood, J.J. (1996). Mismatches of minor histocompatibility antigens between HLA-identical donors and recipients and the development of graft-versus-host disease after bone marrow transplantation. N. Engl. J. Med. 334, 281-285.

Graubert, T.A., DiPersio, J.F., Russell, J.H., and Ley, T.J. (1997). Perforin/granzymedependent and independent mechanisms are both important for the development of graftversus-host disease after murine bone marrow transplantation. J. Clin. Invest. 100, 904-911.

Greinix, H.T., and Knobler, R. (2012). Extracorporeal Photopheresis: Cellular Photoimmunotherapy (Walter de Gruyter).

Greinix, H.T., Volc-Platzer, B., Rabitsch, W., Gmeinhart, B., Guevara-Pineda, C., Kalhs, P., Krutmann, J., Hönigsmann, H., Ciovica, M., and Knobler, R.M. (1998). Successful use of extracorporeal photochemotherapy in the treatment of severe acute and chronic graft-versushost disease. Blood 92, 3098-3104. 
Greinix, H.T., Volc-Platzer, B., Kalhs, P., Fischer, G., Rosenmayr, A., Keil, F., Hönigsmann, H., and Knobler, R.M. (2000). Extracorporeal photochemotherapy in the treatment of severe steroid-refractory acute graft-versus-host disease: a pilot study. Blood 96, 2426-2431.

Greinix, H.T., Knobler, R.M., Worel, N., Schneider, B., Schneeberger, A., Hoecker, P., Mitterbauer, M., Rabitsch, W., Schulenburg, A., and Kalhs, P. (2006a). The effect of intensified extracorporeal photochemotherapy on long-term survival in patients with severe acute graft-versus-host disease. Haematologica 91, 405-408.

Greinix, H.T., Socié, G., Bacigalupo, A., Holler, E., Edinger, M.G., Apperley, J.F., Schwarz, T., Ullrich, S.E., Albert, M.L., Knobler, R.M., et al. (2006b). Assessing the potential role of photopheresis in hematopoietic stem cell transplant. Bone Marrow Transplant. 38, 265-273.

Greinix, H.T., Pohlreich, D., Kouba, M., Körmöczi, U., Lohmann, I., Feldmann, K., Zielinski, C., and Pickl, W.F. (2008). Elevated numbers of immature/transitional CD21- B lymphocytes and deficiency of memory CD27+ B cells identify patients with active chronic graft-versushost disease. Biol. Blood Marrow Transplant. J. Am. Soc. Blood Marrow Transplant. 14, $208-$ 219.

Griffith, L.M., Pavletic, S.Z., Lee, S.J., Martin, P.J., Schultz, K.R., and Vogelsang, G.B. (2008). Chronic Graft-versus-Host Disease--implementation of the National Institutes of Health Consensus Criteria for Clinical Trials. Biol. Blood Marrow Transplant. J. Am. Soc. Blood Marrow Transplant. 14, 379-384.

Hannani, D., Gabert, F., Laurin, D., Sall, M., Molens, J.-P., Hequet, O., Chaperot, L., and Plumas, J. (2010). Photochemotherapy induces the apoptosis of monocytes without impairing their function. Transplantation 89, 492-499.

Hart, J.W., Shiue, L.H., Shpall, E.J., and Alousi, A.M. (2013). Extracorporeal photopheresis in the treatment of graft-versus-host disease: evidence and opinion. Ther. Adv. Hematol. 4, 320-334.

Heinze, A., Elze, M.C., Kloess, S., Ciocarlie, O., Königs, C., Betz, S., Bremm, M., Esser, R., Klingebiel, T., Serban, M., et al. (2013). Age-Matched Dendritic Cell Subpopulations Reference Values in Childhood. Scand. J. Immunol. 77, 213-220.

Hill, G.R., and Ferrara, J.L. (2000). The primacy of the gastrointestinal tract as a target organ of acute graft-versus-host disease: rationale for the use of cytokine shields in allogeneic bone marrow transplantation. Blood 95, 2754-2759.

Hill, G.R., Crawford, J.M., Cooke, K.R., Brinson, Y.S., Pan, L., and Ferrara, J.L. (1997). Total body irradiation and acute graft-versus-host disease: the role of gastrointestinal damage and inflammatory cytokines. Blood 90, 3204-3213.

Hill, G.R., Teshima, T., Gerbitz, A., Pan, L., Cooke, K.R., Brinson, Y.S., Crawford, J.M., and Ferrara, J.L. (1999). Differential roles of IL-1 and TNF-alpha on graft-versus-host disease and graft versus leukemia. J. Clin. Invest. 104, 459-467. 
Hill, G.R., Teshima, T., Rebel, V.I., Krijanovski, O.I., Cooke, K.R., Brinson, Y.S., and Ferrara, J.L. (2000). The p55 TNF-alpha receptor plays a critical role in T cell alloreactivity. J. Immunol. Baltim. Md 1950 164, 656-663.

Hockenbery, D.M., Cruickshank, S., Rodell, T.C., Gooley, T., Schuening, F., Rowley, S., David, D., Brunvand, M., Berryman, B., Abhyankar, S., et al. (2007). A randomized, placebocontrolled trial of oral beclomethasone dipropionate as a prednisone-sparing therapy for gastrointestinal graft-versus-host disease. Blood 109, 4557-4563.

Hołowiecki, J. (2008). Indications for hematopoietic stem cell transplantation. Pol. Arch. Med. Wewnętrznej 118, 658-663.

Isnardi, I., Ng, Y.-S., Menard, L., Meyers, G., Saadoun, D., Srdanovic, I., Samuels, J., Berman, J., Buckner, J.H., Cunningham-Rundles, C., et al. (2010). Complement receptor 2/CD21- human naive B cells contain mostly autoreactive unresponsive clones. Blood 115, 5026-5036.

Jaffee, B.D., and Claman, H.N. (1983). Chronic graft-versus-host disease (GVHD) as a model for scleroderma. I. Description of model systems. Cell. Immunol. 77, 1-12.

Jagasia, M., Greinix, H., Robin, M., Das-Gupta, E., Jacobs, R., Savani, B.N., Engelhardt, B.G., Kassim, A., Worel, N., Knobler, R., et al. (2013). Extracorporeal photopheresis versus anticytokine therapy as a second-line treatment for steroid-refractory acute GVHD: a multicenter comparative analysis. Biol. Blood Marrow Transplant. J. Am. Soc. Blood Marrow Transplant. 19, 1129-1133.

Kami, M., Matsumura, T., Tanaka, Y., Mikami, Y., Miyakoshi, S., Ueyama, J., Morinaga, S., Mori, S., Machida, U., Kanda, Y., et al. (2000). Serum levels of soluble interleukin-2 receptor after bone marrow transplantation: a true marker of acute graft-versus-host disease. Leuk. Lymphoma 38, 533-540.

Kernan, N.A., Collins, N.H., Juliano, L., Cartagena, T., Dupont, B., and O'Reilly, R.J. (1986). Clonable $\mathrm{T}$ lymphocytes in $\mathrm{T}$ cell-depleted bone marrow transplants correlate with development of graft-v-host disease. Blood 68, 770-773.

Kernan, N.A., Bartsch, G., Ash, R.C., Beatty, P.G., Champlin, R., Filipovich, A., Gajewski, J., Hansen, J.A., Henslee-Downey, J., and McCullough, J. (1993). Analysis of 462 transplantations from unrelated donors facilitated by the National Marrow Donor Program. N. Engl. J. Med. 328, 593-602.

Kleinclauss, F., Perruche, S., Masson, E., de Carvalho Bittencourt, M., Biichle, S., RemyMartin, J.-P., Ferrand, C., Martin, M., Bittard, H., Chalopin, J.-M., et al. (2006). Intravenous apoptotic spleen cell infusion induces a TGF-beta-dependent regulatory T-cell expansion. Cell Death Differ. 13, 41-52.

Körbling, M., and Freireich, E.J. (2011). Twenty-five years of peripheral blood stem cell transplantation. Blood 117, 6411-6416. 
Korngold, R. (1992). Lethal graft-versus-host disease in mice directed to multiple minor histocompatibility antigens: features of CD8+ and CD4+ $\mathrm{T}$ cell responses. Bone Marrow Transplant. 9, 355-364.

Korngold, R., and Sprent, J. (1978). Lethal graft-versus-host disease after bone marrow transplantation across minor histocompatibility barriers in mice. Prevention by removing mature T cells from marrow. J. Exp. Med. 148, 1687-1698.

Kuroiwa, T., Kakishita, E., Hamano, T., Kataoka, Y., Seto, Y., Iwata, N., Kaneda, Y., Matsumoto, K., Nakamura, T., Ueki, T., et al. (2001). Hepatocyte growth factor ameliorates acute graft-versus-host disease and promotes hematopoietic function. J. Clin. Invest. 107, 1365-1373.

Kuzmina, Z., Greinix, H.T., Knobler, R., Worel, N., Kouba, M., Weigl, R., Körmöczi, U., Rottal, A., Pohlreich, D., Zielinski, C., et al. (2009). Proportions of immature CD19+CD21- B lymphocytes predict the response to extracorporeal photopheresis in patients with chronic graft-versus-host disease. Blood 114, 744-746.

Lamioni, A., Parisi, F., Isacchi, G., Giorda, E., Di Cesare, S., Landolfo, A., Cenci, F., Bottazzo, G.F., and Carsetti, R. (2005). The immunological effects of extracorporeal photopheresis unraveled: induction of tolerogenic dendritic cells in vitro and regulatory $T$ cells in vivo. Transplantation 79, 846-850.

Lankester, A.C., Visser, L.F.A., Hartwig, N.G., Bredius, R.G.M., Gaspar, H.B., van der Burg, M., van Tol, M.J.D., Gross, T.G., and Egeler, R.M. (2005). Allogeneic stem cell transplantation in X-linked lymphoproliferative disease: two cases in one family and review of the literature. Bone Marrow Transplant. 36, 99-105.

Lau, J., Sartor, M., Bradstock, K.F., Vuckovic, S., Munster, D.J., and Hart, D.N.J. (2007). Activated circulating dendritic cells after hematopoietic stem cell transplantation predict acute graft-versus-host disease. Transplantation 83, 839-846.

Lee, S.J., Zahrieh, D., Agura, E., MacMillan, M.L., Maziarz, R.T., McCarthy, P.L., Ho, V.T., Cutler, C., Alyea, E.P., Antin, J.H., et al. (2004). Effect of up-front daclizumab when combined with steroids for the treatment of acute graft-versus-host disease: results of a randomized trial. Blood 104, 1559-1564.

Levine, J.E., Paczesny, S., Mineishi, S., Braun, T., Choi, S.W., Hutchinson, R.J., Jones, D., Khaled, Y., Kitko, C.L., Bickley, D., et al. (2008). Etanercept plus methylprednisolone as initial therapy for acute graft-versus-host disease. Blood 111, 2470-2475.

Lowin, B., Hahne, M., Mattmann, C., and Tschopp, J. (1994). Cytolytic T-cell cytotoxicity is mediated through perforin and Fas lytic pathways. Nature 370, 650-652.

Lucas, M., Stuart, L.M., Savill, J., and Lacy-Hulbert, A. (2003). Apoptotic cells and innate immune stimuli combine to regulate macrophage cytokine secretion. J. Immunol. Baltim. Md $1950171,2610-2615$.

Luft, T., Conzelmann, M., Benner, A., Rieger, M., Hess, M., Strohhaecker, U., Görner, M., Hegenbart, U., Ho, A.D., and Dreger, P. (2007). Serum cytokeratin-18 fragments as 
quantitative markers of epithelial apoptosis in liver and intestinal graft-versus-host disease. Blood 110, 4535-4542.

Maeda, A., Schwarz, A., Kernebeck, K., Gross, N., Aragane, Y., Peritt, D., and Schwarz, T. (2005a). Intravenous infusion of syngeneic apoptotic cells by photopheresis induces antigenspecific regulatory T cells. J. Immunol. Baltim. Md 1950 174, 5968-5976.

Maeda, A., Beissert, S., Schwarz, T., and Schwarz, A. (2008a). Phenotypic and functional characterization of ultraviolet radiation-induced regulatory T cells. J. Immunol. Baltim. Md $1950180,3065-3071$.

Maeda, A., Schwarz, A., Bullinger, A., Morita, A., Peritt, D., and Schwarz, T. (2008b). Experimental extracorporeal photopheresis inhibits the sensitization and effector phases of contact hypersensitivity via two mechanisms: generation of IL-10 and induction of regulatory T cells. J. Immunol. Baltim. Md 1950 181, 5956-5962.

Maeda, Y., Levy, R.B., Reddy, P., Liu, C., Clouthier, S.G., Teshima, T., and Ferrara, J.L.M. (2005b). Both perforin and Fas ligand are required for the regulation of alloreactive CD8+ T cells during acute graft-versus-host disease. Blood 105, 2023-2027.

Magenau, J.M., Qin, X., Tawara, I., Rogers, C.E., Kitko, C., Schlough, M., Bickley, D., Braun, T.M., Jang, P.-S., Lowler, K.P., et al. (2010). Frequency of CD4(+)CD25(hi)FOXP3(+) regulatory $T$ cells has diagnostic and prognostic value as a biomarker for acute graft-versushost-disease. Biol. Blood Marrow Transplant. J. Am. Soc. Blood Marrow Transplant. 16, 907914.

Marshall, S.R. (2006). Technology insight: ECP for the treatment of GvHD--can we offer selective immune control without generalized immunosuppression? Nat. Clin. Pract. Oncol. 3, 302-314.

Martin, P.J. (1991). Increased disparity for minor histocompatibility antigens as a potential cause of increased GVHD risk in marrow transplantation from unrelated donors compared with related donors. Bone Marrow Transplant. 8, 217-223.

Martin, P.J., Schoch, G., Fisher, L., Byers, V., Anasetti, C., Appelbaum, F.R., Beatty, P.G., Doney, K., McDonald, G.B., and Sanders, J.E. (1990). A retrospective analysis of therapy for acute graft-versus-host disease: initial treatment. Blood 76, 1464-1472.

Martin, P.J., Storer, B.E., Rowley, S.D., Flowers, M.E.D., Lee, S.J., Carpenter, P.A., Wingard, J.R., Shaughnessy, P.J., DeVetten, M.P., Jagasia, M., et al. (2009). Evaluation of mycophenolate mofetil for initial treatment of chronic graft-versus-host disease. Blood 113, 5074-5082.

Martin, P.J., Rizzo, J.D., Wingard, J.R., Ballen, K., Curtin, P.T., Cutler, C., Litzow, M.R., Nieto, Y., Savani, B.N., Schriber, J.R., et al. (2012a). First- and second-line systemic treatment of acute graft-versus-host disease: recommendations of the American Society of Blood and Marrow Transplantation. Biol. Blood Marrow Transplant. J. Am. Soc. Blood Marrow Transplant. 18, 1150-1163. 
Martin, P.J., Rizzo, J.D., Wingard, J.R., Ballen, K., Curtin, P.T., Cutler, C., Litzow, M.R., Nieto, Y., Savani, B.N., Schriber, J.R., et al. (2012b). First and Second-Line Systemic Treatment of Acute Graft-versus-host Disease: Recommendations of the American Society of Blood and Marrow Transplantation. Biol. Blood Marrow Transplant. 18, 1150-1163.

Martínez, C., and Urbano-Ispízua, Á. (2011). Graft-versus-host disease therapy: something else beyond glucocorticoids? Haematologica 96, 1249-1251.

Matsuda, S., and Koyasu, S. (2000). Mechanisms of action of cyclosporine. Immunopharmacology 47, 119-125.

McKenna, K.E., Whittaker, S., Rhodes, L.E., Taylor, P., Lloyd, J., Ibbotson, S., RussellJones, R., British Photodermatology Group, and UK Skin Lymphoma Group (2006). Evidence-based practice of photopheresis 1987-2001: a report of a workshop of the British Photodermatology Group and the U.K. Skin Lymphoma Group. Br. J. Dermatol. 154, 7-20.

Merlin, E., Goncalves-Mendes, N., Hannani, D., de la Torre, A., Farges, M.C., Laroye, H., Demeocq, F., Kanold, J., and Vasson, M.P. (2011). Extracorporeal photochemotherapy induces arginase 1 in patients with graft versus host disease. Transpl. Immunol. 24, 100106.

Mielcarek, M., Storer, B.E., Boeckh, M., Carpenter, P.A., McDonald, G.B., Deeg, H.J., Nash, R.A., Flowers, M.E.D., Doney, K., Lee, S., et al. (2009). Initial therapy of acute graft-versushost disease with low-dose prednisone does not compromise patient outcomes. Blood 113, 2888-2894.

Miyamoto, T., Akashi, K., Hayashi, S., Gondo, H., Murakawa, M., Tanimoto, K., Harada, M., and Niho, Y. (1996). Serum concentration of the soluble interleukin-2 receptor for monitoring acute graft-versus-host disease. Bone Marrow Transplant. 17, 185-190.

Morelli, A.E., Larregina, A.T., Shufesky, W.J., Zahorchak, A.F., Logar, A.J., Papworth, G.D., Wang, Z., Watkins, S.C., Falo, L.D., and Thomson, A.W. (2003). Internalization of circulating apoptotic cells by splenic marginal zone dendritic cells: dependence on complement receptors and effect on cytokine production. Blood 101, 611-620.

Nash, R.A., Antin, J.H., Karanes, C., Fay, J.W., Avalos, B.R., Yeager, A.M., Przepiorka, D., Davies, S., Petersen, F.B., Bartels, P., et al. (2000). Phase 3 study comparing methotrexate and tacrolimus with methotrexate and cyclosporine for prophylaxis of acute graft-versus-host disease after marrow transplantation from unrelated donors. Blood 96, 2062-2068.

Naylor, S. (2003). Biomarkers: current perspectives and future prospects. Expert Rev. Mol. Diagn. 3, 525-529.

Okamoto, T., Takatsuka, H., Fujimori, Y., Wada, H., Iwasaki, T., and Kakishita, E. (2001). Increased hepatocyte growth factor in serum in acute graft-versus-host disease. Bone Marrow Transplant. 28, 197-200.

OKunewick, J.P., Kociban, D.L., Machen, L.L., and Buffo, M.J. (1993). Effect of donor and recipient gender disparities on fatal graft-vs.-host disease in a mouse model for major 
histocompatibility complex-matched unrelated-donor bone marrow transplantation. Exp. Hematol. 21, 1570-1576.

Olson, J.A., Leveson-Gower, D.B., Gill, S., Baker, J., Beilhack, A., and Negrin, R.S. (2010). NK cells mediate reduction of GVHD by inhibiting activated, alloreactive $T$ cells while retaining GVT effects. Blood 115, 4293-4301.

Paczesny, S., Levine, J.E., Braun, T.M., and Ferrara, J.L.M. (2009a). Plasma biomarkers in graft-versus-host disease: a new era? Biol. Blood Marrow Transplant. J. Am. Soc. Blood Marrow Transplant. 15, 33-38.

Paczesny, S., Krijanovski, O.I., Braun, T.M., Choi, S.W., Clouthier, S.G., Kuick, R., Misek, D.E., Cooke, K.R., Kitko, C.L., Weyand, A., et al. (2009b). A biomarker panel for acute graftversus-host disease. Blood 113, 273-278.

Paczesny, S., Raiker, N., Brooks, S., and Mumaw, C. (2013). Graft-versus-host disease biomarkers: omics and personalized medicine. Int. J. Hematol. 98, 275-292.

Pasquini, M.C., Griffith, L.M., Arnold, D.L., Atkins, H.L., Bowen, J.D., Chen, J.T., Freedman, M.S., Kraft, G.H., Mancardi, G.L., Martin, R., et al. (2010). Hematopoietic stem cell transplantation for multiple sclerosis: collaboration of the CIBMTR and EBMT to facilitate international clinical studies. Biol. Blood Marrow Transplant. J. Am. Soc. Blood Marrow Transplant. 16, 1076-1083.

Pathak, M.A., and Fitzpatrick, T.B. (1992). The evolution of photochemotherapy with psoralens and UVA (PUVA): 2000 BC to 1992 AD. J. Photochem. Photobiol. B 14, 3-22.

Pavletic, S.Z., and Fowler, D.H. (2012). Are we making progress in GVHD prophylaxis and treatment? Hematol. Educ. Program Am. Soc. Hematol. Am. Soc. Hematol. Educ. Program 2012, 251-264.

Piguet, P.F., Grau, G.E., Allet, B., and Vassalli, P. (1987). Tumor necrosis factor/cachectin is an effector of skin and gut lesions of the acute phase of graft-vs.-host disease. J. Exp. Med. 166, 1280-1289.

Przepiorka, D., Weisdorf, D., Martin, P., Klingemann, H.G., Beatty, P., Hows, J., and Thomas, E.D. (1995). 1994 Consensus Conference on Acute GVHD Grading. Bone Marrow Transplant. 15, 825-828.

Przepiorka, D., Smith, T.L., Folloder, J., Khouri, I., Ueno, N.T., Mehra, R., Körbling, M., Huh, Y.O., Giralt, S., Gajewski, J., et al. (1999). Risk factors for acute graft-versus-host disease after allogeneic blood stem cell transplantation. Blood 94, 1465-1470.

Ramadan, A., and Paczesny, S. (2015). Various forms of tissue damage and danger signals following hematopoietic stem-cell transplantation. Front. Immunol. 6, 14.

Ratanatharathorn, V., Nash, R.A., Przepiorka, D., Devine, S.M., Klein, J.L., Weisdorf, D., Fay, J.W., Nademanee, A., Antin, J.H., Christiansen, N.P., et al. (1998). Phase III study comparing methotrexate and tacrolimus (prograf, FK506) with methotrexate and cyclosporine 
for graft-versus-host disease prophylaxis after HLA-identical sibling bone marrow transplantation. Blood 92, 2303-2314.

Reddy, P., and Ferrara, J.L.M. (2003). Immunobiology of acute graft-versus-host disease. Blood Rev. 17, 187-194.

Reddy, P., Negrin, R., and Hill, G.R. (2008). Mouse models of bone marrow transplantation. Biol. Blood Marrow Transplant. J. Am. Soc. Blood Marrow Transplant. 14, 129-135.

Rezvani, K., Mielke, S., Ahmadzadeh, M., Kilical, Y., Savani, B.N., Zeilah, J., Keyvanfar, K., Montero, A., Hensel, N., Kurlander, R., et al. (2006). High donor FOXP3-positive regulatory T-cell (Treg) content is associated with a low risk of GVHD following HLA-matched allogeneic SCT. Blood 108, 1291-1297.

Rook, A.H., Freundlich, B., Jegasothy, B.V., Perez, M.I., Barr, W.G., Jimenez, S.A., Rietschel, R.L., Wintroub, B., Kahaleh, M.B., and Varga, J. (1992). Treatment of systemic sclerosis with extracorporeal photochemotherapy. Results of a multicenter trial. Arch. Dermatol. 128, 337-346.

Rowlings, P.A., Przepiorka, D., Klein, J.P., Gale, R.P., Passweg, J.R., Henslee-Downey, P.J., Cahn, J.Y., Calderwood, S., Gratwohl, A., Socié, G., et al. (1997). IBMTR Severity Index for grading acute graft-versus-host disease: retrospective comparison with Glucksberg grade. Br. J. Haematol. 97, 855-864.

Ruutu, T., Gratwohl, A., de Witte, T., Afanasyev, B., Apperley, J., Bacigalupo, A., Dazzi, F., Dreger, P., Duarte, R., Finke, J., et al. (2014). Prophylaxis and treatment of GVHD: EBMTELN working group recommendations for a standardized practice. Bone Marrow Transplant. 49, 168-173.

Sakaguchi, S., Yamaguchi, T., Nomura, T., and Ono, M. (2008). Regulatory T Cells and Immune Tolerance. Cell 133, 775-787.

Schmaltz, C., Alpdogan, O., Horndasch, K.J., Muriglan, S.J., Kappel, B.J., Teshima, T., Ferrara, J.L., Burakoff, S.J., and van den Brink, M.R. (2001). Differential use of Fas ligand and perforin cytotoxic pathways by donor $T$ cells in graft-versus-host disease and graftversus-leukemia effect. Blood 97, 2886-2895.

Schroeder, M.A., and DiPersio, J.F. (2011a). Mouse models of graft-versus-host disease: advances and limitations. Dis. Model. Mech. 4, 318-333.

Schroeder, M.A., and DiPersio, J.F. (2011b). Mouse models of graft-versus-host disease: advances and limitations. Dis. Model. Mech. 4, 318-333.

Schwarte, S., and Hoffmann, M.W. (2005). Influence of radiation protocols on graft-vs-host disease incidence after bone-marrow transplantation in experimental models. Methods Mol. Med. 109, 445-458.

Shlomchik, W.D. (2007). Graft-versus-host disease. Nat. Rev. Immunol. 7, 340-352. 
Shlomchik, W.D., Couzens, M.S., Tang, C.B., McNiff, J., Robert, M.E., Liu, J., Shlomchik, M.J., and Emerson, S.G. (1999). Prevention of graft versus host disease by inactivation of host antigen-presenting cells. Science 285, 412-415.

Snover, D.C., Weisdorf, S.A., Ramsay, N.K., McGlave, P., and Kersey, J.H. (1984). Hepatic graft versus host disease: a study of the predictive value of liver biopsy in diagnosis. Hepatol. Baltim. Md 4, 123-130.

Socié, G., Schmoor, C., Bethge, W.A., Ottinger, H.D., Stelljes, M., Zander, A.R., Volin, L., Ruutu, T., Heim, D.A., Schwerdtfeger, R., et al. (2011). Chronic graft-versus-host disease: long-term results from a randomized trial on graft-versus-host disease prophylaxis with or without anti-T-cell globulin ATG-Fresenius. Blood 117, 6375-6382.

Spisek, R., Gasova, Z., and Bartunkova, J. (2006). Maturation state of dendritic cells during the extracorporeal photopheresis and its relevance for the treatment of chronic graft-versushost disease. Transfusion (Paris) 46, 55-65.

Sprent, J., Schaefer, M., Lo, D., and Korngold, R. (1986). Properties of purified T cell subsets. II. In vivo responses to class I vs. class II H-2 differences. J. Exp. Med. 163, 9981011.

Sprent, J., Schaefer, M., Gao, E.K., and Korngold, R. (1988). Role of T cell subsets in lethal graft-versus-host disease (GVHD) directed to class I versus class II H-2 differences. I. L3T4+ cells can either augment or retard GVHD elicited by Lyt-2+ cells in class I different hosts. J. Exp. Med. 167, 556-569.

Sprent, J., Schaefer, M., and Korngold, R. (1990). Role of T cell subsets in lethal graftversus-host disease (GVHD) directed to class I versus class II H-2 differences. II. Protective effects of L3T4+ cells in anti-class II GVHD. J. Immunol. Baltim. Md 1950 144, 2946-2954.

Steinman, R.M., and Inaba, K. (1999). Myeloid dendritic cells. J. Leukoc. Biol. 66, 205-208.

Steinman, R.M., Turley, S., Mellman, I., and Inaba, K. (2000). The induction of tolerance by dendritic cells that have captured apoptotic cells. J. Exp. Med. 191, 411-416.

Storb, R., Deeg, H.J., Fisher, L., Appelbaum, F., Buckner, C.D., Bensinger, W., Clift, R., Doney, K., Irle, C., and McGuffin, R. (1988). Cyclosporine v methotrexate for graft-v-host disease prevention in patients given marrow grafts for leukemia: long-term follow-up of three controlled trials. Blood 71, 293-298.

Szydlo, R., Goldman, J.M., Klein, J.P., Gale, R.P., Ash, R.C., Bach, F.H., Bradley, B.A., Casper, J.T., Flomenberg, N., Gajewski, J.L., et al. (1997). Results of allogeneic bone marrow transplants for leukemia using donors other than HLA-identical siblings. J. Clin. Oncol. Off. J. Am. Soc. Clin. Oncol. 15, 1767-1777.

Talbott, E., and Craun, G.F. (1995). An Introduction to Environmental Epidemiology (CRC Press).

Tawara, I., Shlomchik, W.D., Jones, A., Zou, W., Nieves, E., Liu, C., Toubai, T., DuranStruuck, R., Sun, Y., Clouthier, S.G., et al. (2010). A crucial role for host APCs in the 
induction of donor CD4+CD25+ regulatory T cell-mediated suppression of experimental graftversus-host disease. J. Immunol. Baltim. Md 1950 185, 3866-3872.

Tischner, D., Theiss, J., Karabinskaya, A., Brandt, J. van den, Reichardt, S.D., Karow, U., Herold, M.J., Lühder, F., Utermöhlen, O., and Reichardt, H.M. (2011). Acid Sphingomyelinase Is Required for Protection of Effector Memory $T$ Cells against Glucocorticoid-Induced Cell Death. J. Immunol. 187, 4509-4516.

Truitt, R.L., and Atasoylu, A.A. (1991). Impact of pretransplant conditioning and donor T cells on chimerism, graft-versus-host disease, graft-versus-leukemia reactivity, and tolerance after bone marrow transplantation. Blood 77, 2515-2523.

Tsirigotis, P., Kapsimalli, V., Baltadakis, I., Kaloyannidis, P., Karakasis, D., Papalexandri, A., Psarra, E., Nosi, E., Konsta, E., Vikentiou, M., et al. (2012). Extracorporeal photopheresis in refractory chronic graft-versus-host disease: the influence on peripheral blood $\mathrm{T}$ cell subpopulations. A study by the Hellenic Association of Hematology. Transfus. Apher. Sci. Off. J. World Apher. Assoc. Off. J. Eur. Soc. Haemapheresis 46, 181-188.

Van Lint, M.T., Uderzo, C., Locasciulli, A., Majolino, I., Scimé, R., Locatelli, F., Giorgiani, G., Arcese, W., lori, A.P., Falda, M., et al. (1998). Early treatment of acute graft-versus-host disease with high- or low-dose 6-methylprednisolone: a multicenter randomized trial from the Italian Group for Bone Marrow Transplantation. Blood 92, 2288-2293.

Via, C.S., Nguyen, P., Shustov, A., Drappa, J., and Elkon, K.B. (1996). A major role for the Fas pathway in acute graft-versus-host disease. J. Immunol. Baltim. Md 1950 157, 53875393.

Visentainer, J.E.L., Lieber, S.R., Persoli, L.B.L., Vigorito, A.C., Aranha, F.J.P., de Brito Eid, K.A., Oliveira, G.B., Miranda, E.C.M., and de Souza, C.A. (2003). Serum cytokine levels and acute graft-versus-host disease after HLA-identical hematopoietic stem cell transplantation. Exp. Hematol. 31, 1044-1050.

Vuckovic, S., Gardiner, D., Field, K., Chapman, G.V., Khalil, D., Gill, D., Marlton, P., Taylor, K., Wright, S., Pinzon-Charry, A., et al. (2004). Monitoring dendritic cells in clinical practice using a new whole blood single-platform TruCOUNT assay. J. Immunol. Methods 284, 7387.

Wang, Y., Gao, Y., Sun, E., and Chen, Z. (2006). [The phagocytosis of apoptotic allogeneic lymphocytes by recipient liver antigen-presenting cells]. Zhonghua Gan Zang Bing Za Zhi Zhonghua Ganzangbing Zazhi Chin. J. Hepatol. 14, 370-374.

Watanabe, N., Narita, M., Furukawa, T., Nakamura, T., Yamahira, A., Masuko, M., Toba, K., Fuse, I., Aizawa, Y., and Takahashi, M. (2011). Kinetics of pDCs, mDCs, yסT cells and regulatory $T$ cells in association with graft versus host disease after hematopoietic stem cell transplantation. Int. J. Lab. Hematol. 33, 378-390.

Weisdorf, D., Hakke, R., Blazar, B., Miller, W., McGlave, P., Ramsay, N., Kersey, J., and Filipovich, A. (1991). Risk factors for acute graft-versus-host disease in histocompatible donor bone marrow transplantation. Transplantation 51, 1197-1203. 
Wolf, D., Wolf, A.M., Fong, D., Rumpold, H., Strasak, A., Clausen, J., and Nachbaur, D. (2007). Regulatory T-cells in the graft and the risk of acute graft-versus-host disease after allogeneic stem cell transplantation. Transplantation 83, 1107-1113.

Wolff, D., Gerbitz, A., Ayuk, F., Kiani, A., Hildebrandt, G.C., Vogelsang, G.B., Elad, S., Lawitschka, A., Socie, G., Pavletic, S.Z., et al. (2010). Consensus conference on clinical practice in chronic graft-versus-host disease (GVHD): first-line and topical treatment of chronic GVHD. Biol. Blood Marrow Transplant. J. Am. Soc. Blood Marrow Transplant. 16, 1611-1628.

Wolnicka-Glubisz, A., Fraczek, J., Skrzeczynska-Moncznik, J., Friedlein, G., Mikolajczyk, T., Sarna, T., and Pryjma, J. (2010). Effect of UVA and 8-methoxypsoralen, 4, 6, 4'trimethylangelicin or chlorpromazine on apoptosis of lymphocytes and their recognition by monocytes. J. Physiol. Pharmacol. Off. J. Pol. Physiol. Soc. 61, 107-114.

Worel, N., and Leitner, G. (2012). Clinical Results of Extracorporeal Photopheresis. Transfus. Med. Hemotherapy Off. Organ Dtsch. Ges. Transfusionsmedizin Immunhamatologie 39, 254-262.

Wysocki, C.A., Panoskaltsis-Mortari, A., Blazar, B.R., and Serody, J.S. (2005). Leukocyte migration and graft-versus-host disease. Blood 105, 4191-4199.

Yamashita, K., Choi, U., Woltz, P.C., Foster, S.F., Sneller, M.C., Hakim, F.T., Fowler, D.H., Bishop, M.R., Pavletic, S.Z., Tamari, M., et al. (2004). Severe chronic graft-versus-host disease is characterized by a preponderance of $\mathrm{CD} 4(+)$ effector memory cells relative to central memory cells. Blood 103, 3986-3988. 


\section{Acknowledgements}

I am deeply grateful to Dr. Holger Budde for making this project possible and giving me the opportunity of joining his work group. His excellent scientific supervision, encouragement, and valuable scientific discussions made it fun and easy to work. Thank you for your guidance, support and friendly relationship during the entire process of my PhD project.

I would like to express my deep gratitude to Prof. Dr. Holger Reichardt for being my supervisor and for his valuable scientific input during our meetings.

I sincerely thank my second referee Prof. Dr. Hubertus Jarry for his helpful scientific discussions during Thesis Committee meetings.

I am grateful to Prof. Dr. Tobias Legler for his guidance and helpful scientific suggestions during my PhD study.

I also extend my sincere thanks to the other members of my examination board: Prof. Dr. Ralf Dressel, Prof. Dr. Peter Burfeind, Prof. Dr. Dieter Kube for taking time to serve as my examiners and for evaluating my thesis despite their busy schedules.

Many thanks go to my co-workers of the Department of Transfusion medicine as well as to our collaboration partners Station Holland for collecting blood samples of blood donors and patients. I would also like to thank our physicians Anne Lone Rau, Dr. Jens-Holger Maas and Prof. Dr. Tobias Legler for informing participants of the ECP biomarker study.

Moreover, I would like to thank José Carreras Stiftung for financing the project of my PhD study.

I am gratefull to all my friends as well as current and former colleagues of the Department of Transfusion medicine for their support as well as a friendly working atmosphere. Special thanks go to Dr. Holger Budde, Daniela Sachwitz, Anne Lone Rau, Sandra Lührig, MarieSophie Sorns, Lena Thieringer.

Mama, Papa thank you for your unconditionally love, moral support, total confidence and always believing in me. Sabrina and Alexander, thank you and your families for always supporting me.

Marcel, you supported me with your love, encouragement and patience throughout my bachelor, master and PhD study. Thank you for covering my back in so many situations and cooking the most delicious food! 


\section{A. Appendix}

\section{A.1. Abbreviations}

$\begin{array}{ll}\mu & \text { micro }\left(10^{-6}\right) \\ { }^{\circ} \mathrm{C} & \text { centigrade } \\ \text { 8-MOP } & \text { 8-methoxypsoralen }\end{array}$

\section{A} aGvHD acute graft-versus-host disease

ALL acute lymphoblastic leukemia

AML acute myeloid leukemia

APC antigen-presenting cell

ATG anti-thymocyte globulin

B

\begin{tabular}{ll}
\hline BM & bone marrow \\
BMT & bone marrow transplantation
\end{tabular}

C

cGvHD chronic graft-versus-host disease

$\mathrm{CML} \quad$ chronic myeloid leukemia

$\mathrm{CO}_{2} \quad$ carbon dioxide

$\mathrm{CR} \quad$ complete remission

CsA cyclosporin A

CTCL cutaneous T cell lymphoma

CTLs cytotoxic $T$ lymphocytes

D

$\begin{array}{ll}\text { d } & \text { day } \\ \text { DCs } & \text { dendritic cells }\end{array}$

$\mathrm{dH}_{2} \mathrm{O}$ distilled water

DMSO dimethylsulfoxide

DNA deoxyribonucleic acid

E

ECP extracorporeal photopheresis

ELISA enzyme-linked immunosorbent assay

et al. et alteres

F

FACS fluorescence-activated cell sorting

Fig. figure

FITC fluorescein

FoxP3 forkhead box protein 3

FSC forward scatter

G

g gram or gravity

GC glucocorticoid

GI gastrointestinal 
GvHD graft-versus-host disease

GvL graft-versus-leukemia

$\underline{\mathbf{H}}$

h human

HGF hepatocyte growth factor

HLA human leukocyte antigen

HRP horseradish peroxidase

HSCs haematopoietic stem cells

HSCT haematopoietic stem cell transplantation

I.v. intravenous

IFN-y interferon-gamma

IL- interleukin

IM ionomycin calcium salt

IVC individually ventilated cages

$\begin{array}{ll}J & \text { jJoule }\end{array}$

JNK jun amino-terminal kinases

K

$\mathrm{kDa} \quad$ kilo dalton

$\underline{\mathbf{L}}$

I liter

LPS lipopolysaccharide

M

m mouse

MACS magnetic-activated cell sorting

mDCs myeloid dendritic cells

MHC major histocompatibility complex

miHAs minor histocompatibility antigens

min minutes

MLR mixed lymphocyte reaction

MMF mycophenolate mofetil

MN monensin solution

MNCs mononuclear cells

MTX methotrexate

$\underline{N}$

$\mathrm{n} \quad$ nano $\left(10^{-9}\right)$ or amount of samples

$\mathrm{NaCl}$ sodium chloride

NFAT nuclear factor of activated T-cells

NK natural killer

$\mathrm{nm} \quad$ nanometer

ns not significant 


\begin{tabular}{ll}
$\mathbf{P}$ & \\
\hline $\mathrm{p}$ & pico $\left(10^{-12}\right)$ \\
$\mathrm{P} / \mathrm{S}$ & penicillin/ streptomycin \\
PBS & phosphate buffered saline \\
PBSCs & $\begin{array}{l}\text { peripheral blood stem cells } \\
\text { phycoerythrin }\end{array}$ \\
PE & negative decimal logarithm of the hydrogen ion concentration \\
pH & phorbol 12-myristate 13-acetate \\
PMA & 8-MOP/UV-A \\
PUVA & \\
R & \\
\hline RT & room temperature \\
S & \\
\hline SCID & severe combined immunodeficiencies \\
SEM & standard error of mean \\
SIL-2R & soluble interleukin-2 receptor \\
SP & spleen \\
SSC & side scatter \\
STNF-R & soluble tumor necrosis factor receptor \\
T & \\
\hline Tab. & table \\
TAC & tacrolimus \\
TCR & T cell receptor \\
TGF-B1 & transforming growth factor-ß1 \\
Th & T helper \\
TNF- $\alpha$ & tumour necrosis factor-alpha \\
Treg & regulatory T \\
$\mathbf{U}$ & \\
\hline UV-A & ultraviolet light type-A \\
& \\
\hline
\end{tabular}




\section{A.2. List of Figures}

Fig. 1: Schematic overview of GvHD pathophysiology................................................ 5

Fig. 2: Scheme of possible modes of action of ECP treatment .....................................11

Fig. 3: Scheme of GvHD induction and ECP therapy in the mouse model .........................40

Fig. 4: C57BL/6->BALB/c transplanted mice injected with PUVA-treated C57BL/6 splenocytes as a model of ECP therapy of aGvHD

Fig. 5: FACS analysis of splenocytes from C57BL/6 $\square \mathrm{BALB} / \mathrm{c}$ transplanted mice after ECP therapy with splenocytes of C57BL/6 origin

Fig. 6: ECP therapy ameliorates disease symptoms in mice suffering from chronic GvHD ...43

Fig. 7: FACS analysis of splenocytes after ECP therapy using cells of B10D2 origin in a mouse model of cGvHD

Fig. 8: ECP therapy using PUVA-treated BALB/c splenocytes aggravates aGvHD in mice ..45

Fig. 9: Flow cytometric analysis of splenocytes isolated from C57BL/6->BALB/c mice after ECP therapy with PUVA-treated BALB/c splenocytes.

Fig. 10: ECP therapy with splenocytes of $\mathrm{C} 3 \mathrm{H}$ origin reduces mortality, the clinical aGvHD score, and weight loss in mouse model of aGvHD.

Fig. 11: FACS analysis of splenocytes from aGvHD mice after ECP therapy with cells of $\mathrm{C} 3 \mathrm{H}$ origin

Fig. 12: Analysis of splenocytes and serum from C57BL/6->BALB/c mice injected with PUVAtreated cells of $\mathrm{C} 3 \mathrm{H}$ origin .51

Fig. 13: ECP therapy of aGvHD using cells from MLR of C57BL/6 and BALB/c origin . .54

Fig. 14: FACS analysis of aGvHD after ECP therapy with cells derived from an MLR .55

Fig. 15: ECP therapy using MLR cells of $\mathrm{C} 3 \mathrm{H}$ origin in the mouse model of acute GvHD ....56 Fig. 16: FACS analysis of splenocytes from aGvHD mice after ECP therapy with cells derived from a MLR of $\mathrm{C} 3 \mathrm{H}$ origin

Fig. 17: Tracking of PUVA-treated CD45.1+ splenocytes after ECP therapy of aGvHD mice58

Fig. 18: Scheme of the blood sampling for the analysis of GvHD and ECP biomarkers .60

Fig. 19: Flow cytometric analysis of potential GvHD and ECP biomarkers measured in the blood of HSCT and GvHD patients....

Fig. 20: Flow cytometric analysis of potential GvHD and ECP biomarkers as absolute cell number in the blood of HSCT and GvHD patients

Fig. 21: Analysis of serum samples from HSCT and GvHD patients by ELISA for the detection of potential GvHD and ECP biomarkers 69

Figure 22: Gating strategies for T cells from human MNCs 102

Figure 23: Gating strategies for identifying human immature B cells amongst all MNCs .....102

Figure 24: Gating strategies for CD3+ CD4+ and CD3+ CD8+ T cell subsets 103 
Figure 25: Three-color flow cytometry gating strategies for identifying human mDCs amongst all MNCs. 104

Figure 26: Three-color gating strategies for the identification of human Treg cells amongst all MNCs . 105

Figure 27: Gating strategy for different T cell subpopulations from murine spleen ... 106

Figure 28: Gating strategy for identifying NK T cells from murine spleen. 106

Figure 29: Flow cytometric gating strategies for Treg cells from murine spleen .107 


\section{A.3. List of Tables}

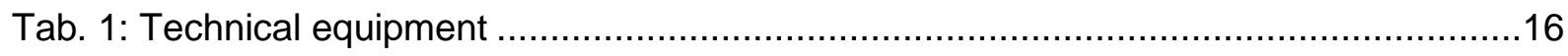

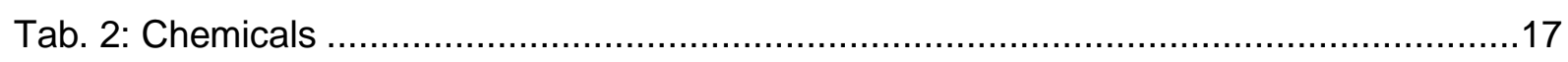

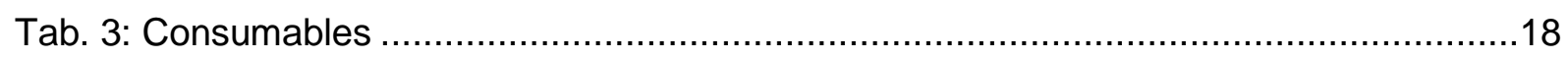

Tab. 4: Antibodies for cell separation................................................................... 19

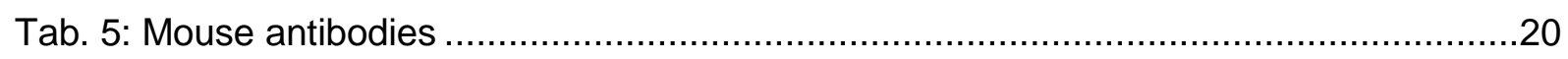

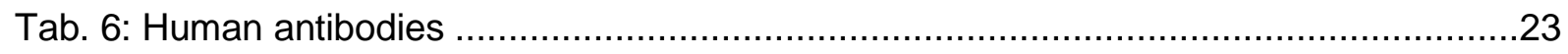

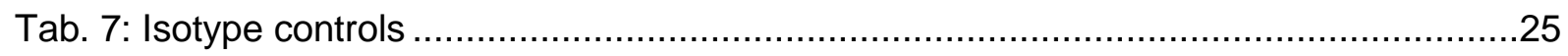

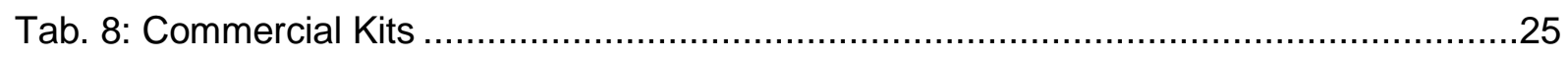

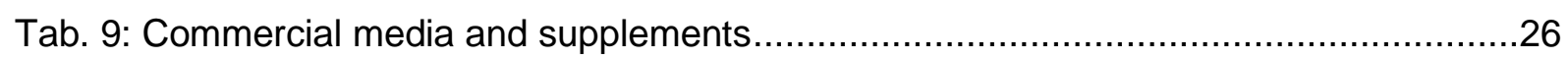

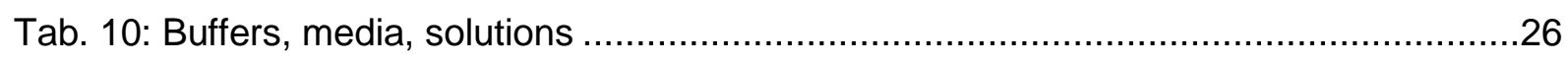

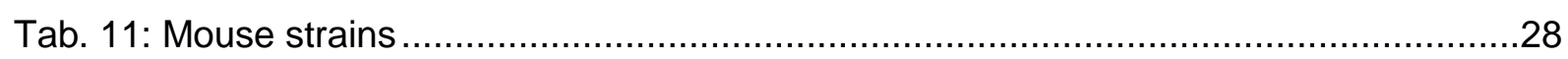

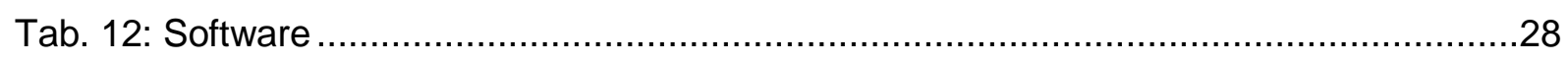

Table 13: Reference ranges of potential cellular biomarkers in percentages of all MNCs .....61

Table 14: Reference values as absolute cell counts of potential cellular biomarkers ...........61

Table 15:Comparison of two donation timepoints from control subjects.............................62

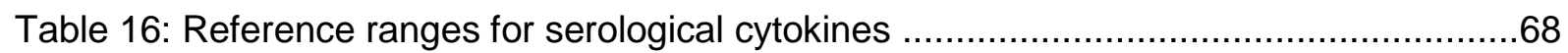

Table 17: Comparison of differences in serological cytokine levels between two timepoints of

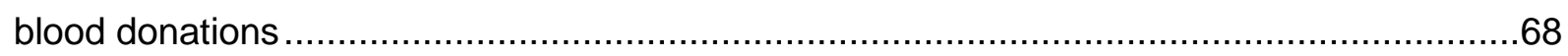


A.4. Gating strategies in flow cytometry
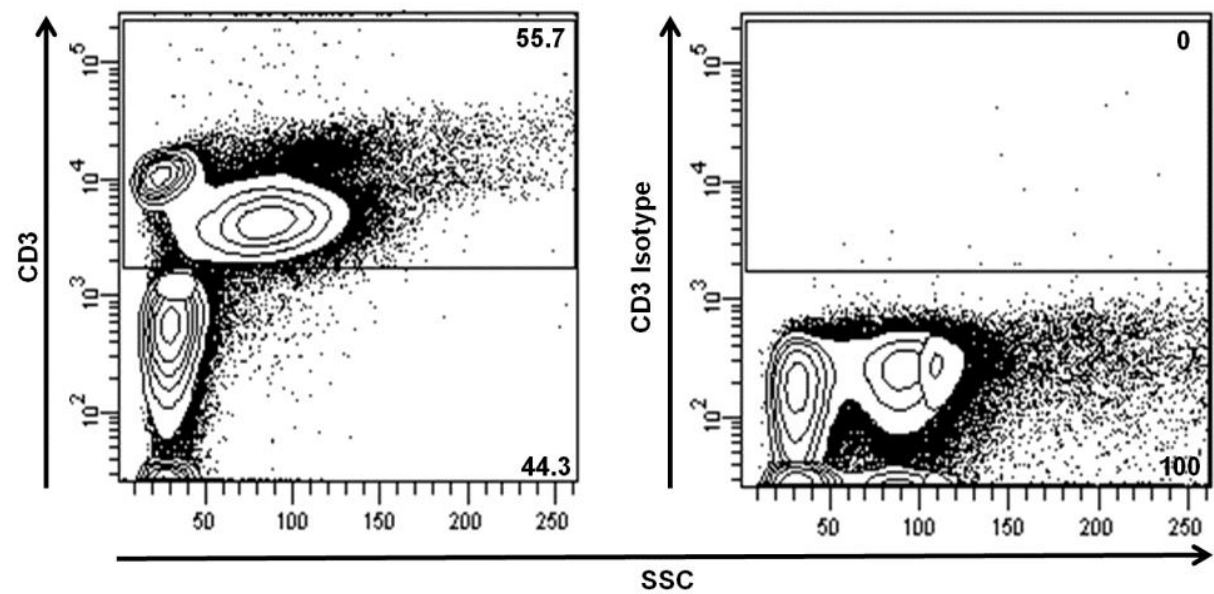

Fig. 22: Gating strategies for T cells from human MNCs.
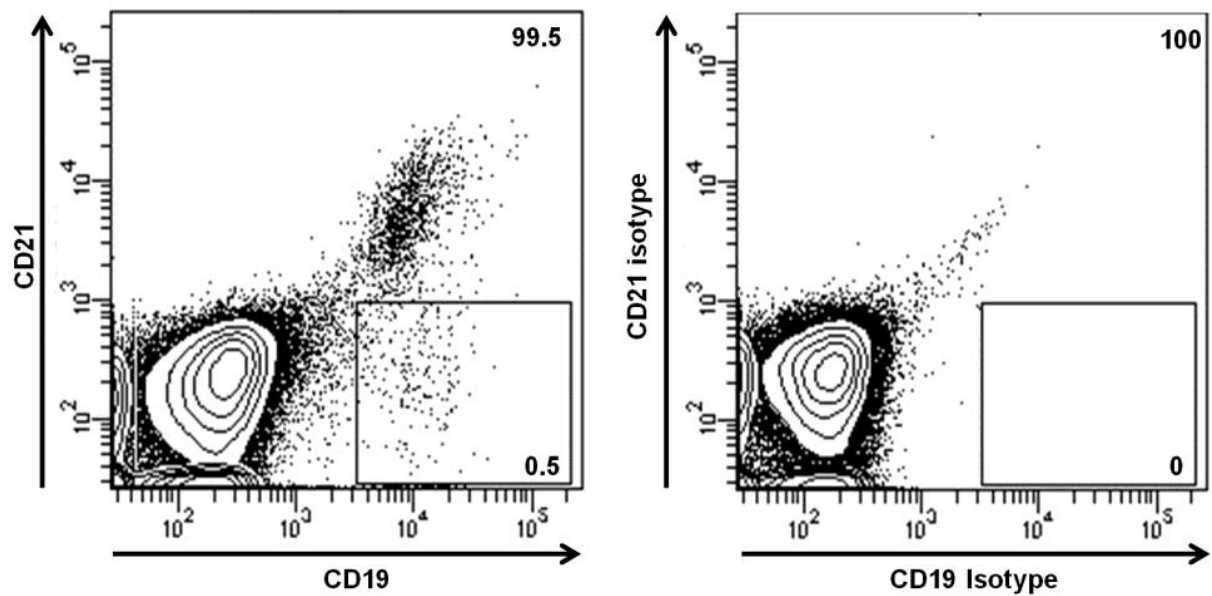

Fig. 23: Gating strategies for identifying human immature B cells amongst all MNCs. 

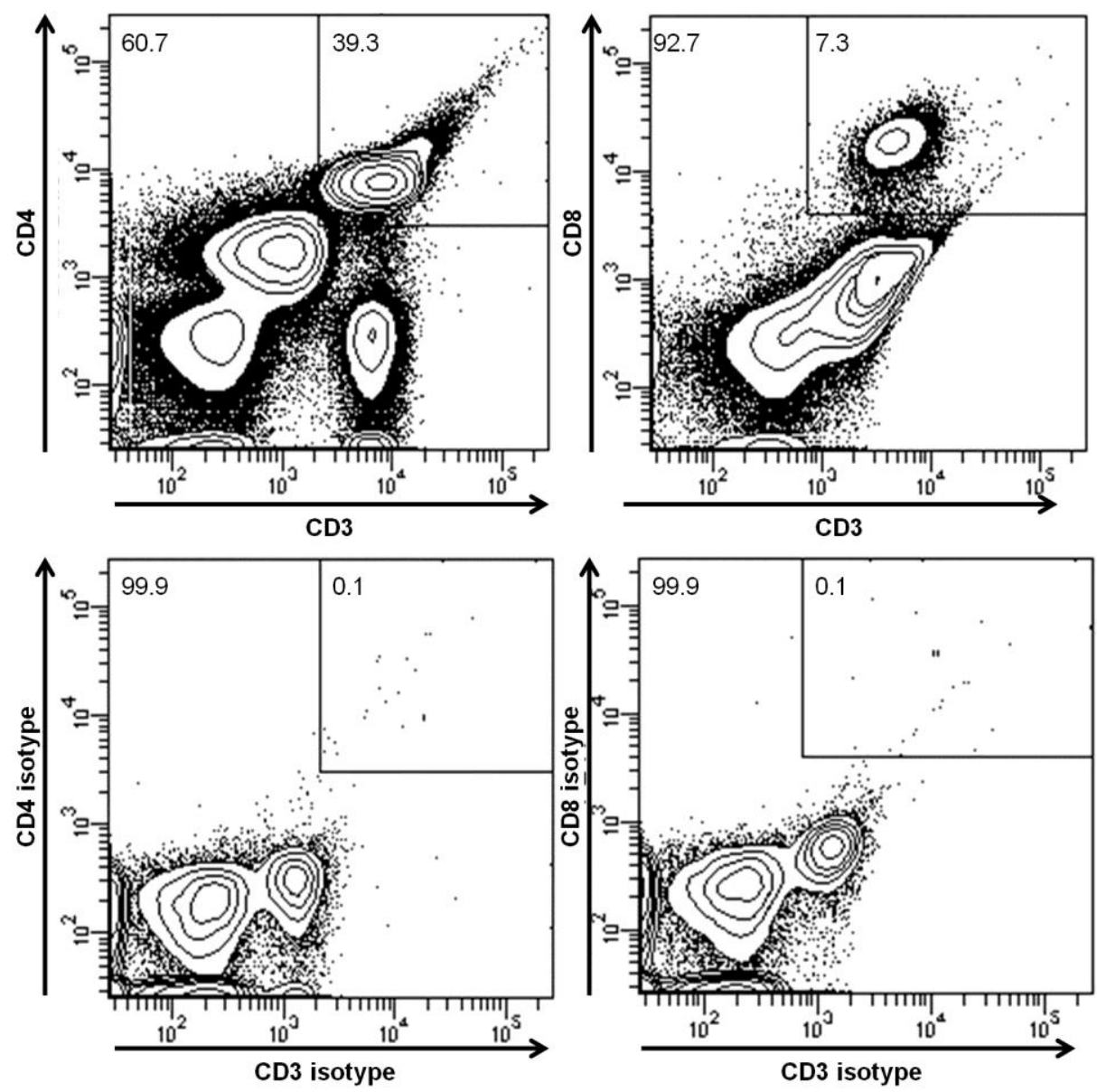

Fig. 24: Gating strategies for $\mathrm{CD}^{+} \mathrm{CD} 4^{+}$and $\mathrm{CD} 3^{+} \mathrm{CD} 8^{+} \mathrm{T}$ cell subsets. 

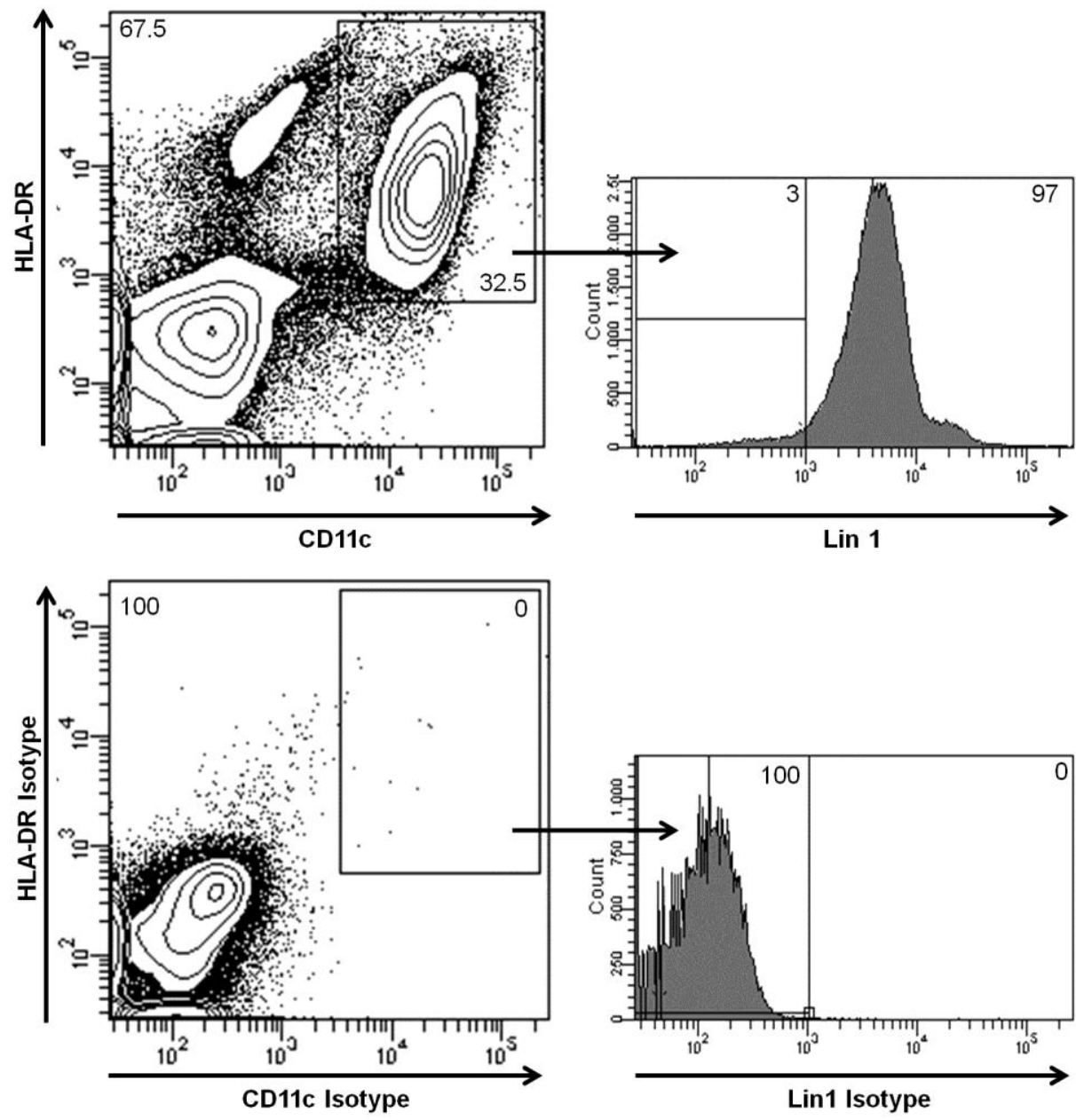

Fig. 25: Three-color flow cytometry gating strategies for identifying human mDCs amongst all MNCs. 

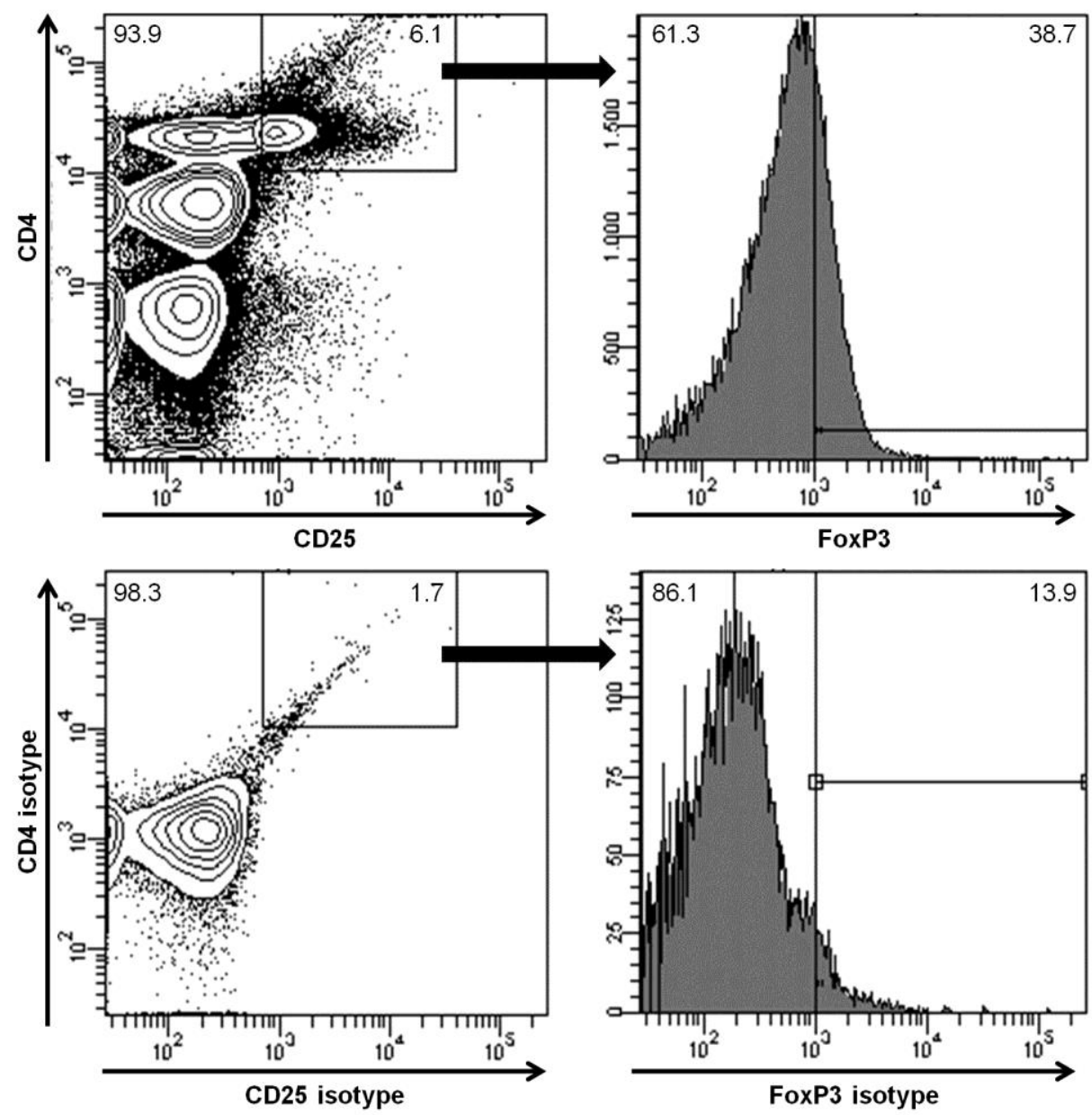

Fig. 26: Three-color gating strategies for the identification of human Treg cells amongst all MNCs. 

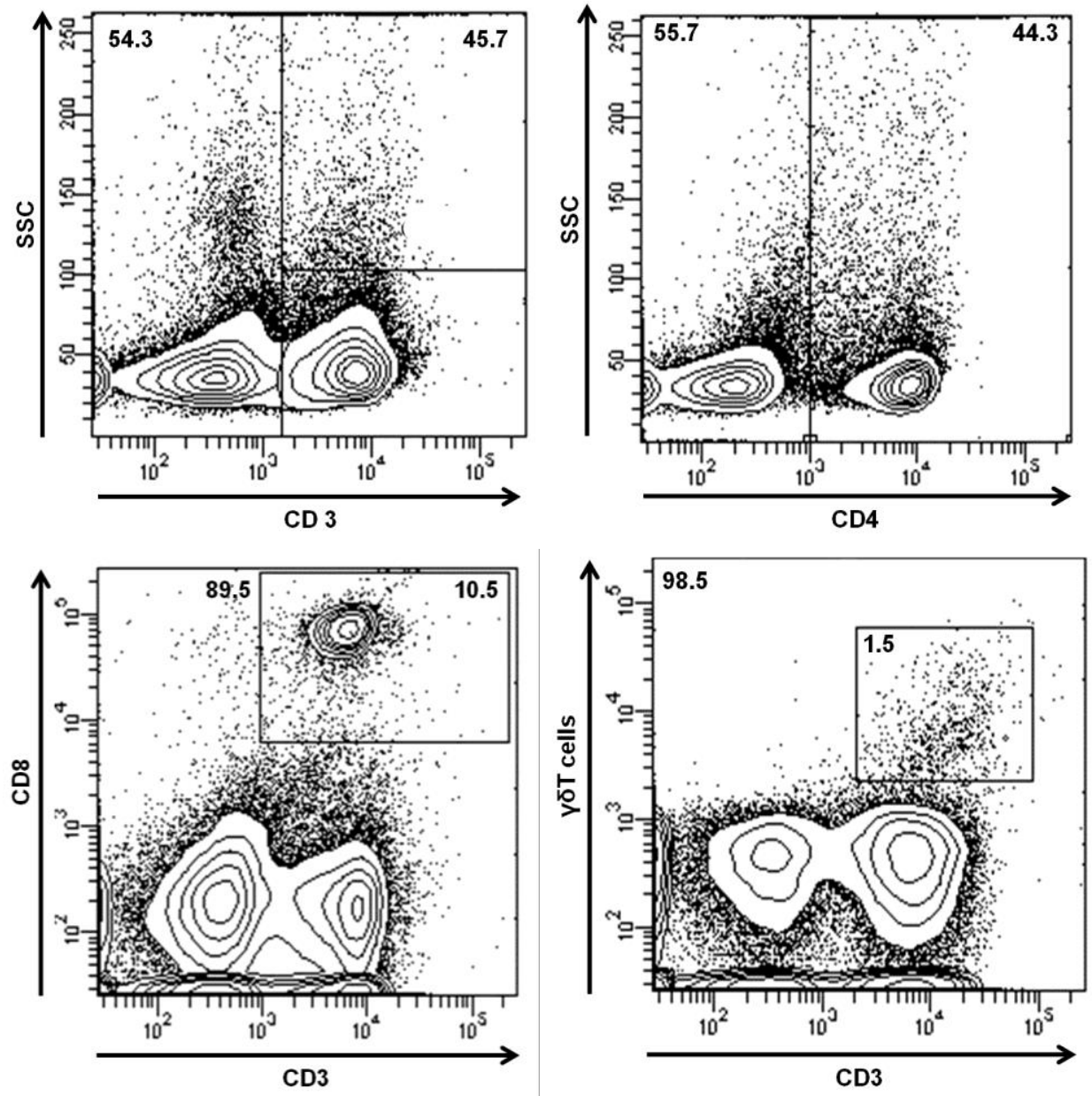

Fig. 27: Gating strategy for different T cell subpopulations from murine spleen.

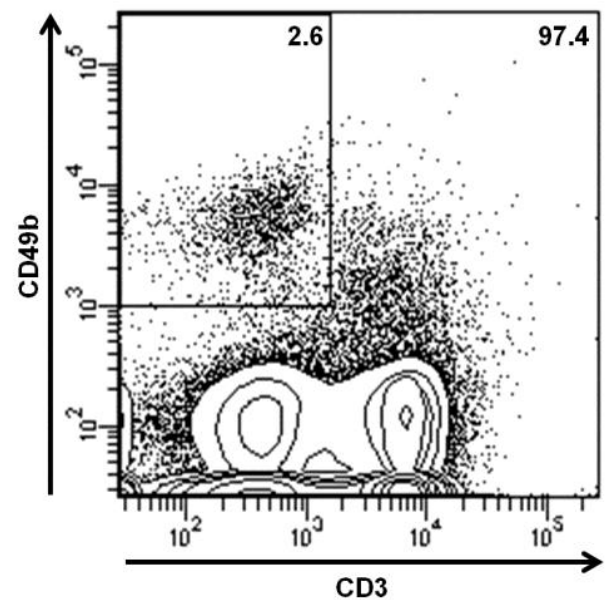

Fig. 28: Gating strategy for identifying NK T cells from murine spleen. 

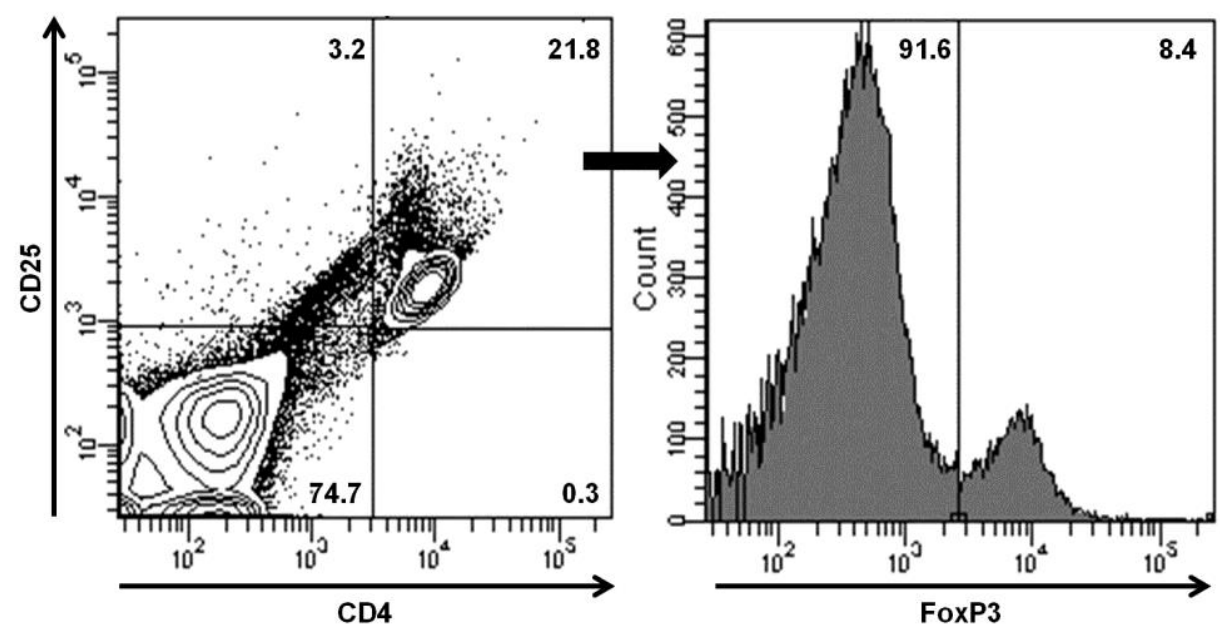

Fig. 29: Flow cytometric gating strategies for Treg cells from murine spleen. 


\section{A.5. Curriculum vitae}

Personal details

Name Susanne Papert geb. Kolb

Date of birth $\quad 06 / 19 / 1985$

Place of birth $\quad$ Coburg, Germany

Nationality german

Address $\quad$ Lenglerner Str. 68, 37079 Göttingen

Education

Since March 2013 PhD study of Molecular Medicine at the Department of Transfusion Medicine, University Medicine of Göttingen, Georg-August-University

PhD Thesis: New approaches to improve Extracorporeal

Photopheresis for the treatment of graft-versus-host disease

2010 - $2012 \quad$ Master of Science study of "Developmental, Neural and Behavioral Biology" at the Georg-August-University Göttingen

Master Thesis : Analysis of putative interaction partners of mouse gene12

$2007-2010 \quad$ Bachelor of Science study of „Biology“

at the Georg-August-University Göttingen

Bachelor Thesis: Ähneln Hunde ihren Besitzern?

1995 - $2005 \quad$ Secondary Schools: Gymnasium Ernestinum \&

Gymnasium Albertinum, Coburg

1991 - $1995 \quad$ Primary School: Richard-Müller Volksschule, Untersiemau

\section{Publications}

Budde, H., Kolb, S., Salinas Tejedor, L., Wulf, G., Reichardt, H.M., Riggert, J., and Legler, T.J. (2014). Modified extracorporeal photopheresis with cells from a healthy donor for acute graft-versus-host disease in a mouse model. PloS One 9, e105896. 
Lührig, S., Kolb, S., Mellies, N., Nolte, J. (2013): The novel BTB-kelch protein, KBTBD8, is located in the Golgi apparatus and translocates to the spindle apparatus during mitosis. Cell Div. 8 (1): 3. 